Portland State University

PDXScholar

$1-1-2012$

\title{
Let's Try to Change It: Psychiatric Stigmatization, Consumer/Survivor Activism, and the Link and Phelan Model
}

María Jimena Alvarado Chavarría

Portland State University

Follow this and additional works at: https://pdxscholar.library.pdx.edu/open_access_etds Let us know how access to this document benefits you.

Recommended Citation

Alvarado Chavarría, María Jimena, "Let's Try to Change It: Psychiatric Stigmatization, Consumer/Survivor Activism, and the Link and Phelan Model" (2012). Dissertations and Theses. Paper 904.

https://doi.org/10.15760/etd.904

This Dissertation is brought to you for free and open access. It has been accepted for inclusion in Dissertations and Theses by an authorized administrator of PDXScholar. Please contact us if we can make this document more accessible: pdxscholar@pdx.edu. 
Let's Try to Change It: Psychiatric Stigmatization,

Consumer/Survivor Activism, and the Link and Phelan Model

by

María Jimena Alvarado Chavarría

A dissertation submitted in partial fulfillment of the requirements for the degree of

\title{
Doctor of Philosophy \\ in \\ Applied Psychology
}

\author{
Dissertation Committee: \\ Janice Haaken, Chair \\ Keith Kaufman \\ Eric Mankowski \\ Melissa Thompson \\ Yves Labissière
}

Portland State University

2012 


\begin{abstract}
Stigma has been described as the most significant obstacle to quality of life for individuals with major psychiatric diagnoses (Sartorious, 1998). Much of the psychological literature on stigma focuses on individual attributes and interactions at the micro level, rather than macro level dynamics. In critiquing this traditional focus, Link and Phelan (2001) present a model in which stigma ensues when labeling, stereotyping, separation, status loss, and discrimination co-occur in a situation of power imbalance. Even as the model fills a gap in conceptualizing stigma, its emphasis on power is unidirectional and fails to account for power as a form of resistance to stigmatization. This study explores the question of how a consumer/survivor activist perspective can inform the Link and Phelan model of stigma. A semi-structured interview methodology was used to gather qualitative data on the perspectives of 10 activists who are both the targets of stigma and active change agents in resisting stigma. The content of the interviews was thematically analyzed based on an iterative coding approach in order to identify the points of overlap with and divergence from the Link and Phelan model. The results of the study support the applicability of the model for psychiatric stigma. The participants' experiences illustrate which aspects of stigmatization take precedence in this context, indicating significant points for intervention. The anti-stigma work discussed by the participants illustrates the power of grassroots resistance, expanding the understanding of power presented in the model. Emergent discursive themes include the importance of similarity, the rejection of negative portrayals of mental illness, and a focus on a shared continuum of human experience. Participants' emphasis on the
\end{abstract}


importance of having their voices silenced was a particularly recurring motif. Several respondents challenge the premises of the Link and Phelan model. These participants emphasize the positive aspects of diagnosis and labeling, while several other participants reject the choice of the term stigma because it may obscure the structural aspects of discrimination. These findings can serve as a guideline for designing future interventions, and focusing on strategies for social change. 


\section{Table of Contents}

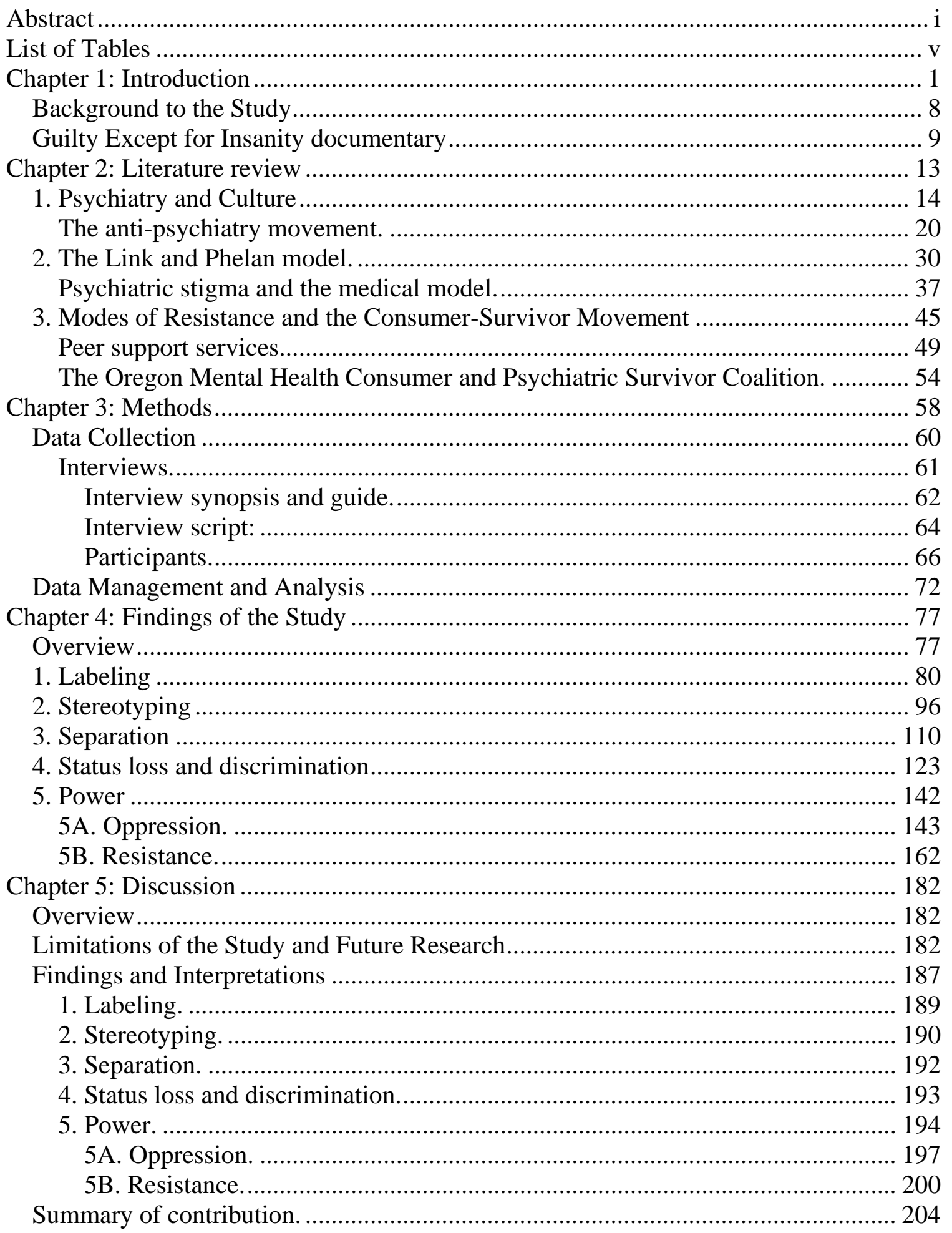




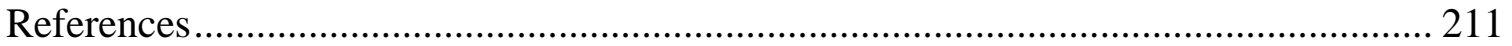

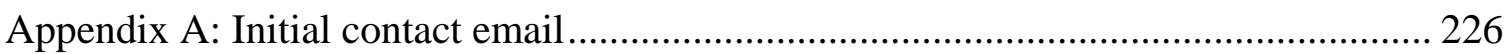

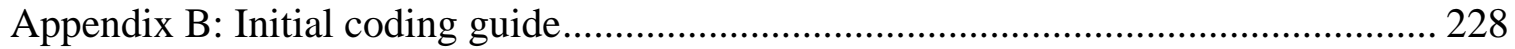

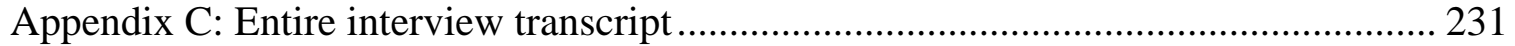




\section{List of Tables}

Table 1: Organizations represented by participants..............................71 


\section{Chapter 1: Introduction}

The stigmatization of those who suffer mental distress has dire consequences for those who are targeted, exacerbating the difficulties they face to the point where it is not easy to distinguish the symptoms that are caused by mental illness from those that are brought on by the effects of stigma (1997). Stigma has been touted as the most significant obstacle to quality of life for people with a psychiatric diagnosis (Sartorius, 1998).

While the effects of stigma have been empirically established (Angermeyer \& Matschinger, 2003; Baumann, 2007; Brohan, Slade, Clement, \& Thornicroft; P. W. Corrigan, Watson, Byrne, \& Davis, 2005; Link \& Phelan, 2006; Major \& O'Brien, 2005), the processes involved in changing stigma have been more elusive and less a focus of empirical inquiry. This dissertation seeks to identify insights that emerge as activists in the mental health field resist stigmatization, and to apply those insights to the prevailing theory on stigmatization.

The discourse around stigma has often centered on cognitive functions or microinteractions in dyads or small groups. Within the last few years there has been a stronger push to situate that understanding within a broader, structural context. Researchers have called for acknowledgement of the political and cultural power involved in creating a stigmatized group, and there have been some initial steps taken to incorporate power as a central element in the conceptualization of stigma.

Link and Phelan (2001) present a model that has gained currency within the field. In their conceptualization, stigma occurs when labeling, stereotyping, separation, status loss and discrimination co-occur in a situation of power imbalance. Link and Phelan 
propose that for stigma to actually occur, it must be situated within a context of unequal power, to allow the powerful group to communicate and enforce practical consequences of the stigma. Link and Phelan propose that power is a central aspect of achieving stigmatization because it allows one group to enact significant societal consequences over another for carrying a stigmatized label. In this way they seem to be focused on political, structural and cultural power as a way of communicating and enforcing stigma. They emphasize power as unidirectional. The stigmatized group cannot reverse the process and stigmatize the dominant group, even if they engage in all the cognitive elements of stigmatization. They simply do not have the power to enforce the societal consequences at a broad enough level for it to become a real stigma.

The inclusion of power within a stigma model resonates with other researchers that have integrated a power analysis into theoretical discussions and empirical research (Rutledge, Abell, Padmore, \& McCann, 2009; Reutter, Stewart, Veenstra, Love, Raphael, \& Makwarimba, 2009; Maman, Abler, Parker, Lane, Chirowodza, Ntogwisangu, et al., 2009; Parker, \& Aggleton, 2003; Green, Davis, Karshmer, Marsh, \& Straight, 2005). However even as they seem to fill a gap in conceptualizing stigma, Link and Phelan fail to adequately develop the power element in their model. It is one of the more nebulous sections in their framework, perhaps because it was a nascent idea. Having laid out the bases of what they mean by power, Link and Phelan do not carry the concept much further. Their emphasis on directionality can oversimplify intricate interactions, because it does not account for the power of resistance or for the complexity of intersecting identities. The authors do not address the power involved in challenging existing relations of domination. Their initial presentation seems to dichotomize groups into 
powerful/powerless, dominant/subordinate, stigmatizer and stigmatized, without considering the ways that identities shift over time.

Understanding the role of power dynamics in stigmatization allows us to address some of the mechanisms that perpetuate the process, and make it particularly difficult to interrupt. However, when we conceive power as unidirectional, we ignore the dialectical dynamics that lead to social change. Conceiving power as unidirectional overlooks the role of people who seek to resist and change the status quo.

This dissertation seeks to address the Link and Phelan model by focusing on the role of resistance in combating stigma. A key aim guiding the dissertation is to advance a more complex understanding of power dynamics in both creating and transforming stigmatization of those identified as mentally ill. It is this particular focus on change that interests me. The authors were not attempting to study social change strategies, but my aim here is to explore what anti-stigma efforts can offer the theory. Following Lewin's call on the importance of attempting to change a phenomenon in order to truly understand it (1946), this study establishes a dialogue between the Link and Phelan model and the grassroots efforts that attempt to change stigmatization.

The dissertation is based on the activities of the Oregon Mental Health Consumer and Psychiatric Survivor Coalition (OCSC) - a group that shares the unifying aim of bringing a power analysis to anti-stigma work and mental health activism ("News and information about OCSC”, n.d.). OCSC is a non-profit organization consisting of an estimated 100 members engaged in providing a united voice for Oregonian mental health consumers and psychiatric survivors at the state level. Through a series of interviews with ten members of OCSC, this study identifies a range of strategies and processes through 
which the coalition members carry out this work and to maps those strategies within a proposed theoretical framework. In this sense the dissertation is both descriptive and theoretical.

The OSCS coalition stems from radical roots and, while it does not reject the medical model of psychiatry explicitly, it does critically question the model and embraces alternative perspectives. This focus on questioning the mental health system and critiquing the traditional medical model of psychiatry presents the opportunity to study a group of activists who come together and share an interest in creating large scale change. The coalition's work can be understood as an attempt to reduce stigma by affecting the structures that govern the lives of consumer-survivors. They must balance conflicting demands when they attempt to access services within the mental health system while at the same time attempting to change the system from its base.

Conventional mental health care is a significant point of tension within mental health movements. There is a wide spectrum when it comes to acceptance of biomedical psychiatric treatment. Some groups embrace the pharmacological model. Others challenge and critique it while still others reject it altogether. OCSC promotes diversity of care, which allows room for those who support the pharmacological treatment approach, but also adamantly rejects forced care and demands space for peer-delivered services.

Participants were selected based on their active participation in OCSC, and in one of the member organizations. Each interview was audio-taped and transcribed. The content of the interviews was thematically analyzed based on an iterative coding approach (Braun \& Clarke, 2006). This thematic content analysis sought to identify the 
points of overlap and divergence with the Link and Phelan model, in particular the role that power plays in stigma and anti-stigma work.

As more research takes up the role of power in stigmatization, we need to communicate with the people who are using their power to resist the stigma that has been placed on them. Social movement theorists argue that those most directly affected by a phenomenon have a privileged understanding of the processes involved and should carry out a leading role in their movement (Swim \& Stangor, 1998). Yet in the field of stigmatization and mental illness, the voices of activists are largely missing from the formal literature. As frontline agents of change, anti-stigma activists have a wealth of information about the difficulties of eradicating stigma. The interviews of members of the coalition allow me to identify the processes they utilize, and their conceptualizations of power to gather insights about how they resist their stigmatized roles and unite to create social change.

By focusing on this coalition I can explore the anti stigma work that is being put into action at a local level. Currently the coalition has been focused on pushing a peerservices model of care, in which consumer-survivors claim their expertise in caring for themselves and others, subverting the role of professionals. The dissertation focuses on peer support as a unifying strategy and seeks insight from the coalition members on the ways they are actively seeking to change the stigma that surrounds them as consumersurvivors. While this dissertation is not a case study on the coalition and its processes, this organization provides a context for exploring a grassroots effort to combat stigma directly. As a community psychologist I am interested in the processes of social change that grassroots movements can facilitate. Working with members of the coalition, I can 
explore the ways that people who are affected by social problems are in a better position to create transformation, than efforts that come from the top-down, or outsiders to the movement. The context of the coalition provides me with enough heterogeneity to gather rich, diverse perspectives, while at the same time providing a homogenous base of activist consumer-survivors who share a political voice and have experience articulating their perspectives.

The question that guides this dissertation is as follows, how does a consumer/survivor activist perspective inform the Link and Phelan model of stigma? By exploring how activists seek to create social change, we can inform the theoretical model that guides our discussion of stigma. Using information from those who actively work to change the problem, we can know more about the phenomenon itself.

The Link and Phelan model seeks to address the process of stigma production at a broad level. This dissertation applies the model to a specific context, psychiatric stigma, to determine whether the model presents a useful framework for research and action in this field. In addition, this dissertation represents a deviation from the model as it was presented by the authors. Link and Phelan addressed the process of producing stigma, but did not focus extensively on what is necessary to interrupt stigma and generate social change. This dissertation seeks to determine the utility of the model in discussing the interruption of psychiatric stigma.

In regards to power and resistance specifically, this study seeks to expand the ways that power is conceptualized in the Link and Phelan model. The findings expand the conceptualization of target populations from passive and dependent to include agency and resistance. By asking participants to elucidate through their own experiences key 
components of the Link and Phelan model, the study moves from a one-directional model to a model that includes consumer/survivors' strategies of stigma resistance. Further, the study sought to understand power dynamics within the coalition and the potential of anti-stigma organizations to reproduce the very power dynamics they seek to overcome. I wanted to understand how rejection of a medical discourse would map onto the Link and Phelan and related anti-stigma models.

The results of the study can be used to inform the field of psychiatric stigma from a perspective that has potential for great insight. By focusing on the work that seeks to change stigma, we can get a better understanding of the difficulties that activists face in trying to generate change. By working with the affected population directly, this study gathers data that is informed by their lived experiences, and uses that to inform the theoretical understanding to the field; using praxis to inform theory. By extending the discussion on the role of power and resistance, we may gain a more complex picture of the ways these factors affect the creation and maintenance of stigma.

Since this study focuses on discursive strategies in the field, controversies over language are central to the project of inquiry. In the field of psychiatric disability the use of language and terminology has been passionately contested. There are debates regarding what people wish to be called, and professional's use of terminology (Cutcliffe \& Hannigan, 2001; Rose, Thornicroft, Pinfold, \& Kassam, 2007). There are significant differences and meanings behind the choice of language and terminology varies widely. Each choice of words belies a conceptualization, a geographical location, and even a social location. Some terms have a strong connection to the medical model, such as patients, residents, mental illness and psychiatric disability. Terms like psychiatric 
survivor and inmate emphasize the potential of psychiatry for creating suffering and trauma (Frese \& Davis, 1997; Swarbrick, 2009). In addition, madness is a term that, much like gay, has been taken up by activists as an assertion of cultural difference. The terms users and consumers intend to reflect the agency and choice that people exercise within the mental health field. The debate on language is in flux and I will use different terms depending on the context of what I am discussing. For the purposes of this dissertation I will mostly adopt the terms ‘mental disorder’ or psychiatric condition’ as they are used in the current Diagnostic and Statistical Manual (DSM-IV). These terms are more focused on description, and don’t imply an underlying disease process.

\section{Background to the Study}

This dissertation emerged from my involvement as a graduate student in the “Guilty Except for Insanity” (GEI) documentary project. This documentary will be descibed in the following section. My role as research assistant and a member of the production crew drew me into the field of forensic psychiatry. The repeated visits to the Oregon State Hospital, residential treatment facilities and various state institutions gave me the opportunity to connect with forensic patients, staff members, administrators, policy makers and multiple community organizations. These interactions allowed me to see some of the complex issues involved in our treatment of those who have been labeled mentally ill. The data gathered in the documentary project served as the basis for my internship with the Oregon Psychiatric Security Review Board (PSRB), in which I helped the Board cut a video piece for anti-stigma work aimed at members of Oregon communities. 
In exploring the strategies used for anti-stigma work, I strove to focus on messaging based on positive aspects celebrating difference, instead of messages that emphasize defect and deficit. I resisted the medical model's emphasis on disease and illness, and followed the groundwork laid out by the consumer survivor movement in their demands for civil rights. Connecting with activists who identify as consumer survivors, I have become more familiar with the approaches they propose for combating stigma, and the ways they resist the labels and paradigms that consider them diseased.

One of these community organizations, the Oregon Consumer Survivor Coalition (OCSC) has been particularly active in pushing for social change, and it is with this coalition that I sought to carry out my dissertation research. I worked with members of the coalition for several months in 2011, and established collaborative relationships with them. From August 2010 to August 2011, I attended meetings, teleconferences and retreats, and participating in online discussion boards. I had the chance to participate in the first strategic planning retreat, and was able to observe the discussion of action priorities. Because of this extended participation, I feel that I have built good rapport with founding members, and that I have an understanding of the path the coalition wishes to take in the coming months.

\section{Guilty Except for Insanity documentary}

This dissertation emerged as part of an ongoing social action documentary film project, Guilty Except for Insanity (GEI), directed by Jan Haaken through the Department of Psychology. This social action field intervention expressly seeks to create social change, and has worked collaboratively with patients, residents, activists and 
professionals. This project has focused on bringing out the humanity of psychiatric patients, presenting a more complex picture of people who enter the hospital through the criminal justice system.

The documentary film project follows the journeys of patients entering the Oregon State Hospital through the guilty except for insanity plea. It explores the diverse circumstances that bring people into the criminal justice system, as well as tracking them through different points in their pathway through the system, including the integration to the broader community through residential treatment facilities (RTFs). The film reflects on the broad historical trends toward incarceration of people who are suffering mental health crises. The project also portrays the insanity of the system that holds patients, staff, and administrators hostage to broader social and political forces, and how the hospital serves as a repository for diffuse social anxieties.

The project began in fall of 2007 as part of a Social Action Research seminar that included both graduate and undergraduate students. The research project has sought to explore the trajectories of the mental health system and the changes in care since the deinstitutionalization movement of the 1970's. In addition, the research project has centered on the increased criminalization of people who suffer from mental disorders, and the dwindling reach of the community mental health system. A key theme in this project focuses on countering fantasies and media representations of dangerousness of those labeled "criminally insane", as well as exploring the anxieties that communities face in regards to the reintegration of incarcerated patients.

The documentary was based on over 60 hours of in-depth interviews with key informants conducted by Jan Haaken, and an additional 50 hours of filming various 
groups and activities at the Oregon State Hospital and four residential treatment facilities, as well as Psychiatric Security Review Board hearings. The interviews have explored the experiences of people within the mental health system from diverse perspectives and include conversations with patients at the Oregon State Hospital, as well as staff and professionals from the hospital and various residential treatment facilities. Members of the criminal justice system, defense attorneys, and statewide administrators, as well as activists working within the field also provided their own experiences and reflections. In some cases the interviews have followed particular characters over a period of years, and have gathered perspectives over time. The themes that were used to guide the interviews were focused on the participants' understanding of the intersection of the mental health and criminal justice systems. Participants were each asked to explain how patients entered the hospital under the insanity plea and the dilemmas that arise in adjudicating the boundary between psychiatry and the law.

These in-depth interviews provided the bases for key themes developed in the documentary. The interviews were all transcribed by members of the research team, including myself. The first wave of analysis of the interview material yielded recurring motifs and central topics that were used as the basis for the film script. The kinds of themes that emerged that warranted a more systematic investigation, and this dissertation emerged as an extension to the project's applied focus. Among the recurring motifs, participants frequently referenced the medical model, particularly in addressing the obstacles in the integration of patients into the community. Patients themselves often appealed to the medical model in emphasizing that they have an illness no different than a medical illness that, when treated, reduces the risk they pose to the community. The 
theme of stigma emerged from the documentary production process as both professionals and patients discussed the high costs associated with stigma: lack of funding, lack of adequate care, and resistance to community integration. As a member of the documentary project team, I have been involved in the collection of data as a research assistant and a member of the film crew. I have participated in academic seminars with Dr. Haaken centered on analysis of discourses on mental disorders, and participated in the thematic analysis of transcribed material and film footage. This dissertation emerges from an existing body of literature on stigmatization and psychiatric disorders, as well as my own participation in the GEI documentary project. The theorists and researchers that have helped to form an understanding of psychiatric stigma provide the foundation for this work. In the following section, I review the relevant literature that provides a background to this dissertation. 


\section{Chapter 2: Literature review}

The literature review serves to contextualize the research question that guides this dissertation: How does a consumer/survivor activist perspective inform the Link and Phelan model of stigma? This chapter is organized as three sections focused on primary themes.

The first section presents a historical focus on the medicalization of mental disorders and a critique of the emergence of psychiatry some of the historical trajectories of our understanding of madness. The ways madness is conceptualized shapes how those conditions are treated and labeled, and provide a starting point for discussing the bases of stigma. This first section allows me to situate some of the historical struggles surrounding conceptions of madness, including the creation of a societal institution designed to control and support those labeled mad. This section also emphasizes the struggles for legitimacy that psychiatry has faced, since they present the bases for the critiques of the model that inform resistance movements.

The second section centers on the literature that explores the concept of stigma, as well as some of the empirical research conducted on stigmatization. I explore broad conceptualizations of stigma first, presenting an overview of the Link and Phelan conceptualization of stigma, and then focus more closely on the aspects of stigma that specifically relate to psychiatric disorders, including the use of the medical model as a tool for combating stigma and the current perspectives and research that challenge its efficacy. This section situates some of the power dynamics involved in creating and maintaining stigmatization and explores some of the limitations of our current 
conceptualizations of stigma. By providing a detailed perspective on the theories that explore stigma, I lay the groundwork for some of the sections that this dissertation intends to expand.

The third section explores the consumer survivor movement as it emerges from a critique of psychiatry, the push for a recovery model that demands an active role for consumer participants in their own treatment and concludes with the background of the consumer-survivor group that informs this dissertation. This section frames the central points of resistance and a reconfiguration of the treatment paradigm that has unwittingly helped to foster stigmatization.

\section{Psychiatry and Culture}

Michel Foucault (1988) argues that mental disorders cannot be understood as a natural condition but instead must be approached as a cultural construct. Foucault’s work questions the role of professionals in producing norms and categories that carry forms of social control. We must consider who has the power to determine the boundary between sanity and madness and how such roles have changed over time. Foucault describes a key historical transition from the clergy to medicine in monitoring this boundary that I describe in more detail in this section. He also pushes us to question the functions madness serves for the broader society. In order to move beyond the individualistic understanding of stigma, we need to view stigma and discrimination as functions of culture, power and difference (Parker \& Aggleton, 2003). Likewise, symbolic interactionism argues that the definitions of mental illness tell us more about the social 
process of diagnosis and figures of authority than it does about internal pathology (Kirk \& Kutchins, 1992).

Foucault (1988) questions the current model of mental illness by detailing how different models have changed through history. By analyzing the changes in discourse and conceptions of madness he draws out the moral codes and power relationships behind them. The three major paradigms that have explained madness in Western discourse have been metaphysical, scientific, and romantic (Haaken, 2008). In the metaphysical understanding madness has some connection to the spiritual realm beyond the physical world, and mad people were believed to be possessed or had a connection to the gods. This discourse was present throughout much of Western history, and only in recent centuries did the paradigm shift to understanding madness from a scientific and medical model. The medical model understands madness as an illness, something to be cured. This model relies heavily on direct observation and seeks a material solution to madness. More recently a romantic discourse has proposed that madness may be viewed from a positive perspective, acknowledging the potential benefits that madness can bring, such as creativity. This paradigm invites us to view madness as a language, a way to communicate and reflect that sane people have less access to.

A historical analysis shows how the dividing line between normality and pathology has shifted over time, indicating that the definition of sanity has been fluid and changing (Porter, 2002). Throughout much of European and American history, individuals who display unusual behaviors were believed to have some connection to gods, spirits or demons. In his detailed history of madness, Roy Porter (2002) explains that even in prehistoric times it is probable people were thought to be possessed by 
demons. Throughout many millennia, and many cultures, the metaphysical explanation for madness was dominant (Stephen P. Hinshaw, 2007). The attributions assigned to the metaphysical connection could be quite diverse, and affected the way deviant behavior was understood. For example in ancient Greece madness was understood as one or more gods taking possession of someone's mind (Conrad \& Schneider, 1980). In other contexts, madness was understood as a direct punishment from a supernatural power because of a moral flaw or a sin (John Read, Mosher, \& Bentall, 2004). This moral perspective ascribed blame to the person and made them responsible for their aberration. The history of the inquisition and witch hunts detail the persecution and torture that has come with the label of deviance (Conrad \& Schneider, 1980). In other cases, a connection to the divine has been thought to be a sign of special powers and has inspired reverence instead of fear (Stephen P. Hinshaw, 2007).

The Western Enlightenment brought a greater focus on reason as the driving force of humanity. Mad people began to be separated from others in what Foucault calls the “great confinement” (Foucault, 1988). By mid-17 $7^{\text {th }}$ century, the Hôpital Général was opened in Paris and served more as a pauper's prison than our current conceptions of a hospital. Social control was a major part of this institution since it served to warehouse the individuals that acted as an affront to the bourgeoisie, such as beggars, prostitutes, criminals and the unemployed. People were confined not for medical treatment but as a call to labor. Foucault argues that their idleness was associated with a lack of reason. This major institution once housed 1\% of the population of Paris (Conrad \& Schneider, 1980) and provided burgeoning capitalism with cheap labor and effective social control. 
These prisons_-which were called hospitals-- served as the repository for the mad until the $18^{\text {th }}$ century, when they began to be segregated into special institutions. The separation was not justified as a way to provide special treatment for the mad, but as a protection to the rest of the inmates, to avoid contagion and impose order (Foucault, 1988). These institutions served mostly as warehouses, and there was not much focus on treatment. Madness was perceived close to animality, with mad people considered fierce and invulnerable. From this perspective, the confinement was focused on discipline and brutalization as ways to subdue these subhuman people (Foucault, 1988). In addition, the isolation of the asylum and its residents from the rest of the community, demarcated a profound difference between them, promoting fear and stigma.

The role of physicians and the emergence of psychiatry were fraught with challenges as they sought to legitimate their positions as the authority in treating madness. As more emphasis was placed on the natural causes of madness, the physicians enter the asylum with proposals of cures and rehabilitation. Patients in the asylum provided psychiatry with a pool of subjects for therapeutic experimentation, but had limited success. Doctors became essential to asylums by the end of the $18^{\text {th }}$ century, in many cases acting as the gatekeepers with the authority to commit and certify people's entrance to the asylum.

The moral reform movement marked a significant change in the treatment of madness, and focused on providing kind, humane treatment to the mad in institutions. Tuke and Pinel are among the moral reformers who removed the chains from the insane and critiqued the existing institutions by stating that it would be difficult to distinguish the effects of madness from the effects of institutionalization (John Read et al., 2004). 
Pinel emphasized the role of natural causes for madness and promoted treatment to socialize mad people into the moral values of a bourgeois society - obedience and work. The medical model and asylum represented a more humane form of treatment, with the increased cost of constant surveillance and social control (Foucault, 1988). The medical model denoted an improvement over a moralistic or religious discourse, instead of framing madness as bad character or demonic possession, the medical model presents mental illness as a condition separate from personhood. This separation reinforced the idea that madness could be treated and brought under therapeutic control.

The idea of madness as mental illness acquired social currency toward the end of the $18^{\text {th }}$ century, as physicians and the medical model begin to dominate the asylums. The field of psychiatry placed great emphasis on description and classification of symptoms, even though it did not have much success with treatment. A somatic explanation for the origins of mental illness pushed physicians to study the nervous system in order to gather evidence for the medical model of madness. Kraepelin and Bleuer are considered pioneers in psychiatry (Sutker \& Adams, 1993) and they exemplify the trends of their time with extensive classification systems and organic etiologies for mental disease (Conrad \& Schneider, 1980).

The medical model of psychiatry in the $20^{\text {th }}$ century has continued to place a great emphasis on a biogenetic cause for mental disorders, even thought there have been great critiques of the evidence used to support it (John Read et al., 2004; T. S. Szasz, 1970). Within this period we see the medical model used to justify the dark chapter of eugenics, resulting in hundreds of thousands of mental patient deaths in Europe and tens of thousands of forced sterilizations in the USA (Stephen P. Hinshaw, 2007). Some of the 
somatic treatments that the century witnessed included electro-convulsive therapy, lobotomies, shock therapy, hydrotherapy and increased emphasis on pharmaceuticals. Institutionalization has been a major undertaking in psychiatry and has been one of the most visible conflicts within the field and within communities. Institutions have been accused of relying on coercion to medicate patients, setting up power differentials and human rights abuses (T. Szasz, 1991). Rosenhan’s (1973) experiences within an institution also speak to us about the potential to fulfill expectations. Psychiatrists have a hard time seeing people within a mental hospital as anything but mentally ill, perpetuating a cycle of pathology.

While psychiatric institutions represented an advance over the brutal warehousing of the past, in the early $20^{\text {th }}$ century the admission numbers continued to rise, at the same time that funding was cut, resulting in inhumane conditions within the psychiatric hospitals (Fakhoury \& Priebe, 2007). The critiques of inhumane treatment and the use of psychotropic medications available in the 1950’s played a role in moving toward deinstitutionalization (S. P. Hinshaw \& Cicchetti, 2000).The 1963 Kennedy bill grew out of the civil rights and free speech movements of the 1950s and early 60s, spawning a move toward community mental health. The premise that guided this approach was the understanding that community-based care could offer the patients more therapeutic and humane care (Aderibigbe, 1997). In some ways this was a very positive move, a reach toward providing care within an individual's community, avoiding the break that comes from uprooting.

Unfortunately, deinstitutionalization also produced a series of problems. The closure of psychiatric hospitals occurred at a fast pace, but the systems of community 
based treatment were not set in place at a similar pace (S. P. Hinshaw \& Cicchetti, 2000). The individuals who had left the psychiatric hospitals entered communities that were not prepared to offer them appropriate support, resulting in rampant unemployment, homelessness and criminalization (Aderibigbe, 1997).

Part of the deinstitutionalization movement involved not just bringing psychiatry into the community, but challenging the whole project of psychiatry. These historical trends and processes have been the focus of various groups that resist psychiatric stigmatization. The people who are the targets of psychiatric stigma often ask us to question the definitions of madness and challenge the legitimacy and power of the institutions that have been used to separate them from society. These aspects will be developed further in connection to the consumer-survivor movement, but at this initial stage I'd like to present some of the sites of tension that surround campaigns to resist stigma. One of the central points of discussion is the legitimacy of diagnosis, which will be taken up in the following section.

\section{The anti-psychiatry movement.}

The history of psychiatry involves periodic crises of legitimacy, what Foucault (1988) describes as the problem of scandal. The medical model introduced an element of social distance for practitioners as they entered intimate areas of mental life. Psychiatry rests on the premises of science. It lays claims to the objectivity, rigor and applied value of science. However, a central problem lies is its inability to define its object of study: mental health (Kirk \& Kutchins, 1992). This claim to scientific status helps obscure the process for decision-making or the power dynamic behind it. The mantle of science lends 
the field substance and naturalizes phenomena that should be questioned and analyzed. The legitimacy of science allows psychiatry to become almost dogmatic and unmovable and helps it achieve legal status_-directly influencing policy and laws. If the field cannot answer the basic question of what it studies, its claims to be a valid diagnostic system become tenuous. Foucault (1988) calls us to be wary of the scientific paradigm for psychiatry, understanding that just as religions once ruled the field of mental illness, the medical model we have now can also be changed.

Psychiatry has been critiqued extensively for the quality of treatment it has provided and the effectiveness of its treatments (P. W. Corrigan, 2007; John Read et al., 2004; T. S. Szasz, 1970). These issues are related to the more basic issue of diagnosis, however, in that treatments are based on clinical judgments within the framework of a classification system. Critiques of psychiatry address the field's inability to define the concept of mental illness (Kirk \& Kutchins, 1992). Even the medical model as a basic framework for how to understand mental illness has been critiqued. Issues of diagnosis and nosology are potentially revolutionary for psychiatry because they have the potential to shake the field at its core. A central point of controversy--the meaning of madness-is as philosophical as it is practical. Without a clear notion of how we conceive mental illness, any system of classification will be superficial.

The field of psychiatry has focused most of its diagnostic efforts on creating a detailed, precise classification system to categorize mental disorders — the diagnostic and statistical manual (DSM). This manual has evolved throughout the decades, each version intending to improve and resolve the critiques the previous one faced (Galatzer-Levy \& Galatzer-Levy, 2007). However, these attempts seem to address the issue of reliability 
more than of validity. By focusing on rates of agreement, psychiatry can be easily distracted from answering the larger questions, such as the etiology of illness and emotional distress (Kirk \& Kutchins, 1992). We should be wary of a system that can’t define the causes of its main subject matter and how the lack of causality alters the effectiveness of the treatment it provides (McHugh, 2005). Even the medical model's main focus, chemical treatment of the brain, has not been clearly demonstrated. For example, there is no adequate test to diagnose a chemical imbalance (John Read et al., 2004).

Even psychiatry’s claim to legitimacy, the reliability of diagnoses, is under heavy attack. Research on the DSM has shown marked sexual dissymmetry in diagnosis. Loring and Powell (1988) use the DSM-III to study how the race and gender of the client and psychiatrist affect diagnosis. The interesting point is that this version of the DSM claimed to have transcended earlier critiques of bias and vulnerability. Dixon, Gordon and Khomusi (1995) also demonstrate some diagnostic weaknesses in the DSM-III. They show that the practitioner's sex and experience can play a very strong role in the diagnoses they assign, challenging the ideal of the DSM being impervious to gender imbalance. Likewise, there is a strong argument surrounding the social distance between the practitioner and the client. These biases can be more pronounced when the clinician is very different than their client in terms of gender and other individual characteristics.

Szasz (1991) argues that there can be no psychiatry without coercion, whether it’s forced institutionalization, forced medication, or forced removal from an institution-it seems like a system designed to trample over individual autonomy. Psychiatry can produce the very conditions it seeks to cure. By emphasizing and pathologizing 
individual differences, it perpetuates a stigma that can easily lead to homelessness, unemployment, lack of insurance and lack of adequate care. In playing a hand in creating such conditions, it then becomes difficult to differentiate whether madness is situated within the person or is an intersection between a person and their context. A major site or resistance to psychiatric stigmatization has been to question the legitimacy of diagnosis. Psychiatry’s emphasis on difference feeds processes of separation and exclusion, contributing to stigmatization. These processes of stigmatization will be explored in the following section.

\section{Theorizing Psychiatric Stigma}

The questions that guide this dissertation focus on our understanding of psychiatric stigma. Specifically, I focus on the role of power dynamics in stigmatization, and the ways that resistance and anti-stigma work can be used to expand existing stigma models. In this section I'll be emphasizing Erving Goffman's work on stigma, and addressing researchers that continue his work on stigmatization and the resistance of stigma. I'll spend significant time discussing Link and Phelan's conceptualization of stigma, and their emphasis on a power analysis since that is the model I wish to expand on. Finally, I'll narrow my focus to stigma that targets psychiatric populations, and address the medical model as the main branch of anti-stigma work.

Erving Goffman’s (1963) work on stigma is widely considered foundational to the current field of stigma research. He created a framework for understanding stigma that has been expanded upon and frequently cited. His work has acted as the theoretical underpinning of many researchers focused on various kinds of stigma. The complexity he brings to the social process of stigma has served as the starting point for many authors. 
His conceptualization has served as a common thread for stigma researchers from many fields.

Goffman (1963) defines stigma as "an attribute that is deeply discrediting within a particular social interaction" and that diminishes the person who bears it "from a whole and usual person to a tainted, discounted one” (p. 3). This definition can seem static at first, with too much emphasis on the bearer and the attribute --obscuring the stigmatizer. However, Goffman emphasizes stigma as a relationship between an attribute and a stereotype. His work asks us to consider the role that interactions and relationships play in creating a link between an attribute and a stereotype.

By focusing on the difference between visible and concealable signs, Goffman emphasizes the integral role that stigmas play in people’s everyday lives. Signs associated with stigma or visible makers of cultural difference operate as the primary schema by which other aspects of personhood are understood. Stigmatized individuals are aware of the saliency of their status, in turn influencing their thoughts and feelings. This is what Goffman terms a discredited individual.

Goffman spoke of discreditable people as those who carry a stigma that is not easily visible, who can conceal their condition and pass as 'normals'. They can use concealment to help cope with the prejudice that their stigma may trigger, but this strategy also comes at a cost. The knowledge that their condition may become known can add new layers of worry and anxiety. They may try to gauge their audience's attitude toward their condition, trying to predict the outcome of disclosure. They may need to scrutinize their words and actions to avoid uncovering their identities; or worry about how to disclose their condition. They may worry that their condition will be revealed by 
some factor outside of their control. This conceptual framework was influenced by the civil rights movement and a wider discourse in the race relations field over "passing." Goffman also categorizes diverse stigmas according to their origin or type. This categorization was not meant to be exclusive - one individual could share different kinds of stigmas—but intends to describe and illustrate some of the diverse processes involved in each. When he speaks of "physical deformities" he discusses the immediate reaction that people have to such visible conditions. In referring to "blemishes of character" he covers conducts that are considered socially deviant and devalued. As a final category he includes "tribal” stigmas, to designate the attributes that are familial, or passed on from generation to generation, such as race, nationality or religion.

The term stigma has been critiqued for its focus on the person who is stigmatized rather than on the person or society making such attributions. Some call for the use of discrimination as a more appropriate term since it focuses on the person affixing the label (P. W. Corrigan \& Penn, 1997; Sayce, 1998). Critics argue that the focus on stigma has been too individualistic, and that the research that supports it has been based on microinteractions (Scambler, 2009). An individualistic approach has led researchers to study the psychological attributes of the individuals directly involved in stigmatization, but has significantly limited the attention given to social power and inequality throughout the process (C. Campbell \& Deacon, 2006). Research examining the sources and consequences of pervasive, socially shaped exclusion from social and economic life are far less common. By focusing on individual stigma the process of stereotyping and discrimination has been overlooked (Fiske, 1998). 
Drawing on Goffman’s classification system, Edward Jones (1984) and his colleagues identify some of the dimensions that differentiate stigmatizing conditions. In particular, they point out the importance of visibility and controllability as determinants of the subjective experience of stigmatized individuals. A condition is considered controllable when it is believed that the condition is the result of the person's behavior, or could be eliminated by the person's behavior. This idea of controllability places responsibility and blame on the individual. It is important to note that the individual might be considered responsible for the onset of the condition, the elimination of the condition, or both. For example, an individual might not be considered responsible for the onset of poverty, but may still be viewed responsible for overcoming it. Controllability is a key concept in stigma research because people who carry stigma thought to be controllable are more rejected and mistreated than those who are thought to be less able to control these markers of difference (Patrick Corrigan, Markowitz, Watson, Rowan, \& Kubiak, 2003; Martin, Pescosolido, \& Tuch, 2000).

Crocker, Major and Steele (1998) also introduce pervasiveness as an important factor in stigmatization. They argue that for the most severely stigmatized identities the stereotypes and devalued status are widely known and agreed upon. The stereotypes may become so ubiquitous that they are accepted as facts. This seeming acceptance of stereotypes may make these preconceptions emerge automatically, even for people who actively try to resist stereotyping. This widespread devaluation will affect the lives of stigmatized individuals in ways that are often difficult to determine.

In regards to combating stigma, Corrigan (2001) conceptualizes three key strategies in anti-stigma campaigns: education, contrast and protest. An education 
strategy centers on contrasting myths and information, while a contact approach connects members of the general public face to face with people who have learned to speak about their psychiatric disabilities. The contact approach seems to be highly effective and promotes longer lasting results (P. W. Corrigan \& O'Shaughnessy, 2007). This approach is difficult to implement widely, however, because it requires extensive training to prepare people to speak about their psychiatric disabilities and the logistics of personal interaction make it more complex than disseminating educational materials. The authors focus on direct protest as their third approach for interrupting stigma. A protest strategy centers on changing broader level messaging through political pressure. Corrigan and O'Shaughnessy (2007) explain that protest strategies have centered on negative representations of people with a psychiatric disorder. The main strategies have included working to prevent media from presenting these images, and cautioning to public to stop believing them. The protest strategy has centered on economic boycotts of the media responsible for the hostile representations, as well as appealing to a moral shaming of those companies.

In regards to interrupting and changing stigma, there has been a tendency to present the targets of stigma as passive victims. Goffman's (1963) foundational work on stigma presents the stigmatized as recipients of an external process; their role lies in becoming accustomed to or managing stigma (Goudge, Manderson, Ngoma, \& Schneider, 2009; Howarth, 2006; Poindexter \& Shippy, 2010). His work ignores the possibility that stigmatized individuals make purposeful efforts to destigmatize themselves. Riessman (2000) points out Goffman’s use of language -- “Individuals "manage" information about themselves; they "react" to (rather than resist or reject) the 
critical appraisals of others” (p. 114) - to illustrate the portrayal of receptivity instead of agency.

The focus on resistance to stigma leads us to a language of agency and transformation. Rather than internalizing the stereotypes imposed by society, people who have been stigmatized can oppose them and counteract negativity by redefining their status as a positive difference instead of a flaw. In some cases, stigma resistance can be strongly focused on renaming a stigmatized status, focusing on the advantages of a status, and by emphasizing benefits rather than losses (Riessman, 2000). Howarth (2006) urges us to explore the efforts that stigmatized people have brought forth to transform the processes of stigma - and calls for a social psychology that can focus on the agency and resistance that targets of stigma have brought to social change.

Stigma research has focused greatly on the construction of stigma, rather than on ways to challenge or interrupt it. Much of the literature has studied the attitudes of those who stigmatize, or on the negative effects of stigma on targeted populations. There has been a dearth on research that explores the processes or resistance and social change from the perspective of targeted populations. Within the few empirical studies that address stigma resistance, the definitions have centered on aspects of agency and transformation (C. Campbell \& Deacon, 2006; Goudge et al., 2009; Poindexter \& Shippy, 2010; Zajicek \& Koski, 2003). Contrasting with Goffman’s language of management (passing, enduring, resignation), stigma resistance is understood as transformative efforts to reconfigure the conditions that engender stigma (T. Morrison \& Whitehead, 2005).

Few empirical studies have directly explored stigma resistance. However a few broad themes have begun to emerge in the findings. In an analysis of women's resistance 
to the stigma of childlessness, Riessman (2000) explores the strategies that women rely on. These strategies include refusing to internalize a deviant label (resistant thinking), taking a stand in an interaction (speaking out and acting up), and deliberately avoiding confrontation (strategic avoidance), or rejecting motherhood. Buseh and Stevens’ (2006) work with people living with HIV and AIDS also emphasizes the resistance of selective disclosure, and presents the additional strategies of redefining stigma as ignorance, and becoming advocates. Zajicek and Koski (2003) take up the strategies described by Riessman (2000) in exploring the resistance strategies of people who are single. Boyle, Hodnicki, and Ferrell (1999) explore the resistance strategies of African American mothers of HIV-positive children and describe a pattern of refusal of labeling and marginalization, and a reliance on culturally patterned behaviors to protect themselves and their children.

Peer support networks and collective efforts are considered positive strategies for reducing stigma. Support networks not only increase the visibility of stigmatized identities, but they help to spread resistance strategies (Buseh \& Stevens, 2006). Support networks provide a space where people can process the negative interactions they’ve experienced, and helps individuals develop the confidence and emotional strength needed to challenge stigma (Howarth, 2006). Connection with a group can be a positive catalyst for creating broad social change. Howarth (2006) proposes that stigma isn’t always a disadvantage, and can be a powerful platform for collective mobilization and resistance. Likewise, Riessman (2000) explores the limitations of individual resistance, calling for collective action in generating lasting social change of stigmatization. 


\section{The Link and Phelan model.}

Much of the stigma literature focuses on social cognitive processes. Social psychologists have devoted a lot of effort to understanding how people construct categories and link them to stereotypes. Link and Phelan (2001) focus on a more sociological understanding, and hope to address some of the critiques that have been wielded at the stigma concept. With their conceptualization they hope to provide some clarity to a concept that has been accused of vagueness and lack of definition.

The concept of stigma has been used widely, and has been understood in very diverse ways. In some cases researchers have not defined their understanding of the term, in others they have used dictionary definitions, and many of them refer to Goffman's (1963) focus on discrediting attributes that reduce the bearer to a tainted person. Some definitions have focused on norms, some have focused on characteristics, but few have addressed Goffman's proposal that stigma lies in the dynamic relationship between attributes and stereotypes. Goffman explicitly pushed for "a language of relationships, not attributes”, however much of the research has developed from a static attribute perspective.

The variability in definitions of stigma might follow from different applications of the concept, as well as the theoretical background of the researcher. The concept of stigma has been applied to very diverse situations, including communicable illnesses, national identity, cancer, and disabilities. The variability of these scenarios affects how researchers think and apply the concept of stigma. For example, there might be more of a fear basis to stigma associated with communicable diseases than there are for cancer. In addition, research on stigma has come from multidisciplinary perspectives, and each field 
has had different emphases and theoretical backgrounds, leading to different conceptualizations of stigma. Link and Phelan recognize this variability and posit that the complexity of the phenomenon benefits from variety in the definitions, as long as the researcher makes their conceptualization explicit.

Link and Phelan discuss some of the controversies in the stigma literature and use those dilemmas as a basis for their own conceptualization. There have been strong critiques of stigma research because it has been carried out without taking into account the perspectives of the people who are directly affected by it. Most research is based on theories that have not been informed by those who live with stigma daily. This can lead to misunderstanding and erroneous assumptions about the phenomenon.

Another major critique of the stigma concept has been the focus on direct interactions between individuals. There has been a strong trend toward understanding some of the cognitive aspects that are involved in stigma, and researchers have primarily studied individual stereotypes, attitudes and micro-level interactions. Research that addresses more broad perspectives of social exclusion has been rare. Link and Phelan push for a more structural understanding of discrimination, focusing more on the producers of exclusion than on the recipients.

Link and Phelan use Goffman’s conceptualization of stigma as a relationship among elements while expanding on that model. They propose that stigma occurs when interrelated elements, or components, converge. They introduce components that address the macro and structural aspects of stigma. In their conceptualization, stigma occurs when labeling, stereotyping, separation, status loss and discrimination co-occur in a situation of 
power imbalance. I will address each of the components in more details in the following paragraphs.

As a first element, Link and Phelan discuss the social construction of difference, calling attention to the processes involved in distinguishing and labeling differences and propose that most human differences are not significant. They argue that some differences are more salient at certain times and in particular cultures, but that the process of differentiation and classification has become naturalized and invisible. When categories are taken for granted and the process is rendered invisible, it is a strong indicator that that particular category carries significant cultural weight. This component emphasizes that labeling is a process, and moves the focus from the person who receives the label, to the one who assigns it. In contrast, focusing on attributes or marks puts the focus on the recipient, possibly obscuring the social processes that were involved in selecting a particular characteristic as socially significant. The authors pose that when terms like attribute, mark or condition are used without clarification, they can implicitly convey that the description is valid, whereas label can lend itself to more critical questioning.

The second element in the Link and Phelan model focuses on the association between differences and negative attributes. Goffman’s work on stigma included discussion of the link between attributes and stereotypes. This focus has been salient in psychological studies on stigma, when researchers seek to understand the cognitive processes that promote connections between characteristics and stereotypes. Among findings in the field, Link and Phelan discuss the automatic and preconscious 
characteristics of some categories, focusing on the ways people might be affected by stereotyping without being aware of it.

As a third element, Link and Phelan draw on the United States’ long history of separating racial and ethnic groups. Separation comes from a strong focus on difference and linking those groups to stereotypes can provide the basis for social distance and exclusion. When the differentiation and separation is extreme, the process can rob groups of their humanity. In some cases the separation is very evident, and there is a conflation of a characteristic with the identity of the labeled person, for example calling a person "a schizophrenic” instead of "having schizophrenia”.

Link and Phelan present status loss and discrimination as the fourth component of their model. Status loss comes as a consequence of negative labeling and stereotyping. Societies intrinsically create hierarchies, and being linked to undesirable characteristics reduces a person to a lower status. Link and Phelan draw on sociological traditions to speak of the ways that people categorize and organize themselves into predictable hierarchies. They use the example of how external status can shape interactions even among small groups that have never met before, to illustrate the effects of stigma in every day interactions. A diminished social status puts a person at a disadvantage in many interactions. Status loss can affect life chances by making a person less desirable for social activities, business projects, etc. creating a cascade of negative effects on opportunity. The inequalities operate very subtly, making it hard to tie the outcome to any single event, but the pattern repeats broad social categories of advantage.

The discrimination component of stigma hones in on Link and Phelan's focus on broad social interaction. The authors argue that conceptions and studies of stigma have 
focused on a simple formula. The main point of focus has been on connecting attitudes to discriminatory behaviors. The relationship to stigma depends on whether attitudes lead to an overt act of discrimination between two people. The theory of reasoned action has been used to understand stigma by focusing on a very specific behavior and analyzing the attitudes and beliefs that lead to that particular action. While these micro-interactions are a part of discrimination, the focus is too narrow. It only addresses some of the variables that lead to disadvantages, but leaves out many forms of discrimination that never occur as an interaction between two people. Such a narrow perspective can be detrimental, because it blinds us to the myriad ways that discrimination occurs.

Link and Phelan propose structural discrimination as an integral aspect of stigma. They borrow from institutional racism to talk about the ways disadvantage is put in place that are outside the realm of personal interactions. They use a few examples to illustrate their point, and most salient is the discussion of schizophrenia. Since this is considered a stigmatized illness, there is less funding for research and treatment. In addition, the treatment facilities are likely to be on the outskirts of town or in disadvantaged neighborhoods. These and other factors might influence the best care providers to treat more affluent clients for different illnesses, leaving the care of people with schizophrenia to practitioners who are not as well-trained. This example is used to illustrate how stigma affected the structure around the person without having had a direct discriminatory interaction.

The model holds that these four components must converge within a context of power imbalance in order to achieve stigma. They argue that this aspect is crucial to the 
definition of stigma because it is the mechanism through which the other components are communicated and enforced in a broader societal context. The access to power allows the dominant group to designate a difference as salient, and to make that difference broadly identified within the culture. The powerful group would have the means to make a particular stereotype widely recognized and accepted, as well as create and perpetuate separation among groups. These differences would be compounded by the control of institutions that affect daily lives like schools, housing and health care. This access to power has the potential to catalyze some lone components of stigma into a social reality. Stigma can only occur when a perspective is backed by enough power to create significant societal consequences for the group that has been labeled.

The Link and Phelan model has gained considerable currency in the stigma research field. Their model is often cited for its innovative understanding of power processes involved in stigma, and has been considered a "major reconceptualization” (Sayce, 2003a, p. 627). Likewise, it is praised for its incorporation of social and structural context that moves beyond individual interactions. Their model has been used as the basis of many empirical studies because of its complexity.

The components proposed by Link and Phelan have been used as the theoretical underpinning of diverse stigma studies. Angermeyer and Matschinger (2005) adopted the model and applied it to study public attitudes about mental illness. Their research supports the model on links between labeling and stereotyping, and that particular stereotypes are correlated with desire for social distance (conceived as a stand-in for discrimination). Rutledge, Abell, Padmore, and McCann (2009) examined the fit of the model to their particular context (HIV in east Caribbean), and reported that the empirical 
data supported the proposed model. The Link and Phelan model has been used to study a wide range of topics, including lesbian and gay families (Robitaille, \& SaintJacques, 2009), poverty stigma (Reutter, Stewart, Veenstra, Love, Raphael, \& Makwarimba, 2009), and the experiences of living with HIV in Swaziland (Shamos, Hartwig, \& Zindela, 2009).

Aside from presenting a conceptualization useful for empirical studies, the Link and Phelan model has been praised for its theoretical innovation. A range of scholars has recognized the relevance of moving away from an interactional perspective of stigma to one that includes the social structures that support it (Parker, \& Aggleton, 2003; Rutledge, Abell, Padmore, \& McCann, 2009; Scambler, 2009; Sayce, 2003). The most prominent discussions center on Link and Phelan's inclusion of power as a central component of stigma, with various authors praising the inclusion of this crucial element that had been overlooked (Rutledge, Abell, Padmore, \& McCann, 2009; Reutter, Stewart, Veenstra, Love, Raphael, \& Makwarimba, 2009; Maman, Abler, Parker, Lane, Chirowodza, Ntogwisangu, et al., 2009; Parker, \& Aggleton, 2003; Green, Davis, Karshmer, Marsh, \& Straight, 2005).

The Link and Phelan model was particularly well received because of its inclusion of the power dimension. Various authors comment on the importance of that particular element, and recognize Link and Phelan for their contribution. Prioritizing power adds a broader structural component that had often been overlooked in stigma frameworks, and stigma researchers have taken up the structural approach that Link and Phelan propose. Presenting power as a central aspect of stigmatization has been a novel contribution that has received a lot of attention. 
Sayce (2003) adopts the Link and Phelan model in proposing an application to anti-stigma strategies. She starts from the Link and Phelan framework to envision how the different elements could be applied in real world anti stigma campaigns. She proposes that their framework should allow for the best understanding of how to disrupt the “social, political and attitudinal” processes that produce stigma (Sayce, 2003a, p. 627). For example, in making use of their element of power, Sayce poses that if it were carried into anti stigma work, it would imply legal sanctions for institutions that perpetuate stigma. She argues that change cannot be based on positive messaging and attitudinal change alone, but that it needs the added enforcement of legal consequences for perpetrators. Likewise, she uses Link and Phelan's understanding of stigma as pervasive to imply that short-term, isolated initiatives are unlikely to create effective change.

\section{Psychiatric stigma and the medical model.}

Having focused so far on the general literature on stigma, I turn now to literature focused on stigmatization of persons who carry a psychiatric label. The stigma that is imposed on people with mental disorders carries such high costs that it becomes difficult to distinguish which social problems arise from the mental condition and which from the social exclusion (P. W. Corrigan \& Penn, 1999). Stigma may be the central issue within psychiatric services since other difficulties may derive from the attitudes that people hold about mental disorders (Sartorius \& Schulze, 2005). It carries profound weight for people experiencing mental disorders, at the policy level, via such things as job and housing discrimination and a lack of medical care and meaningful insurance; as well as at the personal level, through self blame and shame. 
Stigma research of the 1950 s and 1960s found that people experiencing mental disorders were socially rejected and described using fear, distrust and dislike (Jo C. Phelan, Link, Stueve, \& Pescosolido, 2000). This has not changed in the 50 years of ongoing research around stigma. Even as research methods become more sophisticated, the evidence for the intense stigmatization and discrimination faced by those experiencing mental disorders has increased. For example, Page’s (1995) study of landlords found that once prospective renters revealed a history of hospitalization for mental disorders, the property was quickly made unavailable. Finzen (as cited in Schulze, \& Angermeyer, 2003) has come to call stigma the second illness in mental illness.

A large part of research on psychiatric stigma has used the category of mental illness in a broad way, without distinguishing between different disorders. However, some categories within mental disorders have received more public acceptance, for example, depression or eating disorders. By conflating them with more severe and chronic mental disorders like schizophrenia it is more difficult to effectively address the phenomena. People with schizophrenia are often considered more dangerous and unpredictable, evoking more fear, than those with other disorders (Angermeyer \& Matschinger, 2003; Crisp, Gelder, Rix, Meltzer, \& Rowlands, 2000; Gaebel, Zaske, \& Baumann, 2006). The inclusion of dangerousness as a criteria for involuntary commitment to a psychiatric hospital in the 1960s also helped to increase public fear and stereotyping of psychiatric patients (J. C. Phelan \& Link, 1998).

The prevalent psychiatric anti-stigma messaging strategy in the US today centers on the medical model and espouses that mental illness is much like any other physical illness (T. M. Lincoln, Arens, Berger, \& Rief, 2008; J. Read, Haslam, Sayce, \& Davies, 
2006). (P. Corrigan, 2000; Estroff, Lachicotte, Illingworth, \& Johnston, 1991). This perspective, sometimes termed the biogenetic causal attribution model, would like the public to think of these issues in terms of illness and disease, and to recognize their cause as mainly biological (Sandra Dietrich, Matschinger, \& Angermeyer, 2006; T. M. Lincoln et al., 2008; J. Read et al., 2006). This discourse is centered on attributions and causality, and seeks to convince the public that psychiatric disorders originate from genetic heredity, chemical imbalance or brain diseases.

The premise of the biogenetic causal attribution model is that if mental illness is presented as being caused by forces outside a person's control, the public's reactions would be less negative. One of the central goals of this approach was to allow the general public to identify with people with psychiatric disorders and its treatment by drawing on illness as a concept that is readily available. By comparing mental illness to chronic illnesses like diabetes the model sought to normalize mental illness and present it as treatable and manageable based on psychotropic medications. This model had the intention of reducing blame and conferring dignity to the patient/consumer by changing the perception that the illness is within the patient's control, therefore increasing sympathy and helping behavior. The medical model represented an advance over a moralistic or religious discourse, where psychopathology is attributed to bad character or demonic forces. In framing mental illness as a condition separate from personhood, it reinforces the idea that it can be treated and brought under therapeutic control.

This anti-stigma strategy has had some problematic, unexpected costs. By separating personhood from disease, it has increased a sense that people with mental disorders are inherently unpredictable, irrational, and uncontrollable, increasing the 
perception of dangerousness (Read, et al., 2006). This focus on mental disorders as physical illnesses can convey that the illness is not within the person's control, making their behavior unpredictable and incomprehensible, fueling fears.

This model has been more and more widely accepted as the main conceptualization of madness, while at the same time the stigma of schizophrenia has worsened. In the decades between 1950 and 1996 there was an increase in the use of the medical model in the USA, while at the same time there was an increase in the perception that mentally ill people are frightening and violent, as supported by a nationally representative surveys (Jo C. Phelan et al., 2000). Likewise, in Germany there was a trend to desire greater distance from people with schizophrenia as people endorsed biological causes (M. C. Angermeyer \& H. Matschinger, 2005)

The medical model of mental illness has become so ubiquitous that it has become synonymous with knowledge and education. Most anti-stigma efforts attempt to evaluate the extent to which people endorse the medical model as the cause of mental illness, and equate that endorsement with comprehension. The term "mental health literacy" has been used to measure the extent to which people espouse a medical understanding of madness (Jorm, 2000). In more subtle ways other studies equate knowledge with the biomedical paradigm in the way they phrase questions of frame responses. For example, some studies push the idea of mental illness as a brain disease, while others espouse that mental illness is like any other (Watson et al., 2004)

Empirical research challenging the effectiveness of an illness paradigm at reducing stigma has been building through the past decades. The first studies emerged in the US in the 1970's when researchers found that when people espouse an illness 
metaphor they are also less likely to befriend the person (Golding, Becker, Sherman, \& Rappaport, 1975; Sarbin \& Mancuso, 1970). In the 1980’s and 90’s, a few studies emerged that questioned the biogenetic premise. Though there were few studies challenging the chemical paradigm, they represented a growing concern with the unintended consequences of the model. A review article published in 2006 (J. Read et al., 2006) gathered the available material to date, and sought to evaluate how effective the biogenetic causal model was at reducing discrimination against schizophrenia. The study evaluated multiple empirical studies, many of them international, which focused on public attitudes and various explanatory models. Read and his colleagues concluded that biogenetic causal models are related to more negative attitudes toward schizophrenia. In addition the authors determined that the public prefers psychosocial explanations over biogenetic ones for schizophrenia.

There is growing evidence that a disease discourse may actively strengthen stereotypes. A study on undergraduate students found a link between biogenetic explanations and perceptions that mental patients are dangerous, unpredictable and antisocial (John Read \& Harre, 2001). A study on a population of young New Zealanders found a medical model approach was correlated with increased perceptions of unpredictability and dangerousness (Walker \& Read, 2002). A population study in Germany also found a strong correlation between brain disease as the cause of mental disorders and perceptions of dangerousness (Sandra Dietrich et al., 2006). These studies represent only some of the studies conducted to challenge the medical model as an effective stigma-reduction strategy. The body of evidence has been growing in the past 20 years, and has shown most development in the past decade. 
One dilemma in the field of psychiatric stigma has centered on how to measure stigma. Most research to date has focused on quantitative studies, providing participants with fixed, multiple choice items that tend to simplify complex phenomena of discrimination. By relying mostly on self report, the field has not explored implicit and subconscious processes as well as it could (S. P. Hinshaw \& Stier, 2008). In addition, most studies to date have relied on attitudinal measurements of desire for social distance as the main indicators of stigma (Matthias C. Angermeyer \& Herbert Matschinger, 2005; S. Dietrich, Heider, Matschinger, \& Angermeyer, 2006; Mann \& Himelein, 2008; B. Schulze, RichterWerling, Matschinger, \& Angermeyer, 2003). While social distance can be a useful tool, it does not necessarily predict all the relevant ways that discrimination can be enacted. There has been less focus on behavioral discrimination or on attitudes that are less consciously available, even though it has been argued that measuring discrimination in direct ways can be problematic since stereotypes often rely on implicit cognition (Greenwald \& Banaji, 1995).

In 1997, Mehta and Farina conducted a study that fueled a critical look at the medical model. By measuring behaviors instead of attitudes as predictors of stigma, the authors were able to observe the intensity of rejection that their participants exhibited. Participants engaged in a learning task with a confederate researcher, and were asked to communicate with their partner through electric shock as feedback for performance. When the confederate researcher presented a biogenetic explanation for their mental disorder, the participants increased the rate and the intensity of the shocks at a much higher pace than when presented with a psychosocial explanation. Their findings indicate 
that biogenetic causal beliefs did lower blame but at the same time increased punitive behavior.

A biogenetic focus may have detrimental effects on views of recovery. A disease model may promote the idea that the disorder cannot be changed and that there is no hope of a cure. If the cause of the disease is part of a person's genetic code, there is very little chance that is can be changed. A biological explanation for mental disorder has repeatedly been linked with increased pessimism toward treatment, worse prognosis, and more hopelessness (Deacon \& Baird, 2009; Lam \& Salkovskis, 2007; J. C. Phelan, Yang, \& Cruz-Rojas, 2006). These attitudes may discourage personal responsibility and disempower people who are struggling toward recovery.

A fundamental problem with the medical model is the decontextualized way it presents biological factors. By focusing almost exclusively on the biological component of mental disorders it undermines the interaction between the person and their environment. These concerns were presented recently by the president of the American Psychiatric Society, Steven Sharfstein, when he stated that "As a profession, we have allowed the bio-psychosocial model to become the bio-bio-bio model”(Pepper, 2005). More complex models can take into consideration the psychosocial factors that intervene in the onset and course of mental disorder.

By focusing solely on biological factors, the medical model carries a risk of presenting people with a mental disorder as physically different or defective. When a person is described as brain diseased it creates the impression that the person is not able to have valid judgment or be reasonable. This can make people with mental disorders seem inferior, presenting them as less than human, robbing them of their personhood. 
Mehta and Farina (1997) speculate in their study about stigma and behavior that the harshness they observed might be attributed to the perspective that "biochemical aberrations make them almost a different species”(p. 416). A disproportionate emphasis on biology carries a long history of entanglement with eugenics and discrimination. A focus on tainted genes has been used to justify forced sterilization and extermination of people with mental disorders (John Read \& Masson, 2004).

The medical model can endorse a conception that those with mental illness are biologically, fundamentally different than those who are not diagnosed with a psychiatric condition. This uncritical emphasis on difference can help to create an 'other', and reduce an entire group’s complexity. By exaggerating difference, it is easy to see people with mental disorders as categorically separate, a distinct group that is very distant from the norm. Nick Haslam’s research (N. Haslam, 2000; Nick Haslam \& Ernst, 2002; N. Haslam, Rothschild, \& Ernst, 2002) has focused on the connection between essentialist beliefs and prejudice, and has found that essentialist beliefs are strongly correlated with wide-ranging inferences about the subjects-people are likely to fill gaps and make judgments based on limited information. By robbing people of their complexity, essentialist discourses can perpetuate stereotypes and reinforce the stigma that they wish to transform.

Questioning the existing medical model takes on importance as activists seek to change the stigma that has been imposed on them. A discourse centered on deficit and defect does not leave room for pride and celebration of difference. Focusing mostly on attitudinal change and micro interactions ignores the structural aspects of discrimination that serve to maintain hierarchies in place. Depending on professionals and legislators to 
determine courses of treatment and life opportunities alienates consumer-survivors from their own process of recovery. Pushing for small reforms within the medical system might yield small improvements in quality of life, but such reforms may obscure inherent problems of the system.

Resisting the existing power structure involves questioning the medical model since it has been the legitimate, dominant paradigm for the last hundred years. It is embedded in the cultural, economic and political system, and because of that powerful position, gains access to creating rules and standards that have become entrenched. These elements of resistance to dominant structures make the work of anti-stigma activists who question the medical paradigm a particularly rich source for exploring power dynamics, resistance and social change in stigmatization. In the following section I present some of the movements that push for an alternative strategy in combating stigma as the participants who inform this dissertation.

\section{Modes of Resistance and the Consumer-Survivor Movement}

In this third section of the literature review, I introduce the participants that inform this research project. I emphasize some of the characteristics that connect my participants to my research questions and the basis of my criteria for selection of participants. I also discuss the coalition as the site of my study, and present their framework for anti stigma work and social change.

The consumer-survivor movement began to take shape in the United States in the 1970’s as formerly institutionalized patients began to discuss how their basic rights had been violated (Frese \& Davis, 1997). They were strongly influenced by the movements of 
that era, from the civil rights movement, feminism, to the gay rights movements (J. Campbell, 2005). Although they came from diverse backgrounds, these ex-patients rallied around their experiences of being oppressed, demeaned and treated like powerless victims and they organized to put an end to involuntary hospitalization (Frese \& Davis, 1997). The movement comes from political roots that developed out of dissatisfaction with the medical model and resisting societal discrimination (Swarbrick, 2009).

The movement centered on independent groups with various emphases. Most groups began as small groups of people joined to share their experiences and borrowed from the practice of consciousness-raising of the women’s movement (J. Campbell, 2005). Each group developed its own organizational structure and ideologies, but they often shared a distrust of mental health terminology and they emphasized validation of feelings instead of inspecting them for pathology (Chamberlin, 1990). Most of these early groups were focused on liberation such as the Insane Liberation Front in Portland, Oregon, the Mental Patients' Liberation project in New York City, The Mental Patient's Liberation Front in Boston, and the Network Against Psychiatric Assault in San Francisco (Frese \& Davis, 1997).

Lack of funding made it difficult for these early groups to establish a communication network. In San Francisco the groups were able to develop the Madness Network News, which ran for 10 years, and helped solidify the connection between separate groups (Oaks, 2009). In addition, the movement put together an annual conference on Human Rights and Psychiatric Oppression that was held from 1973 to 1985, allowing further opportunities for connection and networking (Frese \& Davis, 
1997). During these years, the movement continued to grow and solidify, with new groups forming in other parts of the country.

The consumer-survivor movement is comprised of two factions: radical psychiatric survivors (sometimes called ex-patients, and ex-inmates) and a moderate mental health consumer group (Swarbrick, 2009). The early movement was led mostly by people who called themselves survivors as a means of drawing attention to the mistreatment they received from the medical system. These groups have been strongly opposed to forced treatment and the medical model of psychiatry, refusing to work with a system they consider dehumanizing and neglectful of individual needs (Swarbrick, 2009). They view the movement as a liberation struggle (Chamberlin, 1990) and propose selfhelp, peer-led activities as an alternative to the mental health system (Swarbrick, 2009). They conduct strong advocacy work to protect the civil rights of people within and outside of mental health institutions, pushing to end forced treatment like electroconvulsive therapy and forced drugging, emphasizing freedom of choice and the right to refuse treatment (Chamberlin, 1995). This survivor focus continues to be strongly represented and MindFreedom is one of the lead organizations (Swarbrick, 2009).

In the 1980s more individuals started identifying with the term consumers. As the movement widened, they became more accepting of the medical model but continued to push for more respect and support from providers (Oaks, 2009). Consumers focused strongly on reforming the existing system, while rejecting the medical model's dependence on experts and pushed for a peer-operated service model (Swarbrick, 2009). Consumers generally work closely with the professional system and share leadership with non-consumers. 
The tension between radical and reformist groups within the anti-psychiatry movement has continued through the decades. The term consumer has been critiqued for its implication of equality of power and freedom of choice within the marketplace. These “consumers” are still subject to forced treatment (Chamberlin, 1990). There have also been extended discussions about the roles of consumer-survivors and non-patients within organizations. In some cases non-patients were included for membership but not for decision-making, in some they participated in all aspects and in others they were completely excluded. Mixed membership tended to yield a move toward reformist policies instead of radical work, and the small minority of non-patients rising to the top of leadership roles and guiding future goals (Chamberlin, 1990).

Consumer-survivor voices are increasingly being heard. In the late 1970s, the US government bestowed a grant for the creation of the Community Support Program (CSP), which included people with psychiatric histories in policy-making (Oaks, 2009). This program also organized conferences by and for consumer-survivors that drew thousands of participants (Swarbrick, 2009). Current federal law requires that states that receive funds for mental health services must now include consumers on all mental health boards (Swarbrick, 2009).

The work and advocacy from the consumer-survivor movement has yielded great results in terms of representation and civil rights. The activists continue to work on improving the lives of people who are subjected to forced treatment, even while they work to end these practices. Likewise, the decades of self-help and peer support have been recognized by professionals and institutions in much wider acceptance and implementation of peer operated services (Swarbrick, 2009). 


\section{Peer support services.}

This dissertation shifts the focus from the dominant psychiatric model to forms of resistance. A key strategy of this activist effort centers on claims made on the state for peer-supported services in opposition to professional services. As part of a push for social change and resistance to psychiatric stigma, the consumer survivor movement strives to support peer-run organizations. These organizations "are alternatives to mainstream mental health services, and they have the dual focus of supporting members and creating systems change” (Nelson, Ochocka, Janzen, \& Trainor, 2006, p. 247). This emphasis on consumer-survivor participation resists the status loss and discrimination that accompanies a psychiatric diagnosis by making visible the valuable contributions that these individuals make to society. Likewise, having peers provide services directly recovers some of the power lost in professional-consumer interactions. Consumers themselves are reclaiming their own expertise on treatment, and sharing it with one another. This presents direct resistance against the conventional medical model that places all responsibility for care on the "tinkering professions” (Goffman, 1963).

Peer-operated services grew out of dissatisfaction with the medical model's focus on illness, detriment and pathology, to include more emphasis on holistic wellness and recovery. These services are operated and controlled by people who have identified as consumers/survivors and seek to address the social and emotional needs of people living with mental illness (J. Campbell, 2005). These services are often funded through the state and private foundations and can be thought of as a separate alternative to the mental health services traditionally offered, or as a complement to the existing system (Swarbrick, 2009). Among other functions, consumer survivor initiatives provide "one- 
to-one peer support, self-help and peer support groups, community economic development, education and training for the public and mental health professionals, advocacy to create systems-level change, opportunities for consumer/survivors to develop their skills, and artistic and cultural activities” (Nelson et al., 2006, p. 248).

Within community psychology, Brett Kloos (2005) explores the overlap of values that community psychology shares with consumer survivor initiatives. The principle of ecology within community psychology can serve to support consumer survivor organizations by providing contexts for analysis of the problem. For example, Kloos states that consumer/survivors are often "identified as being the source of the problems they experience. Difficulties with housing, (...) lack of adherence to treatment recommendations are too often attributed to a failing of the person, without looking at the broader context to account for contributions to difficulties” (2005, p. 439). In addition, Kloos explores the alienation that people with psychiatric disabilities face, and addresses the role of consumer survivor organizations in creating community experiences. Kloos also points out the role of community psychologists in critically analyzing mechanisms of oppression and power differentials as a source of support to consumer/survivor initiatives, a goal that this dissertation seeks to advance.

Peer services stem from a recovery perspective. People in recovery sought to produce their own service alternatives in contrast to the inadequacies and indignities of the mental health system (Swarbrick, 2009). The recovery movement strengthened within the field of community mental health in the 1990s, in an attempt to support consumers in achieving independence, self-management and a better quality of life (Chamberlin, 1990). Recovery can be understood as the process, through which people are able to live, 
work, learn and participate fully in their community (President's New Freedom Commission Report, 2003). In some cases, recovery can refer to the ability to live productively despite a disability, and in others it refers to the remission of symptoms (Swarbrick, 2009).

The consumer-survivor movement has resisted the assumption that a psychiatric label brings chronic illness for life, and instead asserts that mental health recovery is possible, and even probable (Swarbrick, 2009). People who have received psychiatric labels are often presented as passive, vulnerable recipients of service, but the recovery movement emphasizes strengths and pushes for self-determination (J. Campbell, 2005). In addition, the recovery movement seeks to counter discrimination, decrease stigma, promote social justice, and present alternatives to the medical model in achieving wellness (Chamberlin, 1990). The consumer survivor movement lobbied strongly for recognition of the recovery paradigm and it has gained enough currency to be included on the national agenda (Swarbrick, 2009). In the past decade there has been a marked increase in hiring consumers to provide mental health services (Carlson, Rapp, \& McDiarmid, 2001; Rivera, Sullivan, \& Valenti, 2007)

A peer-operated service model maps onto the concept of recovery and serves as a resource for transforming the delivery of mental health services. Peer services present particular benefits in care delivery that professional services cannot. Peer specialists can provide a different perspective, fill different needs, and reach people who have been resistant to the medical system (J. Campbell, 2005). Consumer-providers can count on abilities that include "systems knowledge, 'street smarts,' responsiveness, coping strategies, patience and flexibility, relational emphasis, issue identification, engagement 
abilities, role modeling, advocacy against stigmatization, and educational activity with co-workers" (Carlson et al., 2001 p. 200). People who have gone through severe psychological distress and have shown significant recovery bring a unique insight and understanding to the helping role (Fisher, 1994).

Peer services have also been described as self-help groups, or mutual-help groups, however there have been few studies that investigate the functioning and well-being of these groups. Consumer-operated programs can be understood as groups of ordinary people that are "cost-free, member governed, peer led and made up of people who share the same problem or situation” (Meissen, 1993, p. 448). Wituk, Shepherd, Warren, and Meissen (2002) conducted research on the factors that contribute toward self-help group survival, and found that survival was related to support from organizations and clearinghouses. This finding supports the need for broad structural support for consumer/survivor organizations as they provide support to people with psychiatric disabilities.

Peer specialists also function as important role models in demonstrating what recovery looks like and conveying a sense of hope. Consumer-providers demonstrate in very personal terms that recovery is possible, and that people can succeed at employment, education, and independent living (Carlson et al., 2001). This positive example helps to combat stereotypes of consumer survivors as chronically ill, helping to challenge stigma. In addition, consumers working as providers benefit from an increase in their sense of value and self worth, personal growth and development, and often reduced hospitalizations (Carlson et al., 2001). 
Peer services foster ongoing socialization, empowerment and autonomy, whereas traditional health agencies tend to deliver more acute, treatment-focused services (Segal \& Silverman, 2002). Peer organizations might include drop-in centers, housing, self-help centers, advocacy, and education programs (J. Campbell, 2005; Swarbrick, 2009). Within these organizations, peer providers might work as case manger, case management aide, crisis worker, housing specialist, employment coach, and peer counselor/advocate, clinicians and administrators (Mowbray, Moxley, \& Collins, 1998). Ochocka, Nelson, Janzen, and Trainor (2006) researched some of the effects that taking part as a provider or a recipient of peer support has on participants. Their research indicates that steady association with peer support helped empowerment by increasing stability in work and education settings. In addition, the participants became more involved in their treatment, taking control by researching treatment options, and moving away from the passive role of mental patient. In a similar pattern, Nelson, Ochocka, Janzen, and Trainor (2007) found that consumer/survivors who were consistently engaged in peer support programs showed better outcomes of community integration and social support networks. The participants who were actively involved in consumer/survivor initiatives also reported fewer emergency room visits and fewer psychiatric hospitalizations than did members of a control group.

The recovery movement and the peer-services approach emphasize the role of empowerment and emancipation in improving quality of life for consumer-survivors. The role of mental patients has often been presented as passive, and devoid of power, receiving treatment that was designed and delivered by outsiders and professionals ( $\mathrm{J}$. Campbell, 2005). The consumer survivor movement prizes a focus on empowerment, 
which emphasizes "the role that people with serious mental health problems can play in recovery and the contributions they can make to their communities” (Kloos, 2005, p. 446). Empowerment within recovery has been understood as people who have lesser power gaining control over their lives, and having the ability to influence the structures around them (including mental health care) to gain mastery over all domains in life (Swarbrick, 2009). The consumer survivor movement calls for empowerment for freedom of choice regarding treatment services, influence within service provision, participation in policy and planning, and participation in decision-making at the community level (Harp, 1994).

\section{The Oregon Mental Health Consumer and Psychiatric Survivor Coalition.}

The data of the dissertation are drawn from interviews from members of the Oregon Mental Health Consumer and Psychiatric Survivor Coalition (OCSC), a nonprofit organization that seeks to provide a united voice for Oregonian mental health consumers and psychiatric survivors. This coalition's work for social change has centered on a critique of the dominance of the medical paradigm, which allows me to explore commonalities and differences among activists who share a focus on power dynamics and resistance.

The coalition grew out of a need for a unified voice for psychiatric consumers/survivors at the state level. The state of Oregon previously funded an Office of Consumer-survivor Technical Assistance (OCTA) that supported emerging consumer groups and served as a liaison between the government and consumers. When the state budget was reduced in 2003, the office was closed and there was no other state institution 
to officially assume its role. Some of the efforts of OCTA were taken up by a successor organization, Mental Health America of Oregon/PeerLinc Oregon, in an attempt to continue providing organizational support to consumer-survivor advocacy.

Since 2006, there has been discussion and grassroots organization to form a statewide coalition that would represent consumer interests. Various activists and community organizers have worked to constitute the coalition, which was formally incorporated in 2007, and convened a board of directors in April of 2008. The coalition has become more active in the past year, holding its first all-member meeting through teleconference, and organizing a multi-day strategic planning retreat. After 2010, the collation saw its membership rise dramatically with much wider involvement of members in the activity of the coalition.

OCSC has been strongly supported by a national coalition that hoped to unify a consumer voice at a wider level. The National Coalition for Mental Health Consumersurvivor Organizations, now known as National Coalition for Mental Health Recovery (NCMHR), was also formed during the same period. The statewide and national coalitions have been in close contact, and share many of the same goals and structures. This national coalition counts with representation from 32 states; the state of Oregon is represented by OCSC.

The OCSC’s mission statement seeks “To establish a statewide network of people who identify as having a psychiatric diagnosis, and/or who feel labeled by one; to share ideas; provide mutual support; work toward common goals; strengthen peer-run organizations; and advocate for positive change in the mental health system”(Oaks, 2009). The coalition seeks to connect people who have been labeled with a psychiatric 
diagnosis and provide a network that supports communication and advocacy. The coalition strives for systemic change that includes a stronger consumer-survivor voice and participation. One of their emphases is the development of peer-run organizations.

The coalition has sought to include voices that have been excluded and marginalized from mental health discussions. They have taken up the motto from the disability rights movement of "nothing about us without us" as a demand for voice and participation in the decisions that affect their lives. As a grassroots organization, the constituency is reflected in the leadership; there is a conscientious effort to include consumer-survivor voices at every level of the organization, and this emphasis is written into its bylaws and structures. The intent is that the people most affected are present in leadership roles. The coalition's structures are designed to bring in voices that are often overlooked, by ensuring geographical diversity. The coalition actively recruits organizations, but pursues individual participation as well. In this way, they extend open invitations and public meetings to ensure that individuals that are not represented through organizations have a chance to participate as well.

The survivor movement has been advocating against forced treatment and mainstream psychiatric practices in the United States since the late 1960s. These groups considered the medical model of psychiatry to be potentially damaging and emphasized the perils of surviving within the mental health system (Oaks, 2009). The consumer movement emerged in the 1980s, characterized by more acceptance of the medical model, while still advocating for better care and more community support. These movements pushed for more consumer-survivor involvement in policy creation, and the availability of alternative treatment options. Likewise, the emerging advocacy groups 
resisted the increasingly biological focus of psychiatry, rejecting or questioning the dependence on psychopharmacology (Oaks, 2009).

The coalition was launched as the result of many diverse groups coming together, but it received critical support from one survivor organization. Mindfreedom Oregon played a pivotal role in getting the coalition started, including donating many staff hours, hosting online materials for the coalition, and lending office space. Mindfreedom aligns with Mad Pride--a radical organization that has worked hard to maintain independence, receiving no funding from the psychiatric industry ("Introductory FAQ's about MFI", n.d.)This radical framework has been present in the coalition's planning and strategizing, when members question the political costs associated with receiving funding from large institutions.

A push for peer-delivered services has been at the forefront of the coalition's recent work. It was a central topic of discussion and planning during the 2010 strategy retreat. This topic is emerging as a naturally occurring point of convergence for the members and organizations within OCSC. In the coalition's online communications, issues of peer training, services and organizations were discussed at length in 16 out of the 48 email exchanges that were not mainly focused on logistics in the 6-month period between September 2010 and March 2011. The high number of online communication on this subject indicates a noticeable interest from members of the coalition on peerprovided services. 


\section{Chapter 3: Methods}

In order to clarify the epistemological frame that guides the dissertation, I present key assumptions that guide me as a researcher. These epistemological principles are reflected in the research design and carried out in the methodological choices.

Based on the premises of qualitative research, this dissertation does not seek to accomplish the positivist goals of objectivity and generalizability. Instead, I recognize science as intrinsically subjective. From choosing topics to research design, a research project is marked by each researcher’s subjectivity (Fine \& Vanderslice, 1992). A central tenet of qualitative research is that knowledge is contextually situated, which implies not only that the participant's responses must be understood within their broader context, but that the researcher's role must be contextualized as well. Since the researcher's values are affected by their own social location, objectivity cannot be a stated goal and each researcher must reflect on the lenses they bring to their analyses and interpretation (Christians, 2000).

Based on a social constructionist epistemology, this dissertation seeks to understand how meaning and knowledge are constructed within a social setting. Burr (1995) poses that social constructionism is sceptical, and critical of knowledge that is taken for granted. Since meaning and experience are largely influenced by language, researchers are not objective observers measuring the world, but rather engaged in the cocreation of knowledge. Likewise, Burr calls for historical and cultural specificity, recognizing that meaning-making is situational and unfolds within a particular time and place. Braun and Clark refer to the use of thematic analysis within a constructivist 
epistemology by presenting it as "a method that works both to reflect reality and to unpick or unravel the surface of 'reality"” (2006, p. 81)

The methods follow from these epistemological commitments in the following ways. My choice of participants is guided by my own commitment to social change. The research participants carry a deep commitment to and experience with the phenomenon of interest. They are not simply sources of data, but rather are active participants working to change the phenomenon.

This dissertation seeks to understand how activists in the mental health field are resisting stigmatization, and to use that knowledge to map the strategies onto a conceptual model of stigma. The study explores the work of the OCSC to understand the role that power and resistance play in anti-stigma work, and inform an understanding of stigma. By interviewing members of this coalition I seek to understand the activism they carry out, in particular their focus on peer support programs. Their practical work can help inform the ways we think about stigma and present a more nuanced understanding of the role of power and resistance in changing stigma.

The question that guides this dissertation is as follows: How does a consumer/survivor perspective inform the Link and Phelan model of stigma? This question guides the inquiry into the ways that social change efforts can inform the conceptual understanding of stigma. In particular I explore the role of power, which, while described as crucial by Link and Phelan (2001), was not developed analytically.

The study is based on semi-structured interviews with members of OCSC. Participants were selected based on their activity within the coalition and experience working with one of the member organizations. The interviews were audio-taped and 
transcribed. The content of the interviews was thematically analyzed based on an iterative coding approach (Ritchie \& Lewis, 2003). This thematic content analysis sought to identify shared concepts and strategies of stigma reduction among the activists. The analysis explored the contrasting approaches and complexities that these activists describe.

In the tradition of participatory action research, this dissertation follows a question that has emerged organically from the population most directly affected. The focus on peer support services is at the forefront of the coalition's work as one of the current priorities for action. In this way, the emphasis is not artificially imposed by a researcher, but rather follows the lead of the participants. This is a dilemma that members of OCSC have demonstrated interest in. In addition, this dissertation seeks to emulate Lewin's (1946) cyclical model of action research, by using information gathered from the field to inform the existing theory and future research.

\section{Data Collection}

The data for this study were gathered through semi-structured interviews conducted with 10 members of OCSC. The interviews ranged from 50 to 80 minute with each participant, and the questions were structured around the Link and Phelan model of stigma. The participants were active members of OCSC, and the sampling strategy centered on locating key informants with an experienced trajectory in the movement. 


\section{Interviews.}

The research data was gathered through conducting semi-structured interviews with 10 participants. Semi structured interviewing means that the participants were asked similar questions but there was flexibility to follow up with additional questions and to probe based on responses (Smith, 1995). The decision to use qualitative interviews as a source of data was based on my interest in studying activist strategies that combat stigma. Semi-structured interviews and qualitative analysis are particularly suited to this topic since they address the complexity of a process that has personal and social meanings for participants and is politically controversial (Smith, 1995). Interviews were most appropriate within the field of qualitative methods because they allow the participants to reflect on their own conceptualizations of the issues.

The semi-structured interview is in keeping with a conversational and collaborative approach to the process of inquiry, while also permitting control over the focus of the interview (Smith, 1995). This approach draws on the premise that knowledge is a dynamic and co-constructed process rather than one of extracting information from a passive subject (Järvinen, 2000). Using individual interviews allows for participants to develop complex ideas in an accepting, non-confrontational environment. By interacting with the participants during the interview I was able to identify key points and ask for clarification, making use of a less-structured interview strategy. In particular I focused on drawing out participant's responses, eliciting their understandings of sites of meaning and conflict.

My interviewing experience came primarily from my four-year undergraduate training as a psychologist. My training in Costa Rica prepared me for a position as a 
supervised clinical, educational, or social psychologist. As such, most of my coursework included fieldwork and case management. Throughout this training, I conducted interviews with clinical clients and their families (four separate cases), one educational client, and her family; one institutional education case with the respective administrators; one institutional case with a local clinic, and its administrators; and one institutional organization case with a customer service office, and its respective administrators. My work with a disaster intervention brigade gave me extensive training in crisis intervention and interviewing, where I conducted approximately thirty individual sessions. This position as an administrator of the brigade included training other students on interviewing and crisis intervention skills. My work as a sexual assault advocate, where I carried a caseload of 20 clients, also combined crisis intervention and intake interviews. These interviewing experiences helped me prepare for conducting interviews with marginalized populations, and helped me develop empathy and conversational skills that were valuable for interviewing within this dissertation.

\section{Interview synopsis and guide.}

The research interviews provided a context for participants to present their approaches to reducing stigma. The questions were designed to be broad enough to encourage the interviewee to present the rationale behind various arguments and to allow for a range of responses. Many of the questions were guided by the existing literature on stigma and my own experience communicating with members of OCSC, participating in the strategic retreat, and following the coalition's online discussions. 
Based on a review of the stigma literature, the information gathered through extensive interviewing of the psychiatric community in the GEI project, and participation in email discussion lists, the interview guide was structured around emergent themes. The observations generated through participation in the coalition's strategic retreat suggested key motifs that I expected to find in data analyzed in my proposed study, for example the emphasis on peer services as a source of empowerment and resistance against devaluation of status. The coalition has generated extensive discourse in framing their anti-stigma work.

A single interview was conducted with each of 10 participants, and they ranged in duration between 50 and 80 minutes. A sample size of 10 was considered to be sufficient to adequately address the research question, Following Kuzel’s (1992) assessment of a range between 5-20 participants as typical for a research study.

The interview schedule conformed to the elements of the Link and Phelan model, which is organized around four sequential aspects of stigma within an unequal power distribution. The questions were derived from the language and issues discussed by coalition members, and the elements of the stigma model that informs this dissertation. I focused first on presenting the model, then asking a question about each of the elements in the model. The questions were organized by their affinity to an element of the model. This allowed me to explore each of the elements with the participant, and get a sense of what aspects they found most useful, or in most need of expansion. The initial questions were meant to generate conversation around a particular issue, and the follow-up prompts helped keep the interview on track and allow for ideas to develop in more depth (they are indicated with brackets). The interview structure is as follows. 


\section{Interview script:}

There's an interesting model being used to explain the processes involved in how stigma gets created, and I'd like to talk with you about it. Your experience as a consumer/survivor, and your activist work make you an expert on the subject, and I'd like to know what you think of the model, and how useful it can be.

1. These authors, Link and Phelan, say that the first step to creating stigma starts with distinctions, differences and labeling.

From what I've heard around the coalition, I know there are lots of conversations about labels and diagnoses. How do you usually talk to people about what's involved in a label or in a diagnosis?

[There are debates on whether we should say "a schizophrenic” or "a person diagnosed with schizophrenia”, whether it's better to say patient, client, consumer or survivor] [What do you think is the impact of referring to someone as "a schizophrenic" as opposed to "a person diagnosed with schizophrenia”

2. The next step in the model is connecting the label to something negative. For psychiatric diagnoses, people seem to come from very different perspectives. Some people say that it’s “an illness like any other” and other folks present it as just another form of human diversity. How do you think about these approaches? [When it comes to changing stigma, what message would you use?] [What does the phrase "broken brain" mean to you? How would you connect that to antistigma work?] 
3. This stigma model we're trying to understand has a third element about how people are separated off from others in the process of being stigmatized. How would you describe this part of the process?

I know there's been a strong push for community integration, having consumer/survivors live in the least restrictive setting. Why should community integration be such a high priority?

[Could stigma be connected to separation from the community?]

[Some people say that being excluded from society is one of the reasons that stigma is hard to change. What do you think about that?]

4. So far we've talked about labeling, and then negative stereotypes and separation. There is a fourth element — that discrimination becomes institutionalized. It's not just about one person being prejudiced, but the way that institutions themselves discriminate against groups of people.

[example for prompt: which projects get funding from the legislature, which illnesses get more sympathy and care, what coverage insurance offers, which accommodations employers make when hiring...]

Which institutions do you think we should start with? What would be the first priorities? [Which institutions are going to be harder?]

If you wanted to improve the lives of people with a psychiatric diagnosis, and you could start anywhere, where would you start? What's the most urgent issue?

[What would work better for a long-term change?]

5. Link and Phelan say that unequal power all of these components in some way. They say that something only becomes a real stigma when it is backed by political power: the 
power to write laws, to change institutions, to exclude people from housing. How does that match with your experience?

The model does not take into account grassroots or bottom-up power-the potential power of those affected by stigma. How do you see that form of power working against stigma?

\section{Participants.}

The study was based on a purposeful sample to locate and intentionally choose participants for this study, a sampling method whose logic and power are derived not from large samples or random assignment, but from the selection of information-rich cases (Patton, 1990). These are participants from whom researchers may learn a great deal about matters that are central to the purpose of the research (Patton, 1990).

Since these participants hold multiple identities as consumer/survivors, service providers, activists, change agents and coalition members, their experiences are varied and informed by these multiple perspectives. Participants understand stigma from their own experience within the system, and also as change agents. They both resist the stigma attached to them, and help to interrupt the process for others. Because of these experience and social locations, participants can potentially explicate the role of power dynamics in the conceptualization of stigma, and the ways that resistance and anti-stigma activism can inform our understanding of stigma.

Participants were selected based on their participation in the coalition, and their experience working against psychiatric stigma. The selection criteria served as a starting point for ensuring a nuanced and complex understanding of the phenomenon. I sought out 
participants based on the richness of their experience in consumer/survivor activism and an experienced commitment to countering psychiatric stigma. My experience with the coalition, participating in meetings, teleconferences, retreats, and online discussion boards has allowed me to gain some familiarity with various coalition members, and has given me information about their trajectory as activists.

The primary selection criterion for participation was their experience in articulating a position on consumer/survivor issues. This criterion was based on key premises of this study that 1 ) the most valuable insights and contributions emerge from those who have experienced the problem of interest first hand, and 2) those who hold a deep commitment to the problem are more apt to carry knowledge related to processes of social change. In order to ensure that the participants have experience in thinking and talking about consumer/survivor issues, I worked with people who have been active in OCSC as well as having an experienced trajectory working with one of the member organizations. This purposeful sampling approach involved eliciting participation from people who are already invested in the topic and are located in a position to provide insights.

My initial recruitment strategy involved seeking out members of the coalition who had substantial experience as activists, as well as representing a variety of the member organizations. Through my contact with the coalition, I had the opportunity to hear about many of the participant's activist trajectories, several which have been working in the field for decades. With the exception of one of the respondents, I had some familiarity with all of the participants through their ongoing work in the coalition. As an initial step I contacted activists who I had established a relationship with through 
my contact with the coalition. I also reviewed the coalition's documentation on each organization’s representative, and sought those members out. At the end of each interview I asked the participant if they had recommendations of other members of the coalition who had substantial experience, and in many cases received the names of people whom I had already interviewed, or was in the process of recruiting. This repetition of names helped to validate that the participants were well established in the field. In order to explore a range of perspectives within the coalition, I interviewed no more than two participants from each member organization and from eight of the organizations in the coalition. Based on my understanding of knowledge as situated within a specific context, I sought out balance within the participants of gender, ethnicity, age, sexual orientation, and physical ability. This allowed me to seek out a range of ideas while enlisting social change agents to elucidate a theoretical model.

To recruit participants, I contacted individuals by email (see appendix A) to introduce the project and then followed up with a phone call to ask about their interest in participating. The initial email to participants described the study and the participants’ involvement in it. In the follow up phone call the process was discussed further, and I gauged participant's willingness and ability to participate. A total of 14 people were asked to participate. Three of them declined due to time constraints, and a fourth one was not available because he had moved out of state. In order to better understand the context of these numbers, I estimate that the coalition is comprised of approximately 100 members, based on my observation of coalition events and online discussion. As always, not all members share the same level of involvement. 
Confidentiality was discussed during the initial phone call and at the beginning of the interview. The participants were told that their identities would be kept confidential through the use of pseudonyms. The participants understood that there would be no names or identifying characteristics attached to quotes in the final documents. They were also assured that only a limited group of people would have access to identifying information.

The logistics of the interview were set up through email and phone communication, and the location was based on the participant's convenience. I offered to meet them where they felt comfortable speaking, and I suggested a coffee shop, their homes, or a private space at their place of work. I conducted the interviews in coffee shops for five of the participants, while two preferred to speak at their homes, and three chose their workplace. Due to the geographical diversity of the participants, five were interviewed in Portland, three in Eugene, and two in Salem.

In the interviews I sought to bring out the participants' multiple perspectives by asking about different experiences, both professional and personal, in order to avoid having them feel that they must represent their organization's point of view. I kept the interview anchored in the emerging dilemmas in the literature as well as the language used in the field in order to elude highly scripted, stereotypical responses. In addition, a process of consultation between interviews with my supervisor assisted me in opening the interview as an exploratory space for participants to delve into the complexity of their work.

My choice of interview participants was based on the double identity of members of OCSC, both as consumer/survivors of the psychiatric system, and as advocates within 
a social movement. I chose not to pry for details about the participant's medical history, preferring instead to follow the coalition's definition of their membership as “people who identify as having a psychiatric diagnosis, and/or who feel labeled by one” (OCSC, 2008, p. 4). Identifying ones’ self as having or being labeled by a psychiatric diagnosis is the standard that guides the coalition's membership. Issues of treatment, diagnosis and history of hospitalization can be divisive and controversial within the coalition, and as the findings show, act as sites of exclusion or legitimacy. Likewise, I worried that asking for a detailed medical history would repeat the pattern of stigmatization that the participants face, in which their identity as patients supersedes their humanity. Through my interaction in the community I was aware that professionals often focus on psychiatric diagnoses, even when they are not relevant to the situation. While their experience as subjects of stigma was important to the research, their diagnostic history was not part of my analytical strategy. My choice to forego medical history limits the demographic description of the participants, acting as an obstacle to transferability, but I decided that the costs of possibly repeating patterns of exclusion were a bigger concern to the project. As it was, some of the participants have shared some of their treatment history, allowing for some glimpses into their past.

The participants presented a broad range of experience in the consumer/survivor movement. One of them had been working in the movement for a few years, while the majority had been active for at least 10 years, in some cases over 30 . The roles that these participants have taken in their diverse organizations have been quite varied. Some had been in charge of pioneering multiple organizations, taking a leadership role in their creation, and some had been working as entry-level case managers. The positions that the 
members held in their organizations were quite fluid, many of them hold multiple positions within multiple organizations, councils and committees. There was a noticeable overlap within this small community, members worked on the same coalitions and boards, and in the case of three participants, they were transitioning from one organization to another as the interviews were taking place. The boundaries among organization were not rigid, and many participants had been members of a number of the organizations over time. The organizations represented in this sample are described in the following table.

Table 1: Organizations represented by participants

\begin{tabular}{|ll|}
\hline Name & Description of organization \\
\hline Empowerment & $\begin{array}{l}\text { Non-profit organization that describes itself as run by people with } \\
\text { Initiatives, Inc }\end{array}$ \\
& $\begin{array}{l}\text { Their work is focused on supporting people on a path to recovery } \\
\text { by helping people with mental health diagnoses determine their } \\
\text { goals and hire providers that could assist them in meeting those } \\
\text { goals. }\end{array}$ \\
\hline $\begin{array}{l}\text { Mental Health } \\
\text { America of Oregon }\end{array}$ & $\begin{array}{l}\text { Non-profit organization that provides diverse services for } \\
\text { consumer/survivor groups. They can assist groups by helping them } \\
\text { organize and start new groups, support them in developing } \\
\text { structures such as boards and bylaws, and assist in strategic } \\
\text { planning. They also provide training for consumer/survivor groups } \\
\text { in areas of fiscal responsibility, development of infrastructure and } \\
\text { self-management tools, funding proposals and grant writing, and } \\
\text { mentoring the groups in diverse ways. }\end{array}$ \\
\hline $\begin{array}{l}\text { Non-profit organization that provides peer-to-peer support for } \\
\text { people with a mental health diagnosis or that are facing mental } \\
\text { health challenges. They coordinate a crisis support service with a } \\
\text { local hospital, provide recovery and wellness services and } \\
\text { employment support. They also provide peer specialist, leadership } \\
\text { and facilitation trainings. }\end{array}$ \\
\hline $\begin{array}{l}\text { This non-profit organization has been active for over 25 years, and } \\
\text { focuses on a radical critique to psychiatry, denouncing human } \\
\text { rights violations within the mental health system and providing a } \\
\text { platform for advocacy and political change. They promote humane } \\
\text { alternatives in mental health, and support the self-determination of } \\
\text { psychiatric survivors and mental health consumers. }\end{array}$ \\
International
\end{tabular}




\begin{tabular}{|c|c|}
\hline $\begin{array}{l}\text { Benton County } \\
\text { Peer Wellness } \\
\text { Specialists } \\
\text { Program }\end{array}$ & $\begin{array}{l}\text { This program is part of the Department of Public Health and is run } \\
\text { by consumer/peers who have attended a state training program. } \\
\text { Peer Specialist training program approved by the state of Oregon. } \\
\text { They focus on supporting clients of the Health Department on a } \\
\text { path to recovery through person-directed planning, giving the client } \\
\text { more control over their treatment options. }\end{array}$ \\
\hline $\begin{array}{l}\text { ShelterCare } \\
\text { Consumer Council }\end{array}$ & $\begin{array}{l}\text { This organization represents the participants of the ShelterCare } \\
\text { program, which provides housing support services for people with } \\
\text { psychiatric disabilities. The council supports the consumers in } \\
\text { handling grievances, and being active participants in their } \\
\text { treatment. They have crafter communication materials for the } \\
\text { consumers and the staff. }\end{array}$ \\
\hline $\begin{array}{l}\text { Peer support } \\
\text { services at Oregon } \\
\text { State Hospital }\end{array}$ & $\begin{array}{l}\text { Peer-to peer services provided at the Oregon State Hospital by } \\
\text { recovery specialists. Providing training, support, and engaging } \\
\text { patients to become active participants on their path to recovery and } \\
\text { wellness. }\end{array}$ \\
\hline $\begin{array}{l}\text { Office of consumer } \\
\text { affairs - } \\
\text { Western State } \\
\text { Hospital }\end{array}$ & $\begin{array}{l}\text { This office provides a consumer voice to discussions of policy and } \\
\text { treatment issues that impact patients. Designs and implements } \\
\text { various consumer-centered activities, and provides training to staff } \\
\text { and patients on recovery services. }\end{array}$ \\
\hline
\end{tabular}

\section{Data Management and Analysis}

The Link and Phelan model served as the conceptual lens guiding the analysis and interpretation phase of the dissertation. The analysis focused on participants' understanding of their anti-stigma work, and the role that power plays in their resistance to stigma. I conducted a thematic content analysis of the transcribed interviews, identifying themes within the material. Data analysis was a process of systematic classification that allows for an interpretation of the content of textual data to identify themes and patterns (Hsieh \& Shannon, 2005). The goals for the analytic phase were defined as follows;

- Identify themes that assist in explicating the model (for example, salience and relevance of the elements) 
- Identify themes that explicate power dynamics at each phase of the model

- Identify themes that include an argument or activist strategy that can inform the model (for example discussions about applicability or usefulness of the model for creating social change)

A thematic content analysis methodology allowed me to classify sections of text into a manageable number of categories that represent similar meaning (Weber, 1990). The categories refer to patterns or themes within the content of the text that are directly expressed or derived from the data through analysis (Hsieh \& Shannon, 2005).

Organizing the raw data into categories facilitated the process of searching for similarity and contrast among the categories themselves, allowing for analysis of the themes that emerged.

Content analysis allows for a wide range of analytical strategies to address various research goals. Some projects may work with a strictly textual analysis, quantifying the frequency of words within a text; while others might be more impressionistic, focusing on inference and interpretations (Hsieh \& Shannon, 2005). This dissertation did not center on quantifying information, but in some cases used descriptive numbers related to recurring themes and areas of converging emphasis.

The analytical strategy for this dissertation went beyond a description and summation of data to develop interpretation and analysis. Patton (1990) calls for a rich description of data as an initial step, but urges researchers to move beyond simply showing patterns in the data. In the process of interpretation and analysis, we make sense of data "to theorize the significance of the patterns and their broader meanings and implications” (Braun \& Clarke, 2006, p. 84). In this way, I focus on understanding the 
multiple meanings of participants' stories to go beyond a literal reading of their words. Braun and Clarke (2006) discuss the importance of using a thematic content analysis to "examine the underlying ideas, assumptions, conceptualizations and ideologies that are theorized as shaping or informing the semantic content of the data” (2006, p. 84).

I followed Marshall and Rossman’s (1999) recommendation of using the preliminary research questions and the related literature as guides for the initial stages of analysis. I attempted to map the Link and Phelan model onto the responses, in particular searching for sites that correspond with the model's understanding of power. As a guide for my analysis, I looked for responses that connect back to the model's four elements. As a first step toward analysis, I created a set of a priori categories to serve as an initial coding guide (see appendix B). The categories were derived from the Link and Phelan model of stigma, and my own involvement with OCSC. This coding guide evolved as new themes emerge, but did provide me with initial support in working with a large number of transcripts since it would not be possible to retain an overall sense of them through memory alone (Smith, 1995).

The use of a pre-existing set of codes as an initial coding guide has been termed a directed approach (Hsieh \& Shannon, 2005), or a theoretical analytical strategy (Braun \& Clarke, 2006). Since this dissertation seeks to extend the Link and Phelan model of stigma, in particular in regard to their conceptualization of power, the use of a directed strategy for analysis is particularly appropriate (Hsieh \& Shannon, 2005). The Link and Phelan model has helped focus my research question, as well as provided me with initial insight into the goals of anti-stigma work. Likewise, the model provided me with a first 
step in analyzing the appearance of themes and relationships between categories (Hsieh \& Shannon, 2005).

The specific process for analysis was derived from Braun and Clarke’s (2006) outline of procedures for thematic content analysis. First, the audio file of each interview was transcribed. Each interview was added to the existing database of relevant materials and data. I read each transcript for content before conducting the next interview to allow me to identify key themes. I worked with Nvivo, a qualitative data processing software to assign codes to each interview. This allowed me to refer to relevant pieces of text, while also making it convenient to return to the broader interview. Braun and Clarke describe the analytical process as a move back and forth between the entire data set, the coded quotes that are being analyzed and the analysis that is being produced. This recursive process involves returning to previous phases to examine their congruence with current interpretations.

When all the transcripts were finalized, I read each transcript to become immersed in the material, jotting down initial ideas as they emerged. As I read the transcripts I sought quotes that provided rich material for analysis, preserving each quote by coding it in the interview and conserving the original context. I worked with the initial coding guide, which was central to my analysis of all the materials. As I found material that was not included in the initial guide, I continued to add and refine categories.

As I reviewed materials I tagged each piece according to the coding guide, allowing me to identify repeating patterns and document connections between the motifs and participants. Once all the material was coded, I recombined the data to group segments that had similar content, allowing me to review data one broad theme at a time. 
This will gave me a chance to compare and contrast participants’ perspectives. I noted the themes that were shared across multiple participants, as well as points of divergence between them.

This thematic analysis strategy is similar to the one utilized to carry out my master's thesis research (Alvarado, 2007). In that project I also conducted a thematic analysis and utilized coding as a way of identifying patterns and contrasts within written material. I conducted a quantitative measurement of a particular criterion, since one of the goals of the project was to gauge how much a particular topic was being covered. Even though I used descriptive numbers to organize the results, the bulk of the project was focused on qualitatively understanding how the participants were conceiving the specific subject. 


\section{Chapter 4: Findings of the Study}

\section{Overview}

The data for this study was gathered through semi-structured interviews with 10 consumer/survivor activists. The interviews ranged from 50 to 80 minutes. The interviews were structured according to the Link and Phelan model of stigma, and the questions and prompts sought to have the participants illustrate the different aspects of stigma that they encounter, as well as their anti-stigma work as activists. The interviews were planned to allow me to compare and contrast the positions of the participants to the Link and Phelan model. The questions were designed based on the model, as well as my experience with members of the coalition, and existing literature.

For the first element of the model, labeling, the question was focused on choice of language, asking for their choice of terminology around labeling and diagnosis. For the second element, negative stereotyping, the question addressed negative associations with diagnosis, such as “broken brain” or "illness like any other”. In the third element, separation, the question concentrated on exclusion and integration within communities. For the fourth element, status loss and discrimination, the question probed how participants conceptualized processes for creating structural change, and what their priority strategies would be for creating change. The final question asked them to explore the connection between power and stigma in their experience, as well as directly prompting them to address grassroots power. Because of the semi-structured format of the interview, the answers to questions did not follow a strict order, with topics emerging at different points. Because of this choice in interviewing method, the material was 
analyzed not by question, but according to the themes that emerged and their connection to the model.

The research question that guides this dissertation is as follows: How does a consumer/survivor activist perspective inform the Link and Phelan model of stigma? The Link and Phelan model serves as the conceptual lens that guides the analysis phase of the dissertation. The specific analytical goals that structure this analysis focus on identifying themes that assist in explicating the model, explicating power dynamics, and identifying activist strategies that inform the model.

The findings section addresses these analytical goals, and it is organized according to the elements of the Link and Phelan model of stigma. While these elements are not discrete and there can be overlap in many areas, I have used the sequence of components to structure my presentation of findings. Within each section, I discuss how the Link and Phelan model applies within the context of psychiatric stigma, identifying areas of correspondence, as well as exploring the scenarios that diverge. In this way I hope to illustrate the applicability of the model in this context of stigma, as well as to elaborate on aspects of the model that were not taken into account in the conception of the model.

The analytical strategy for this dissertation is content analysis, focused on the emergence of themes. This way of organizing the data allows me to speak about the patterns that I observe in the participants' responses and I have organized the findings to compile similar topics together. This organizational strategy does not imply that the themes are disconnected, nor that the elements are discrete. Indeed, each theme cuts 
across multiple elements and even within each excerpt of the participants’ words it is important to understand the way that several of the elements come into play.

For ease of readability I have grouped similar items to present a coherent thread throughout the findings. For example, when discussing issues of power and resistance it is not possible to limit the discussion to a single element since Link and Phelan present power imbalance as the underlying current through the entire process. Likewise, the discussion of power is grouped by similar topics such as lack of legitimacy or agency and participation. While these issues are intricately connected, I have separated them and grouped them into themes to assist in organization, but there is no implication that they occur separately.

The findings chapter is organized into five major sections that correspond with the four elements of the stigma model as well as the separate component of power. Beginning with labeling, the focus is on issues of language, diagnosis, and differentiation. The second element, stereotyping, is centered on negative stereotyping, discussions of chronicity, disease, and flaws. The third section, separation, addresses issues of exclusion and dehumanization. The fourth element of status loss and discrimination centers on the structural aspects that affect life outcomes. Finally, Link and Phelan propose power as the underlying current that catalyzes the other elements into creating stigma. I discuss at length the power differentials that concur with the Link and Phelan model as well as proposing a different conception of the power involved in resisting the process of stigmatization. 


\section{Labeling}

Link and Phelan present Labeling as the first element in their conceptualization of stigma. They emphasize the active choice involved in determining the social relevance of various characteristics of the stigmatized person or group. Difference is socially constructed as diverse attributes that are assigned salience, but the very process of construction becomes so normalized and naturalized as to become invisible. They emphasize that labeling is a process, and focus on the person assigning the label rather than characteristics of the recipient. The language Link and Phelan choose is meant to emphasize that labeling is a process, and moves the focus from the person who receives the label to the one who assigns it. By evidencing labels as constructions they intend to make the process visible, allowing for critical analysis and questioning.

In their responses, all participants in this study illustrate some of the ways that the stigma model plays out in the social construction of psychiatric diagnoses. There is a compelling match between the concepts that Link and Phelan present and the experiences of the participants in describing labeling as a social process. In addition to a direct connection to the model that Link and Phelan present, the participants also focused on the ways that they and others oppose the labeling process. They are active players in resisting the labels that have been placed on them, as well as in proposing alternative approaches to diagnosis and labeling.

The participants’ responses support Link and Phelan’s emphasis on uncovering the process of labeling and calling attention to the mechanisms and people involved in defining them as different. They questioned and challenged the procedures that would set them apart from others. As one participant states, "I think that people need to know that 
this person isn't just somebody that is schizophrenic. That someone gave them that label” (S.K.). Thinking about the people involved in labeling takes away the idea that these labels are natural and unquestionable.

This participant, while trying to avoid labeling, still prefers language that calls attention to the labeling process:

Well, I tell people to try to avoid labels if they can. If you're talking to someone and you want them to know, there's times you have to use that language. So there's times you have to say “this person is a person who was diagnosed with, or labeled with”. I like that better than saying "this person is a person with schizophrenia”. "This person is actually a person who was labeled or diagnosed by someone with schizophrenia”. (S.K.) The participant goes out of her way to emphasize the fact that the diagnosis was assigned “by someone”. This emphasis matches with the approach Link and Phelan have taken of moving away from a language of attributes assigned to targets of stigma, to focus on the person handing over the label.

This emphasis on revealing the labeling process was repeated by seven of the participants. One participant calls direct attention to the person assigning the label: "Because I think that people need to know that this person isn't just somebody that is schizophrenic. That someone gave them that label” (S.K.). She develops her point later on by addressing the inconsistency of diagnostic judgments, and how they are applied in social settings.

There's a lot of people walking around here that people would say that that person is a person with schizophrenia if that person had already received 
that label. .... I mean there's police officers, there’s teachers, there’s a lot of these people that if they went to a psychiatrist they would be labeled or diagnosed with a certain thing, with schizophrenia, with bipolar, major depression with psychotic features. (S.K.)

In this way the participants invite us to question the validity of the diagnosis, and they resist the passive role assigned to them by the medical model. In this latter excerpt, the participant challenges the veracity of the designation by talking about people who might fit the parameters of a psychiatric diagnosis, but haven't been labeled yet. The participants ask us to question the relevance and accuracy of the diagnostic system by calling attention to how arbitrary and unreliable the application of categories can be. Another participant calls attention to the diagnostic process, asking us to question what is defined as pathological: “That's where I think that the areas become a little grayer about who's going to be the arbiter of normal” (L.S.).

The discussion surrounding labeling and diagnosis centered on challenging and questioning the labels assigned. In the previous cases the challenge centered on exposing the person and process involved in labeling, but the participants also took other avenues for challenge.

In one case, the participant questions the validity of the category itself, refuting the authority of the psychiatric model of illness: “They kept saying 'we've unmasked your underlying bipolar', and it's like 'how do you know where this starts and this ends?"' (C.R.). Continuing in this vein, another participant discusses the vagueness of the label, and the breadth of symptoms it covers: 
You can get committed or taken to an emergency room and labeled for not being able to stop crying, for god's sakes. And unfortunately they'll give you the same label as the guy who just shot somebody because you're psychotic and that lack of differentiation is really toxic. (C.F.)

This participant discusses the damage that oversimplification and lack of differentiation can bring on. By assigning people in very different situations the same label, it extends the negative associations that perpetuate stigma and discrimination. For example:

That was the same as Russell Weston, the guy that runs up to the white house looking for the time tunnel and tries to shoot a bunch of people and gets shot. So there's no differentiation, there’s no specific category, the labels are very crude and they're subjective, and you can send the person to 5 different people and they can come out with 5 different diagnoses that can all be valid. (C.F.)

This comment critiques the validity of the diagnostic system and the reliability with which it can be applied. In this other comment, the participant echoes the argument that Link and Phelan bring forth, that labels are based on gross oversimplifications in order to be able to fit people into categories:

My personal belief is that they're artificial categories, you can get some predictive value out of it, but essentially it's taken an environmentally integrated organic problem and encapsulating it in a totally blunt instrument. The DSM is not good, and you get better outcomes if you don’t label people and if you treat them in their environment. (C.F.) 
The issue of language has been strongly contested in the history of the consumer/survivor movement. These participants echo some of the discussions present in the broader movement, and also support some of Link and Phelan's points on terminology. A lot of importance is placed on the power to choose one's label, instead of having one imposed from the outside:

To me if somebody wants to call it an illness, fine, if somebody wants to call it a disease, fine. The individual, him or herself though. If you want to do it and that person doesn't want it, then out of decency you would hope you'd shut up, bite your tongue or whatever. When I'm working with someone who is uncomfortable using the term illness or disease I just ask them, I say "what do you want? Do you have something you want to call this? Or do you just not want to call it anything?” (L.S.)

The simple act of respecting a person's preferences in the area of terminology carries tremendous weight. Allowing each person to define their own experience, as well as recognizing the painful load that terms carry is a powerful move in resisting stigma. This participant speaks about the diversity in language, and the significance of language choice:

When it comes to language that you're trying to use in the mental health field, ... it's so much up to the individual and how that person identifies. There's a very large spectrum of people who might be with the more traditional medical model and do not mind being called patient, and there's some people who think it's completely stigmatizing and offensive to label them patient. (M.J.) 
Likewise, this participant discusses the respect for people's choice of language: "allowing each individual to define for him or herself what is a quality life. And if that means that you don't want people using labels, ... saying that you have a disease, then fine, because some people need that” (L.S.).

This participant addresses the ways she alters her language in accordance to the context:

I say a person with lived experience of severe mental health issues. But if I’m talking to a physician I would probably just say I've been diagnosed with schizoaffective disorder. I’d say 'when I was 19 I was diagnosed with schizophrenia', so I talk about it in terms of the diagnosis, because that's what they care about, the medical model diagnosis. (K.H.)

The participant expresses her preference for language that prioritizes her identity as a person, and describes her experience in language that does not match a psychiatric diagnosis. However, when she enters a territory that supports the medical model, she switches to traditional medical language. By using the medical terminology she is not necessarily endorsing it, but utilizing it as a way to communicate within the existing health care system.

The issue of language and terminology has been central to the push from the consumer survivor movement. Taking the Link and Phelan model into consideration, this would act as the foundational aspect of stigma: the process by which differences are designated and labeled forms the basis of creating stigma.

The consumer/survivor movement has pushed for the possibility of defining their own terminology instead of having one imposed. The language continues to be in flux, 
but the movement demands the right to deliberate and discuss the meaning of language to avoid imposing terms that promote exclusion.

At the same time this advocate recognizes that language can serve as a mantle that obscures people's ideology, allowing for more subtle forms of discrimination: We've worked hard at helping people to at least have an air of openness, of being more sensitive to differences. And so ... it gets people sometimes in a place where they can say the right things, but it's not making a change in how they act. So the behavior doesn't correspond to the language that they're using, which to me is the most significant thing. In fact if I had to choose, would I want someone to say something bad toward me or act badly toward me? I would choose the former. If you're gonna say something bad but then you're gonna behave in a way that doesn't adversely affect me, then fine. (L.S.)

In this scenario the participant discusses the ways in which language can be used to placate or dismiss while failing to address the person's real concerns. He acknowledges that there have been gains in sensitizing practitioners to the power of language, but that it can be a superficial change does not change discriminatory behavior.

As a departure from the Link and Phelan discussion on labeling, two of the participants also talk about the positive aspects that labeling and diagnosis can bring. In the case of psychiatric diagnoses, labeling can be more than a precursor to stigma, it can provide a much needed explanation for personal experiences, as well as a sense of validation and an approach to a community of peers. While this was a minority opinion, these participants illustrate an aspect of labeling that Link and Phelan did not address in 
their model--the ways that a label can be an initial step in resisting stigma through a validation of lived experience as well as of seeing oneself as part of a community of sufferers. As this participant states:

But for other people it was "my diagnosis made me understand why I do these certain things that don't seem to fit in. It helped me relate to other people with the same diagnosis... That really opened my eye to... what's really important is how is that diagnosis delivered, and how is that diagnosis received. And even before how is the diagnosis delivered, how is the consumer prepared to receive the diagnosis. From the very beginning of the process to the end, it seems to me that in there lies a great potential for using diagnosis really as a tool for recovery and empowerment. (A.P.)

This participant explores the ways that the process of establishing a diagnosis can be a positive experience if the consumer has been prepared to receive the information. He emphasizes the opportunity for personal connection that the diagnosis can offer, being able to share experiences with others like him. Likewise, this participant talks about the validation that can come from a diagnosis, I actually know some people who found the label liberating. Like I have a friend who has some pretty intense struggles that he terms ADHD and he was completely liberated when as an adult the got that label. Because he's the standard, very bright, but he struggled in school, things didn't make sense. He's got these little siblings like that things were coming to really easily, he seemed like an underachiever. And so having an "oh this makes 
sense”, it's like "oh my god! This is exactly what!" You know, so that made a lot of sense. (C.R.)

In this case the diagnosis provided validation; an explanation for aspects that have seemed confusing or unclear, an external support agreeing with issues that have been internal in the past.

A central issue regarding labeling was the separation of personhood and diagnosis. Participants preferred terminology that was based on adjectives instead of nouns as a way of emphasizing their humanity. In this way, they resist a discourse that is based on a more totalizing response and over-objectifies them, and equates their identity with disease. Many participants discussed the importance of separating people's identity from their psychiatric diagnosis, refusing to have their identities reduced to a medical label. This corresponds with Link and Phelan's discussion of labeling as oversimplification, an initial step in generating stigma. This participant illustrates the point:

It's not as common to say "I was diagnosed with”, or "I have", it's definitely "I am", it's a lot more definitive. The way that it was taught to me, you’d never hear somebody say "I am cancer". ... language can be, maybe not intentionally, but pretty subliminally powerful as far as identifying yourself, how you feel about your diagnosis, and it being part of your identity, and how people are able to relate, and your self image”. (M.J.)

She talks about the prevalence of equating diagnosis with personhood, and also discusses some of the personal consequences of being exposed to that characterization. 
The primacy that a psychiatric label takes in a person's identity is understood to be a reduction of a person's complexity, a process of dehumanization that corresponds with Link and Phelan's discussion of stigma creation. One participant states: “when somebody says 'he's a schizophrenic' or 'she's a manic depressive' for whatever reason that becomes for many people the significant qualifying element, or the defining characteristic of that person” (L.S.). This emphasis on the label as primary corresponds with Link and Phelan's discussion of the labeling process in stigmatization. Their conceptualization proposes that as a label is assigned, complexity is reduced and the social salience of the category is increased, a concept illustrated by this participant:

"If you have a deviant status, if you're anything outside of the WASP sector, that [the diagnosis] becomes your primary status. It can be such a minute part of who you are ... it's part of mental health, as soon as it's known ... it tends to be what people, the number one thing that comes to their mind. (M.J.)

The reduction of personhood to a label represents the first step in the creation of stigma, according to Link and Phelan. This participant talks about the way that this dynamic operates in interactions with other consumer/survivors: "I think "there’s so much more about you I want to know rather than your diagnosis, I don't really care what your diagnosis is. I care about your experiences, what you have experienced, what you do experience, but the label I don’t really care about” (A.L.).

The participants rejected this imposed reduction in identity, pushing for a more complex understanding. This participant speaks about the rejection of imposed labels, and acceptance of alternative conceptualizations: "I think is the most damaging around 
discrimination and stigma is that stripping away your identity that Goffman talks about. And when you take away people's hopes and dreams, that does way way too much damage, and so getting people connected back to their hopes and dreams...” (A.L.). This participant rejects the assumption that psychiatric illnesses are chronic, and points out the hopelessness of such a position. By pushing for the right to have dreams, this participant is refusing to have her goals diminished. She identifies with Goffman’s (1963) work, rejecting the reduction of identity inherent in stereotyping.

This reclamation of identity is deeply felt and widely held among the participants. This participant talks about the emotional impact that language and identity have on her: “it really pains me when I hear people introduce themselves as their diagnoses, 'hi, I'm so and so, I'm borderline' sometimes that even comes up before their name does, and it breaks my heart” (A.L.). Likewise, another participant talks about the emotional pain involved in how people use language: "it actually hurts to hear that type of language, I mean I understand that so much of it is ignorance, but I am not 'a cutter' I am not 'a depressive, I'm a person who's experienced certain things” (C.R.). One participant speaks about the incredible impact that separating personhood from label has had for her:

I can nearly remember the time when it dawned on me that I was not my diagnosis. It was so profound this epiphany, I'm not L.T. the schizophrenic. I'm an artist, I do all these other things and those are the things that really define my life, that set me free. To realize that is huge. (L.T.)

A choice of language that has been taken up by the consumer survivor movement has been called person-first language. This terminology focuses on the recognition that 
personhood should come first, and that people’s identity should not be reduced to a diagnosis. As this participant states, "I believe in person first language, so I might say a person with schizophrenia, bipolar, borderline. Rarely do I say a schizophrenic” (K.H.). Another participant speaks about the impacts of using this language: "using that personcentered, person-first language has direct effects on people being able to recover, or lessening the secondary trauma that happens with being labeled that happens to people” (C.R.).

In regards to choice of language, this participant calls attention to the role of professionals in determining the terminology that people use to describe their situation: "I'm always not a fan of, a therapist taught me called the ic-ing, alcohol-ic, or schizophren-ic, that kind of trending. A lot of people also say, I've heard, and I think this is language derived from their practitioners or from their providers, saying things like 'I'm bipolar'” (M.J.). Likewise, this participant speaks about the ways that medical terminology and labels are internalized, making it difficult for a person to define their own experience: "I hear that all the time, and I say "that's not you speaking, that's your treatment team speaking" and this idea that we have to make people parrot the words that they’re mentally ill, it’s part of stripping away identity” (A.L.).

The participants call attention to the ways that the labels and their messages become internalized, making them almost impossible to question or reject: "if you view parts of you as symptoms it gets a little sticky around what's yours and what has meaning, and what's sick and something that someone outside of you needs to do something about” (C.R.). In this other situation, the participant discusses the structures that support a diagnostic system, and pushes people into accepting a label: "the only way to get your 
benefits is by admitting that you're sick, or somebody identifying you as sick, all these things go along with the disability label. The problem is that you have to buy into that disability label” (C.F.). In this way the consumer/survivor is forced to accept the label that is imposed in order to receive support, and that label can be detrimental when internalized.

An avenue for resistance to imposed labels has been to honor the terminology that people have defined for themselves. In this way, participants recognize the value of reclaiming ownership of one’s identity. This participant talks about her language choices: "I refer to people I talk about, people with mental health challenges or mental health issues, because I don't want to define their own experience, and I feel that if you leave it at challenges or issues that leaves people free to describe it however they want to describe it” (A.L.). Allowing people to choose their own terminology is an important step in interrupting the stigma created by external labels.

Link and Phelan present their first element in creating stigma as a human difference that is imbued with social significance, and then used as a label to distinguish people. The participants spoke repeatedly of similarity instead of difference, of finding common ground with others. They emphasized the ways that people with psychiatric diagnoses are not so different from others. This serves as a challenge to the emphasis on difference that pushes stigma forward. In this way, the participants are resisting the imposition that they are outsiders, beyond the bounds of normalcy.

Many participants posed that receiving a psychiatric diagnosis could happen to the people that least expect it. Given the right circumstances, anyone could find themselves in that position. There is emphasis placed on the idea that every person has 
the potential, or is vulnerable to the process of diagnostic labeling. Some of the patients emphasized the role of trauma: “Chances are if you've been abused emotionally, sexually, physically there’s gonna be some trauma left behind, and that very well can manifest into a health problem and I believe that is something that many people in our society have experienced” (M.J.). In a similar vein, this participant discusses how severe trauma has the potential of putting people in crisis: "That would be enough to freak anybody out” (C.F.). This sentiment is echoed by another participant: “every one of us given the right combo can go into all sorts of states” (C.R.).

The participants downplay the boundary between normal and abnormal, emphasizing that everyone has a potential for crisis: "when you see that really it's just a chance of fate, and you could be on the other side of that equation” (A.L.). Likewise, one participant talks about the fragile border between patient and staff: "Anyone could end up being a patient here. They give examples at the NEO without mentioning names: 'I know someone who was a staff person here, who had no history of anything, and that person is, or was a patient'” (L.S.). This perspective stands in contrast to the medical model understanding of mental illness. By emphasizing the commonality of psychiatric distress as well as the environmental factors that can lead to a crisis, these participants are moving away from pathology into normalization of their experiences.

A message of similarity is in line with Link and Phelan's conceptualization of opposing stigma. If stigma is based on differentiation, a powerful anti-stigma strategy is to emphasize commonality and normalize experiences that are defined as extreme. In this case, the participant refers to a recent report that emphasizes the prevalence of psychiatric diagnoses in order to normalize them: 
It goes really back to the surgeon's general report, and the main media message that came out of that report is that mental health is fundamental to health... it was really about the idea of not segregating people, the one in five message was a result of that (K.H.)

By speaking about one in five, this participant is referring to a statistic released by the surgeon general (U.S. Department of Health and Human Services, 1999) that explained that in any one-year period one out of every five people in the Unites States have a diagnosable mental illness. This messaging is used to discuss how much more common a psychiatric diagnosis is than is usually understood.

Similarity was also discussed as a way to shorten the distance between practitioner and consumer. As this participant states, "We have counselors who have been labeled who are looking in the DSM and labeling us. But we don't know that they were labeled, that's the difference” (S.K.). In this way the participant calls to attention the similarity between counselors and consumers, moving toward equalizing the relationship. This implies a rejection of the distance imposed by the medical relationship, and an emphasis on the similarity between the parties.

One way that the participants reduce social distance is by understanding human experience as a continuum. This idea challenges the border between what's normal and abnormal by emphasizing that the difference is based on degrees, not absolute differences. This challenges the medical model's focus on pathology and interrupts stigma by challenging the premise of difference.

The participants emphasized the common experiences that are shared across many as a way to minimize the experiences that have been inflated by labels: 
What's coming up more and more is that it's a spectrum, a continuum of human behavior, of consciousness. And so more and more it’s being accepted that these people, consumers just have a different of perceiving the world and interacting with the world. ...And so then you really do start to see that continuum. (A.P.)

These participants are emphasizing the similarities among people, instead of focusing on difference. The reference to the continuum implies that having psychiatric symptoms does not set people aside, but keeps them as part of a broader shared experience. The reference to being human addresses the ways that people with psychiatric diagnoses are stigmatized as less than human or incomplete persons. Similarity was also addressed while demanding tolerance for difference. This participant talks about making room for diversity:

That was one of the hallmarks of many of Louis Armstrong's songs, being able to identify that we're different people and being able to appreciate that difference. Not try to make a melting pot where those differences go away but at the same time realizing that there are commonalities. The fact that we're all humans will always make us more similar than dissimilar. (L.S.)

This participant is speaking about the rights of people to be different, while still being accepted. Moving back to emphasize commonalities brings him to reclaim the humanity of people with psychiatric diagnosis.

The participants’ responses correspond to the element of labeling in the Link and Phelan model. In the context of psychiatric stigma, the participants emphasize issues of 
language and the arbitrariness and unreliability of diagnosis. They resist the stigmatization process by calling attention to the person who assigns the label, critiquing the diagnostic process, and reclaiming the right to choose their own definition. The participants resist labeling by insisting on separating personhood from diagnoses, and promoting person-first language. The participants also resist differentiation by emphasizing similarity and a continuum of shared experience. In the next section I analyze the connection between the second element of the model, stereotyping, and emergent themes in the interview data.

\section{Stereotyping}

The second component in the Link and Phelan stigma model is stereotyping. Their conception of stereotyping focuses on the linkage between differences and undesirable characteristics. The authors speak about the preconscious level of stereotypes that leads people to make split-second decisions. In addition, the authors point out that this is the most salient aspect of stigma within the psychological literature. While there are stereotypes that emphasize desirable characteristics, the authors focus exclusively on association with negative attributes.

In regards to psychiatric diagnoses, all of the participants focus on themes that support this element of the Link and Phelan model. The illness discourse is focused on flaws and defects, and the participants’ responses to this messaging are centered on resisting and changing it. They reject the emphasis on chronicity and lifetime illness, while they also shift the dialogue to issues of human diversity and the right to be different without being cast aside. 
There is a strong correspondence between this element of the model and the themes that emerge in participants' responses. This participant's words seem to echo Link and Phelan's proposal, speaking about the connection he sees between labeling and negativity:

The label is not able to be distinguished from the disease the way it works. There are different and more tolerable ways to refer to the disease, and more derogatory ways to refer to the disease, but if you're basically using it first as an identifier, and then the identifier itself has a qualitative aspect to it that is pretty negative (interruption) (C.F.)

He focuses on the importance of the linkage between a label and negativity to discuss the processes of stigmatization. Unfortunately, an interruption during the interview did not allow us to continue with this train of thought. Another response that supports the theoretical proposal of the model can be seen in this excerpt: "to me, if someone attaches a label to something that they would not want on themselves ... then to me they have already taken the step toward stigmatizing an individual”(L.S.). This participant is emphasizing the social aspect of negativity, rejecting an association that others would not accept. Similarly, another participant makes light of labels by bringing focus onto the negative connotations they carry: “As long as the term is identified as a deficiency in its meaning, you could call them purple cabbages and it would still have the same derogatory effect” (C.F.). Once more, this participant supports the Link and Phelan model by discussing prejudice as the basis for stigmatization: "Stigma is like a light version of prejudice. I know people have taken some pains to make a fine distinction as 
to what stigma is as opposed to what prejudice would be, but it really is grounded in prejudging people” (C.F.).

Negative stereotypes play a detrimental role in personal interactions. In this scenario this woman encounters stigma in what she hoped would be a safe space: "it was a social justice class, and I talked about being homeless. And this woman... looks at me and says 'I'm not very comfortable being around mentally ill people’” (A.L.). Likewise, another participant discusses the possibility of having negative stereotypes taint the interactions she has with others:

I just think telling somebody right off when they don’t know you, they're gonna have these ideas about who you are already in their head so they don't get to know you. And then every time you do something odd, they're gonna say “oh, you know she's just crazy” instead of saying “that's just part of who she is” or something like that. (B.T.)

This other participant discusses the negative interactions that can come with a stigmatized identity: “somebody who’s stigmatized doesn't generate empathy, they generate enmity and fear and concern, apprehension. Somebody that's a trauma victim ... generates sympathy” (C.F.). This point of view emphasizes the social costs involved in stigma, including the push for social distance. His comparison of a psychiatric diagnosis with a trauma victim serves to contrast the different social roles attached to both labels.

The participants illustrate many of the ways that negative stereotyping is attached to psychiatric labels. The everyday prevalence of negative stereotypes makes them ubiquitous and hard to resist: 
It's really acceptable and very common for the culture to make fun, discredit, stigmatize and make jokes about people with mental illness ... how common is it for all of us to use the adjective of crazy? I do it at least 10 times a day. (M.J.)

The respondent also explains how stereotypes are embedded in preconceived notions of people with psychiatric diagnoses. These stereotypes inform the ways that people interact with them: "even people who are fairly ignorant of what it means to have schizophrenia, or manic depressive illness or bipolar disorder they all have these vague assumptions” (L.S.).

The participants discuss the negativity that surrounds a psychiatric label. They critique the emphasis on problems, flaws, defects and limitations that they encounter in various interactions. The negative stereotypes are perpetuated across multiple scenarios: “those stereotypes are so prevalent in society. You see them on TV and you don’t ever see anybody who's got a job or has a family” (B.T.). This participant talks about the difference between a negative and a positive approach:

That's part of why I love ... person directed planning. Because you ask people and you get a sense of what their skills and capacities and strengths are that you don't get when you go through a typical treatment planning process that's always focused on the problem. And well if you always focus on the problem ... if all you have is a hammer, everything looks like a nail. (A.L.)

This participant is asking us to consider what a lens does to our perspective. By considering only limitations, it is less likely that observers will identify strengths. This 
idea is supported by another participant: “we have so focused on the things people can’t do or we think they can’t do, that ... we've disabled them even more, made them more profoundly disabled because of how we think about it” (A.L.).

The effect that schools of thought have on our worldview was central to the participants. There was a strong critique of the medical model because of its focus on deficits and dysfunction - tendencies that contribute to stereotyping. This critique of the medical model includes the premise of an underlying defect, often associated with chronicity. There was also discussion of the role that practitioners and medical establishments play in promoting negative stereotypes, as well as a rejection of the treatment options it offers.

In regards to psychiatric stigma, an illness perspective can have a direct connection to negative stereotyping because of the premise that symptoms constitute a chronic illness that will last a lifetime. This participant illustrates: “organizations say it's an illness, biochemical, or sometimes 'it's just something that this persons has' and they expect them not to recover. And they tell them 'you are always gonna be like this, the rest of your life”’ (S.K.). This participant illustrates the feeling of perpetuity that such an approach can convey: “just 15 years ago NAMI was selling everybody the bill of goods that mental illness was a lifetime sentence that you could only hope to maintain” (C.F.).

This idea of unending troubles fuels the negative stereotypes that serve as a basis for stigmatization. In this case, the participant talks about the way these ideas serve to color interactions:

I think people are not aware of the recovery aspects of mental health challenges. I think that also adds to the layer of stigma because once 
you're diagnosed, people don’t think you're ever gonna lose that ever again. It's like you're a loose cannon, something could always go wrong. (M.J.) This participant talks about the ways that an illness perspective can generate even more problems, creating a self-fulfilling mechanism:

They offer them no hope, and you offer somebody no hope... then they do see themselves a having no hope. They are like some of the people who are walking around ... so into their own world that they're just basically talking to themselves out loud talking to themselves and yelling. (S.K.) One form of resistance to the medical discourse centers on recovery and hope. Rejecting a model that offers little hope, the consumer survivor movement has focused on issues of strength and the positive aspects of people's lives. This participant discusses the importance of sharing a perspective of hope: “I don’t think that the message about recovery has gotten out there, that people do get better and live meaningful productive lives, and I think that's part of what has to happen too. That message has to get out there” (A.L.). In the same vein, this participant emphasizes positive change and the possibility of self-care: "I see mental health symptoms and mental health problems as that there can be recovery, there can be improvement made by the person themselves without having someone act on them, or some drug or whatever all the time” (S.K.).

By emphasizing strengths instead of limitations, a recovery perspective pushes for positive, concrete change in people's lives. This participant talks about the positivity of hope and higher expectations, taking small steps in improving quality of life:

There's organizations that come on more positive, and say ... 'I think you're capable of doing some things, you may be taking medication, but I 
think you're capable of volunteering', and it doesn't always have to be work, 'I think you're capable of going to take an art class, I think you're capable of taking the bus, I think you're capable of doing more than sitting around here smoking all day’. (S.K.)

This participant proposes her priorities for changing the way that consumer/survivors are treated:

What if every person who starts experiencing extreme states got the message in everywhere they went that this is a part of human experience? that people with unbelievably intense and extreme experiences get well, and they had a whole toolbox of stuff, and they were in the driver's seat around that, the expectation is that you are gonna get better. Someone said this yesterday ... we say "recovery is possible” like SAHMSA, but what she says is, "given certain conditions recovery is actually probable”.

\section{(A.L.)}

This inspiring perspective asks us to consider what it will take to make recovery probable, what changes we need to see at a broad level in order to make hopes and aspirations accessible.

The participants present an impassioned critique of the ways the medical model and traditional support services foster negativity and stereotyping. They focus on the negative outcomes that traditional treatment provides, in some cases discussing the damage this perspective can generate, an iatrogenic cycle. The very people that are intended to heal can end up contributing to the suffering that people experience. This participant illustrates: 
We get people that come out of school that are studying abnormal psychology books and people are already behaviorologists when they walk into the first internship.... They've been handed a curriculum that totally redefines and reifies, solidifies all those conceptions that may or may not really be accurate, but it's what the professionals base their interventions on, like the diagnostics, like the medical model. They're handed that and they don't even question it. At that point you're already in a deficit situation as far as stigma, it will be a byproduct of your point of view that exists just because of where you got your point of view from. (C.F.) This participant critiques the stance of providers, calling attention to the way that the small aspects of a relationship evidence underlying negative stereotypes:

If you really want to change stigma or discrimination then you have to stop perpetuating it. If you are a mental health provider, how do you write about people? do you write about them in a way that's ... respectful of the person as an individual? or do you write about them as an object? (A.L.) In more direct interactions, the participants recount events where providers' stereotypes became more evident: "I feel like the hospital staff have a tendency to treat people like they're two years old, or they're stupid. And just because I have an illness doesn't mean that I'm and idiot” (B.T.). This other participant speaks about the information management she engages in as she considers how to disclose to a provider:

I just made an appointment with a primary care provider and ... I was thinking "how am I going to present myself to this physician in such a way that the fact that I have schizoaffective disorder or schizophrenia doesn't 
cause a bad reaction?” She'll see from the medications I'm taking that I do have a significant psych issues so I can't hide it ... I'm used to giving this information and often having an adverse reaction, especially from a health care provider. (L.T.)

Facing negative stereotyping from a provider can be especially disturbing, both because it is meant to be a relationship of trust and support, and because there is an expectation that professional training and experience should include sensitivity to the problem of stereotyping. This scenario brings out stereotyping in a very explicit way: Yeah, it's kind of creepy actually. That they have protocols in emergency rooms if they see that kind of psychiatric label in somebody's charts as to what they can do or don't do.

[ interviewer] And is it specifically...

BPD yeah, which is the 'worst diagnosis you can have, your worst clients' is how I've had it described when I first asked about it. (L.S.)

In a similar vein, the participants discuss the way that the treatments themselves can be damaging and feed negative stereotypes. This participant discusses the role that medication can have in reducing quality of life: "I believe we're creating more mental illness through the way we use medications, like the iatrogenic, the worsening long term outcomes” (C.R.). The emphasis on pharmaceuticals as the main source of treatment leaves people vulnerable to overmedication, and the lack of information on drug interactions is particularly problematic when considering this participant's point: When you get side effects from it, you give a pill for that. And then when you get side effects from that pill, you give a pill for that. And then when 
you find out that the person's having some symptoms that are like they had when they first came to you, then you give them another drug, and then that drug has all its symptoms. So there's people on 12 or 15 pills. (S.K.) This cycle of dependence on medication has detrimental impact on people's daily lives, in turn feeding the negative stereotypes that are attached to psychiatric labels. In time it becomes difficult to distinguish where different characteristics originate: "the problem with our current psych medications is they have so many side effects for so many different people, and usually the people who are prescribing to you tend to view even your side effects as part of your illness” (C.R.). This participant discusses the difficulties in creating change within a chemical medical model:

Unless you are directly exposed or you specifically go and seek out this kind of information no one's gonna give it to you... not only are doctors not aware of it, because it's not something that they respect or validate, it's kind of a threat as well to the medical system that people don't need to be on medication their whole life... Actually prolonged medication can be even more harmful in some cases. (M.J.)

The participants reject an illness perspective that is based on a construction of internal defects and personal flaws. An illness message can serve to increase feelings of hopelessness and shame: "when I hear some of the anti stigma campaigns I come away feeling dirty, I come away feeling less than” (A.L.). This participant discusses the way that psychiatric conditions have been attributed to personal weakness: "they were seen as somehow responsible, that there was some character flaw that they had. I remember even 
a principal at one point who... goes "It's not our fault if this child lacks intestinal [sic] fortitude" (L.S.).

Many of the participants object to the illness discourse and challenge its accuracy: "I don't really think of it in terms of being an illness, I don't really subscribe to that" (L.T.). Likewise this participant rejects the analogies that are made to compare mental illness to physical illness: “I don't buy the 'illness like any other' thing” (C.R.). Similarly, this participant questions the validity of the illness argument:

You have the people who want to say "If you have schizophrenia, it's the same thing as if you had diabetes... I ... object to that comparison on the grounds that we have objective tests that can be applied to determine if someone has diabetes. We do not have those tests to determining whether someone has schizophrenia. (L.S.)

This participant critiqued the accuracy of an illness model in diagnosing, while this other one critiques the illness model in terms of treatment:

We have other tools in our toolbox besides medication. I think that also does a disservice to folks because if mental illness was like every other illness then it would respond to medication and people would be cured or would be not having problems. And yet people do have problems even after taking medication. (A.L.)

This participant asks us to give up the expectation that mental health can be thought of as similar to medical illnesses: "I think people want that sort of safety, that definite factor of "ok, well it's a medical problem, so is it cured or is it not?" 
and obviously there's a bigger gray area in mental health than in other situations” (M.J.).

The intersection between the consumer survivor movement and the Link and Phelan model is particularly interesting because there is a potential for interrupting negative stereotyping. Consumer survivor activists often support a positive understanding of madness, often calling for mad pride, which rejects the negative stereotyping inherent in stigmatization. This point of view stands in contrasts to an illness model centered on deficits. The responses among this group of participants reflect this recognition of positive aspects of madness. This participant states: “I'm mad and I did my best to make it a wonderful thing and make it so it doesn't interfere with what I do with my life and it can be a source of some of the things I'm able to do” (L.T.).

The participants recognize some of the costs of madness, but also emphasize the potential for benefits. This participant discusses the ways that madness connects to the positive aspects of her life: “I'm trying to figure out what is this madness, and can there be some good with it that's not over romanticizing. I know that my art is connected to a dark deep fertile soil” (L.T.). This theme is carried on in this participant's focus on improvement: "there are people who live every day experiencing voices and they don't interfere with their quality of life. For some people they actually improve their quality of life, so that's allowing a space for that” (C.R.).

The focus on positivity is not restricted to an individual understanding, but also carried on to social analysis. This participant focuses on the social value of madness: "it was just understood 'well they do things different than us, let's let them use those different behaviors for the benefit of our community”” (A.P.). By focusing on the 
contribution to a broader community, this participant resists the negative stereotyping that frames madness as a drain, and situates people with psychiatric diagnoses as full participants in their culture. This other participant rejects the social messaging that implies diminished social value: "I think of the stigma campaigns ... most of them I find offensive because there's pity behind it and I'm really not interested in pity. I want understanding, but not necessarily pity. We all have things that we can or can't do” (A.L.). By emphasizing the fact that everyone has different limitations, this participant is bringing out the shared experience that this implies.

In the previous section similarity and the construct of a continuum were discussed as ways of resisting the emphasis on difference that labels imply. In this section the discussion continues as the participants emphasize diversity and the spectrum of human experience. This emphasis on similarity, continuum, diversity and a spectrum of experience was shared by all of the 10 participants, making it one of the strongest themes in the responses. This participant explains how she thinks about shared experience: "real human beings... there is this spectrum of experiences, that everyone has, and all of us, every single person moves along that spectrum during their life” (C.R.). This focus on shared experience and acceptance of diversity acts as a challenge to negative stereotyping. The participants interrupt the premise of negativity, and push for acceptance of the diversity and variety of human experience.

The theme of mental diversity and acceptance of difference was emphasized as a way of understanding different behaviors and experiences: "What if every person who starts experiencing extreme states got the message in everywhere they went that this is a part of human experience” (C.R.). This focus on acceptance is repeated in this response: 
"it really requires people to become, in the larger culture to be more comfortable with a diversity of behaviors, acceptance” (C.F.). One participant discusses the resistance she faces when using a diversity approach: "A whole lot of us are really invested in the world being not being a spectrum, being made up of normal well people and the sick people” (C.R.). This participant talks about creating a space where rejection and negativity are not the norm: “just creating an environment that says that whatever your interpretation is of this, your experience is not inherently bad, it's how it affects you. Hearing voices is not necessarily bad” (C.R.). Once more, the focus on positivity instead of detriment is present: "I think that talking about diversity, talking about strength is much better than saying anti stigma” (L.T.). Likewise, this participant talks about actively recognizing the value in difference:

...Destroying the diversity of the culture. People that see things differently are actually valuable because the vision in the society is not necessarily comprehensive. To be able to see beyond the present circumstances and understand problems that will arise or things that need to be understood or worked on. It probably isn't the most socially coherent process, but is a necessity of civilization. (C.F.)

The second element within the Link and Phelan model, stereotyping, was a powerful theme for the participants. Their responses illustrate the way stereotyping plays out in a context of psychiatric stigma, including the ubiquity of negative stereotyping they face. The participants present some of their strategies for resistance, such as rejecting the defects implicit in an illness perspective, and challenging the chronicity and hopelessness it promotes. Their resistance centers on valuing human diversity, and 
reclaiming the right to be different. There is also a focus on the positive aspect of madness, both for individuals and at a social level. These strategies serve to interrupt the negative stereotyping that Link and Phelan propose as central to the process of stigmatization. In the next section I discuss issues of separation and exclusion.

\section{Separation}

The third component in the Link and Phelan stigma model centers on the separation of 'Us' from 'Them', the process of acting on differences through practices of exclusion. The authors propose that associating labels with negative stereotypes becomes the justification for considering the labeled group as fundamentally different. This differentiation then becomes the rationale for mistreatment and oppression. Taken to extreme cases, this process can render the labeled group "not human”. The authors discuss this dehumanization by presenting cases where the person's identity and their label are conflated, such as the case of "the schizophrenic”.

In understanding how the Link and Phelan model can be applied to the stigmatization of people with psychiatric diagnoses, the participants' responses illustrate some of their priorities. There is extended discussion of issues of exclusion, separation and lack of participation. In addition, the responses illustrate the processes of dehumanization that these participants face. Moreover, the participants brought up discussions of secrecy and addressed how disclosure can mark the beginning of exclusion for participants. The participants also resist the social exclusion imposed by stigma, and speak about their push for inclusion. 
The theme of exclusion is prevalent among the participants' responses. The participants speak about social distancing as one form of separation based on perceptions of mental illness: “As long the majority of the population understands these people as different, then there will remain that separation” (A.P.). Likewise, this participant speaks about being cast aside: "you make that divide wider and wider between you and the greater culture because of the label .... It makes you more and more of an outcast” (C.F.). This thematic of separation plays a strong role in the participants' narratives. This participant speaks about the telltale cues that signify separation and distance from others, and the difficulty in lessening that distance:

No one's really talking about that as poverty, and it's segregation. ...you've got your apartment in a place that everyone knows is subsidized housing unit, you've got your food stamps, so when you go get your groceries, you know. You have nothing going on during the day... if you do that for enough years, then you add on how hard is it to get to jump back over that huge chasm. (C.R.)

In the case of psychiatric stigma, the issue of separation includes being confined to an institution. The participants cite the role of fear in fueling separation and differentiation. They offer multiple examples of people pushing them away because of fear: "90\% of the movies on TV are about people that are eccentric or different. And people will pay to go see movies about them, but they don't want them living in their neighborhood, they don’t want something that isn’t sanitized” (C.F.). This other participant talks about the consequences of trying to categorize people, to focus on difference: "the art of segmenting is part of the reaction to having to put people in boxes, 
'well this is them and not me' when in fact it's usually based in fear” (K.H.). This participant discusses the way that fear makes it difficult to truly integrate people who are in residential facilities into the broader community:

They talk so big about community inclusion, and community integration "oh, those are our goals". For one thing, the community is not ready for people that you say have this label. They're already stigmatized, the public already have this from higher sources, that these people with this are different, they're to be feared, they can get violent easily, so they already have these ideas about them. (S.K.)

Even when facilities are geographically close to residential areas, they can be kept socially invisible, as this participant illustrates:

The first time I had been to POSH, I have lived in NE Portland almost all my life ... and I've never even seen it. ... it's a huge hospital and you would never know it was there, and I find that really, there's a huge movement for exclusion, for segregation, not seen not heard. (M.J.)

The resistance that the participants face from communities acts as a very tangible illustration of separation and exclusion. This participant talks about the discourse that is used to fuel separation: "people thinking they're keeping everyone safe 'we're going to keep you safe, we're going to keep this element away from you'....That's primarily where I see the motive behind legislature and separation, it's seen for the greater good of the people” (M.J.). This kind of messaging is based on segregation and distance, serving to reiterate Us and Them dichotomies. The association between disease and fear and distance is eloquently illustrated by this participant: 
It became medicalized over time, and with the medicalization it became identified with a disease. And with any aversion to a disease, like society tends to, like leprosy which is a good example, they'd sequester people for fear that they might catch it, but also people didn’t want to be around it. (C.F.)

Even within the mental health system, the participants address some of the more covert separations between peer specialists and traditional providers. The difficulty in fully including peers into their roles can translate into subtle exclusions: "they want to hear us, but ... they can be kind of intimidating, and again I don't think that's intentional but the result is that some people end up feeling edged out, or less relevant, uncomfortable to talk” (B.T.). Likewise, this other participant who works as a peer specialist within a traditional medical institution states: "I feel a little more comfortable around the patients than I do the staff, and that is true to some extent. Not all staff, but for some staff, especially whose mindset is very much in 'us and them'” (L.S.).

This participant critiques the distancing inherent in a traditional therapeutic relationship:

And the mental health profession is really good at putting distance between the professional and the person they're supposed to be helping. And that clinical gaze for lack of a better word, I find to be offensive. People talk about boundaries and that you have to be separate. But you can be authentic and in a human relationship and still have boundaries, they're not mutually exclusive. (A.L.) 
This sensation of distance, of being treated differently by a therapist is echoed by this participant: “I believe that the terminology and the diagnosis isn’t as important as the treatment of the person just as a person” (M.J.), as well as this one:

You are given a really intensive training, and it's for people who have identified it was like 40 hours, you're given all these really amazing tools, and the culmination of the training is that in order to support people you treat a person like a person, that's really how it can be summed up. (M.J.) The issue of separation and exclusion can become ubiquitous, making it so commonplace as to seem logical and normal. This participant recognizes an underlying rejection and distancing from people who are intending to be inclusive:

I had more than a few people ... basically say "I'm so glad you finally found a place that fits you, I'm glad you found a place where you can be successful”. Like I wouldn't be capable of holding the same job as a research worker at some other agency, very much in the sense of "It's really nice that there's a place for people like you ... people who have mental health problems need special jobs and should be kind of kept separate in their own kind of jobs, instead of regular people jobs”. (M.J.) Link and Phelan discuss the effects of separation and differentiation as a process through which people can be thought of as less than human. This participant almost echoes Link and Phelan’s proposal: “Just removing the personhood from the individual. Then as soon as you do that I think that it's much easier to objectify a person and then it becomes easier to do things to that person, because they're not really a person anymore" (L.S.). In this way a reduced identity is presented as a stepping stone to broader social 
consequences, including stigma. Objectifying people is presented as a negative consequence to distancing and dehumanization, particularly within a therapeutic relationship:

The term you might be looking for... is turning people into behavioral objects. Where they become objects of their behavior and they can be manipulated that way as far as what that person needs to do ...I think that as you look at the impact in people's lives for people that are generally processed through the system, they become packaged. Once they have their package of treatment a certain way, it’s dehumanizing. Nobody would call it stigma because they're basically calling it help, but it's highly stigmatizing and it reinforces all those things that a person doesn't want to feel about themselves, so it's counterproductive therapeutically. (C.F.)

The challenge to their humanity resonated deeply within their experience. This participant hopes to resist the process of dehumanization: "the primary thing is to help work, is to maybe begin to undo a little bit of, hopefully for the most part, what has been an unconscious process of dehumanizing, or depersonalizing” (L.S.). The participant emphasizes similarity and shared experience as a way of resisting dehumanization:

I think that we all hear voices. And I mean it, I think that you do, and I think that I do, and I think that if we don't see this as a part of a continuum of the human experience, then that takes us one step closer to the stigmatizing process because it does create an Other, because this person isn’t complete, not maybe that they're not human, but they're not 
completely human, they're not completely part of the human experience. (L.S.)

The issue of humanity, and belonging to human experience came up repeatedly and in various contexts. When discussing people's requests to see her medical records, this participant explains her refusal: “it tends to otherize people and I really don't take to being otherized. I want you to relate to me as a human being” (A.L.). This participant reiterates the concern that relationships are affected by labels and separation: "trauma can't be addressed until you remove the stigma from the relationship. The way that people are seen tends to marginalize their problems and marginalize their humanity” (C.F.).

In the context of dehumanization, the theme of treatment was brought up repeatedly. The participants bring up examples of situations where they were treated almost as a different type of people. When discussing a school's treatment of children with psychiatric labels, this participant says: "it was still deeply entrenched that there were clear policies and procedures in place that the purpose of them was to punish these children for exhibiting behaviors that interfered with the functioning of the normals" (L.S.). Likewise, one this other participant was able to receive help, it came in the form of a hospitalization, where she felt the suffocating effects of the institution:

For the past 27 years I've been just as depressed, just as suicidal as I ever have been, but all of a sudden, because I made a call and asked for help, I wasn't even allowed to have plastic utensils ... I haven't seen sunlight in 5 days... I've been eating with my hands for 5 days, I've been spoken to 
like I'm an imbecile, and I haven't been allowed the common courtesy of wearing a bra. (M.J.)

The dehumanization within hospitals pushes these participants to question the very principles on which they operate. This patient challenges the humanity of the punishment/rewards systems set up in psychiatric hospitals:

You're not allowed by law to punish patients. But every patient here knows if you lose privileges you're being punished. So what does that say to the patient, when you send them somewhere and all their privileges are being taken away? “I’m being punished”. (L.S.)

Likewise, this participant illustrates some of the effects that being locked away can bring about, and the way that can exacerbate a difficult situation:

When you're in a hospital setting like that it can be incredibly isolating. There is this sense of, maybe it's just me but I've heard other people have the same experience, thinking "oh my god, I'm totally lost, this is going to be my life now, it's gotten so bad that I can't take care of myself anymore, even if I can, people don't trust me to take care of myself" and ... you're not helping anyone squash that question in their mind. (M.J.)

For some participants, secrecy and fear of disclosure often accompany separation and exclusion. The participants discuss the ways that they manage information about themselves, choosing how and when to disclose their status, and weighing the consequences of making the information public. Since a psychiatric diagnosis is not a visible stigma, the decision about when to disclose can mark the beginning of differentiation and exclusion within relationships. Disclosing becomes a moment of peril: 
"you also have to be careful about who you tell, because if you tell the wrong person, it could be used against you” (B.T.). In this case, the participant feels compelled to disclose to a group in order to confront someone about their discriminatory behavior: It's happened to me twice this week. I have been at places here in meetings, where somebody has made a comment and then I had to say to them "I'm an expatient" and the person was first upset, and then embarrassed, and I think rightfully so. (L.S.)

The need to keep the diagnosis secret is powerful because of the potential consequences involved in disclosing it, including in accessing health insurance. "There’s just so many cultural taboos attached around this, and so many reasons why people don’t feel comfortable disclosing, for discrimination, or health insurance, or that you'll be damaged goods to somebody” (M.J.). This other participant talks about withholding her symptoms and diagnosis from care providers in order to protect her insurance status:

I am not exactly sure how I had the power and understanding to know this, but I've never told who my insurance was paying that I've cut myself in the past. I know enough not to get that information into the system, and I know the labels that get put on people. (C.R.)

The participants discuss the processes of silencing that accompany the tension of secrecy. Managing when to disclose, who knows the secret, and from whom is it important to keep it can become a personal drain: "It's not unusual to talk to someone who has been hospitalized, and then to find out that no one in this person's immediate family knows that they’ve ever been hospitalized. That to me is a telling statement” (L.S.). Another participant talks about this same anxiety: "Right, and for some it might be 
best to have diagnosis be a secret. The only person that knows that this person has been diagnosed is that person” (A.P.). This participant talks about the interactions that silence people, including offhand jokes, as well as the personal costs of having to keep an identity closeted:

But in the outside world ... it's similar to the Tom Hanks character in Philadelphia, when he said that they were telling a joke about how does... Yeah, the hot yogurt Exactly! And he said "what I learned was to shut my mouth and to make sure I don’t ever let anybody know”. And a significant part of who he was, which was already hidden, became completely isolated and it diminished who he was because it said "here's a part of who I am that can't have expression in this environment” and it was a major part of his life. (L.S.) The participants also discuss disclosure within a therapeutic relationship to criticize counselors who don’t disclose their own psychiatric diagnoses to their clients. This participant questions the unequal access to information, wherein the information about psychiatric status is not reciprocal: "A lot of times that person who labeled is already labeled by someone else. We have counselors who have been labeled looking in the DSM and labeling us. But we don't know that they were labeled, that's the difference” (S.K.). This other participant talks about the separation imposed by the therapeutic relationship and the distance that this creates:

The strange thing is that I know there's professional people that have a diagnosis of a mental illness, but because of the way people are trained in college, you're not supposed to tell everybody, especially your clients that 
you live with schizophrenia. ... I don't think it’s good because it separates you from the person you're trying to help, but at the same time it's not about you, so you don’t wanna be talking about yourself. (B.T.)

The theme of inclusion emerged as a resistance to the separation imposed by stigma. The participants discuss the ways they've pushed to be included in decision making, as care providers and as members of their community. Inclusion is also considered a central part of any process of personal recovery or social change: "so much of recovery I've seen, for people and for myself, is letting go of that separation” (C.R.).

The struggle for inclusion has focused in part on work life and service provision to other consumer/survivors. This participant speaks about the push to open workplaces, and to be able to share stories of successful workers: "People with mental health problems have all kinds of challenges, but they also live incredible lives. I want to hear more about their incredible lives and I want to hear about how you deal with these kinds of challenges and still work” (A.L.). This participant shares relief when a change in management brings about more inclusion for peer specialists within a mental health institution: "one of the best signs for me is that he’s hiring peers, and he has said basically 'we will have a peer on every ward at this hospital’” (C.R.). This participant goes on to talk about the need for full participation at all levels of care and inclusion into the processes that affect them: "as it should be, I mean, of course a huge number of people who are involved in staff and the administration of services for people who are experiencing extreme states would have experienced them!” (C.R.)

The participants discuss the importance of inclusion in the broader community, and wanting to feel an integral part of the society instead of being cast aside. This 
participant discusses how her grandmother was cared for by her community in times of crisis, instead of being separated: "My grandmother never talked very much after that. So, in the community at that time, she had nerves, and everyone just wrapped all around her, and life kinda went on" (C.R.). The importance of full integration in the community has been recognized by policy in the Olmsted decision. This participant discusses the gap between the policy's intention and its implementation by institutions: I love the Olmsted decision because they changed the language. They did not say "least restrictive setting" in the Olmsted decision, they said "most integrated setting in the community”. And when you think about the differences in those two phrases, in the least restrictive setting the only thing you're focused on is safety. In the most integrated in the community means that you're focused on integration, and you can still address safety simultaneously... I kept arguing for "most integrated setting in the community". I said delete "the least restrictive setting". And I got pushback from somebody at the state. (A.L.)

Finally, the theme of inclusion serves as a focus for generating social change. The participants discuss their goals and dreams for creating a less stigmatizing world, and inclusion is at the center of their proposals:

I could be taking everyone coming from a place of being segregated from each other, because of course that's the most dangerous thing is to get people with a good idea together in one place, and that's where change really begins to happen. (M.J.) 
When considering what she'd do if she could start generating change anywhere, this participant spoke of doing away with separation and creating a new model of inclusion: I would seriously use all of the money that they put in OSH, I don't want to say I would tear it down, but I would most assuredly look at moving the millions of dollars from there and create some kind of really neat enclave there that would not be segregative. (K.H.)

Likewise, when this participant speaks of his priority in creating a society that would improve the quality of life of consumer/survivors, his main emphasis is on inclusion: So that society would be inclusive enough, and you wouldn't segment out people, you wouldn't begin the process of differentiation based upon disease or behavior, that you'd have a safe environment where everybody from the president on down could go ask for help without it becoming an issue of their fitness to participate in the culture, and that's really what's happened. So it would go back out the other way, it would be a nurturing environment in that sense, or one that it was safe to be different, safe to be yourself. (C.F.)

For this participant the issue of inclusion connects with a spiritual worldview that guides her path:

Focusing what we have in common and how we connect, integration, interrelationships and interconnectedness. I like the model of the ocean with the waves that come up and they look like separate waves and they go back down and yet the ocean is a coherent body and I feel like we as people are like that. (L.T.) 
In this way, inclusion becomes one of the central priorities for resisting stigma and generating lasting social change.

The third element of the Link and Phelan model is strongly represented in the participants' responses. The participants illustrate this element's applicability by calling attention to sites of exclusion such as the therapeutic relationship, acceptance into communities, and the role of peer specialists. The topic of disclosure and information management is central when considering issues of separation within a context of psychiatric stigma, since disclosure can mark the beginning of exclusion. The participants resist these processes by calling attention to the dehumanizing practices that turn them into objects and illustrate the issue with multiple examples of inhuman treatment. Another resistance strategy is a strong push for inclusion within policies and agencies, and various participants emphasized inclusion as central to their ideal strategies for social change. The fourth section addresses issues of discrimination and loss of status.

\section{Status loss and discrimination}

The fourth element in the Link and Phelan stigma model is status loss and discrimination. The authors propose that status loss is a consequence of negative labeling, stereotyping and separation. By addressing social hierarchies, the authors speak about the social costs of having a devalued status, including loss of opportunities and diminished life chances. The authors discuss the subtlety of inequality, which makes it hard to pinpoint the cause of any particular outcome, but do emphasize that the broad patterns repeat categories of disadvantage. 
The focus on discrimination in this model continues to address the subtle aspects of stigmatization, calling attention to the way that life chances are affected even when there is no direct interaction that results in overt stigmatization. The authors move away from the research trend of analyzing direct micro-interactions to address more structural discrimination. In this way, their conceptualization of stigma takes into account the systems and institutions that serve to perpetuate discrimination at a macro level.

The participants' responses reaffirm the element of status loss and discrimination within the model, and illustrate its applicability to a context of psychiatric stigma. Their responses address the inequality of life outcomes and patterns of structural discrimination in aspects of work life, insurance and treatment options and access to treatment. The participants also focus on the ways that they resist these elements by reclaiming their own value, rejecting a devalued status and push for participation in creating social change.

Three of the participants preferred the term discrimination to stigma. They were working with a more traditional understanding of the word stigma, not following Link and Phelan's proposal of subsuming discrimination as a precursor to stigma. They chose to emphasize the role of the discriminator instead of the target, calling attention to the roots of stereotyping and exclusion. This participant explains:

I even hate the word stigma...because it's a cop-out, because people don't own their own part in it. And really what we're talking about is discrimination, and people are very uncomfortable with that word. And so I usually will talk about discrimination. I sometimes will say stigma and discrimination, just trying to get a message across because I want to be heard, not just push people away. (A.L.) 
This participant emphasizes the challenges that the term carries, and also recognizes the possible social cost of choosing a confrontational term. This other participant echoes the focus on the root of stigma, while also recognizing that the popular understanding of the word stigma does not delve deeply into the issues of discrimination:

That's kind of where the concept comes from, stigma aversion, which most people I think if you ask them what it really is, it would be discrimination or prejudice, it’s not really stigma. Stigma is like a light version of prejudice as it tends to be used and I know people have taken some pains to make a fine distinction as to what stigma is as opposed to what prejudice would be, but it really is grounded in prejudging people. (C.F.)

This participant also presents prejudice as the root of stigmatization, "the word I use a lot is social prejudice, that's kind of my word of choice; I say social prejudice and discrimination” (L.T.). And from that same participant:

I was thinking about the role that we ourselves who experience prejudice and discrimination, the role that I myself have played in creating stigma for myself, or discrimination towards myself. One thing I'm aware of that's very rampant in the consumer survivor community, is two things: it's Us against Them or Them against Us. And then sometimes a lot of people feeling victimized by the system ... and both of those positions I find very problematic in terms of generating increased prejudice and discrimination. (L.T.) 
In this response, the particiant shifts the focus from the role of those who prejudge to the problem of internalization of prejudice. She emphasizes the ways that consumer survivors have identified with the discourse of separation that excludes them from society, and the ways they have repeated those patterns.

The participants refer to the loss of status brought on by exclusion and stereotyping. This participant describes the drastic change in social identity she underwent: "I went from an adult asking for help to incapable, dangerous person who was locked away in the ER for 5 days” (M.J.). Likewise, this participant addresses the consequences brought on by losing status: "people have status ... that will have disadvantages and will be excluded form certain social processes, which can be brutal” (C.F.).

Link and Phelan make special note of the visibility of particular identities and how even though most people with psychiatric diagnoses do not typically show outward signs, in some cases it is possible to infer that they do have a psychiatric condition. Certain patterns of behavior are associated with psychiatric diagnoses, and the people who exhibit them must contend with a visible stigma, for example incoherent speech, difficulties in making eye contact, or inappropriate laughing or crying. This participant echoes the crucial role that visibility has in the case of psychiatric stigma:

It's because you have this mental health problem that shows. See a lot of it is what shows, and what people observe... then that determines what kind of place or setting that you live in a lot of the time, or how much help you get. (S.K.) 
In other cases, having the diagnosis become public brings on a loss of status that leads to decreased livelihood: "I read an article where a really famous actress was admitted to a treatment facility and was diagnosed with bipolar, and this was on every newspaper cover and ... she's totally discredited now” (M.J.). In another case, the participant talks about the way that loss of status became internalized for her: "it's stigmatizing, because if they tell you that you need a more restrictive place, then that makes you feel 'oh gosh! I'm so terrible, I'm so hopeless and I'm so different than other people and everybody must know, everybody must see’” (S.K.).

The inequality in life outcomes brought on by structural discrimination was emphasized by most of the participants. This participant explain that some of the theorists he adheres to "divide the literal consequences of being identified with a different social group. They don't identify it particularly with mental health, it’s people that are different and their life prospects become reduced" (C.F.). This focus on reduced expectations was brought up repeatedly when multiple participants cited research that attempted to measure the reduction in lifespan for people with a psychiatric diagnosis:

I feel like if people who have mental health challenges were not at heath disparity, if we had the same quality and quantity of life as what we would call the general population... But the statistics do say that we die 25 years earlier on average, so that's not a myth, that's more hard data. (L.T.) This other participant brings up the same study to illustrate the way that these finding were co-opted to wrest more control away from consumer survivors:

They found out that on average we're living 25 years less than other people. And they did that study, but then they used that study to stigmatize 
and put people more in those boxes: 'and we're gonna do this to them, we're gonna organize this to make them well' (S.K.)

In this case, the focus of differential life outcomes is on the access to quality services: “The problem of people with psychiatric diseases dying an average of 25 years earlier than the general population is because not only do we have less access to care, but the care that we get can be tainted” (L.T.).

The effects of access to quality care on life chances are brought up again by this participant:

I'm really interested in what they're doing in Finland and Sweden ... they're getting better results with people who are having their first psychotic break. Eighty percent of folks within five years are back in the community and only twenty percent are going on to longer-term disability, and I think that's an incredible number. I realize that there's a lot of things in that health care system that we don't have such as universal health care, etc. but I’m like: “we can’t learn from that? we can’t pull some of what they're doing and start using it?”. (A.L.)

By emphasizing the contrast in treatment results this response challenges the local institutions to step up to the level of care that other systems can provide. This other participant also mourns the inability of the current treatment system to provide better quality of life for its consumers:

You go to different agencies and it appears like people are just being cycled through, there’s no recovery outcomes for people, it’s just "you come see me once a week, or once a month, and you do this therapy, and 
you take that medicine" and I don’t think that's really recovery and it's not giving someone a life. (B.T.)

The participants see overall quality of life as the standard of care, and by that measure conclude that the outcome of the services provided in the United States is not acceptable. When discussing the cycles of dependence fostered by the current support system, this participant states: “once you get it into it it's so hard to get out of it. ... I mean, it's a life, but is it a life?” (C.R.). Likewise, this participant urges opportunities for self-sufficiency and genuine engagement as foundational for quality of life:

There's so much work to be done around work and financial selfsufficiency. How many humans would be doing OK in terms of mental health if they didn't have a thing that they care about that they do? I'm not saying it has to be a job, there are plenty of people who, it's parenting, it's school, it's peer work, it's the stuff you give a shit about. I think that's a huge piece. (C.R.)

An overarching theme in the participants' responses was the way that they call attention and denounce patterns of structural discrimination. In this way, there is a strong correspondence with the premise that Link and Phelan put forth, considering discrimination central to the process of stigma creation. This participant considers the intricacies of social change by emphasizing the informal aspects of systems: "there’s other pieces to our society, it's not just about the policies, that's part of it but it think it's more layered and more complex” (A.L.). 
The participants emphasized access to resources and services as a central component to understanding structural discrimination. This participant considers the impact of access to services on the life outcome of people with a psychiatric diagnosis:

I can speak from experience, having mental illness is extremely expensive. If you want to take care of yourself... if I do all the things that I know I need to do to be well, which really aren't anything above and beyond what ... a person who's going through a rough patch in their life: you might want to go to therapy, you want to join a gym, you want to eat healthy, you might want to take medication or herb supplements, those are all things that I really want to be mindful of that I would want to use my health insurance for all of those services.... accessing that when you don't have health insurance can be devastating. That's why I feel that ... people who are unemployed or don't have health insurance or are low income are constantly in a state of crisis, because you don't have access. (M.J.)

In a similar vein, this participant recognizes the privilege and advantages she's had in navigating the treatment system, and wonders at the difficulties she has even under such auspicious circumstances:

The work it took for me to find people in the system who would actually hear me, and that, just hearing that, you can hear everything that I have going for me that helped me in my path: I have education, I have the resources to pay out of pocket for the right person, I had access to a computer to do all that research, private insurance... (C.R.)

The access to institutional legitimacy is discussed by this participant: 
I was just thinking about that model, and it's not just the power of people who label, but it’s people in power in any situation, I mean, the district attorney. You can pick up a phone and say "I'm the district attorney" that alone gets you into any door. (A.L.)

This participant calls attention to differential access based on title and hierarchy, in contrast to the barriers that consumer/survivors face. Likewise, the following participant describes how she deferred to a person in authority, even though she holds some authority and is well-versed in the field:

I have everything: I'm educated, I have support, I managed to maintain employment through my struggles, I'm familiar with social services, I have worked in DD, and I was still like: "maybe you're right, ok, I'll add in this other crazy med”. (C.R.)

The respondent asks us to think about the challenges in resisting the authority of a psychiatrist. She emphasizes the structural advantages she holds over many of her peers that should have served her as tools for resisting the opinion of her psychiatrist. Despite these advantages, she finds herself deferring to the doctor's opinion even when she disagrees..

This participant explores the structural obstacles that people with psychiatric diagnoses cope with in trying to balance work and their health needs:

if someone were to take FMLA, which really is no skin off the employers back ... we know that you're not obligated to disclose what's going on to your employers, but in fact, that doesn't really happen very often. If you're not going to be at work people want to know why ... "I need 
documentation to protect you job” ... if you were to say "I was diagnosed with major depressive disorder, I want to start taking medication and go to therapy and be in groups for the next 30 days” there definitely would be some judgment there. (M.J.)

This response illustrates the difficulties that are brought on by disclosing a stigmatized identity. The implication is that if one were to take medical leave for a different medical reason, the response from employers would be more favorable. This situation exemplifies the aspect of stigma that Link and Phelan would like us to consider with this fourth element: the devalued status that psychiatric stigma places on a worker acts as an obstacle in a work setting, making it more difficult to seek care.

The participants also critique the functioning of the criminal justice system. This response is focused on the inconsistency of the commitment process:

You meet people at the Oregon State Hospital ... the arbitrariness of who ends up there versus the people that I know who are out and engaging with the criminal justice system repeatedly, mainly because of their mental health experiences, who don't end up in that system it is a total crapshoot. (C.R.)

By pointing out the irregularity of the law enforcement and judicial processes, this participant asks us to question the validity of incarcerating some, but not others. When discussing the deaths of people with psychiatric diagnoses at the hands of police officers, this participant stated:

My complaint is they spend too much time trying to teach police officers to be clinicians rather than teaching them de-escalation skills, I don't need 
a police office to ask me about my medication ... I don’t need a police officer to even know my diagnosis, I don’t really care. It’s none of their business. What you need in a police officer for somebody that's experiencing emotional stress is de-escalation skills. (A.L.)

She points out a case of structural discrimination, critiquing the lack of training that officers receive in interacting with people in a psychiatric crisis. In this case, this institutional flaw is particularly dire, both because of the severity of possible consequences and because of the frequency of interactions between police offices and people with psychiatric diagnoses.

Critiques of the medical establishment and insurance system were of utmost importance to the participants. Their extended experience navigating the systems, both as users and peer specialists, gives them a unique perspective. Their experience as activists within a critical social movement has allowed them to develop pointed critiques and valuable ideas for improving these systems. The intersection between structural discrimination and access to treatment is particularly dire for people with psychiatric diagnoses, since mental health coverage often lags far behind medical coverage.

Participants were critical of the obstacles in funding treatment, and the insurance policies that would cover some, but not other diagnoses: "they had 33 diagnoses and they reduced that to 29. So a diagnosis like anxiety disorder isn’t funded anymore” (B.T.). This participant points out the frustration in finding that someone who was considered deserving of treatment was left out by a simple change in policy, without consideration for the implications. Likewise, this participant discusses a common scenario in which practitioners feel pressured to fit people into a diagnosis that might not be appropriate in 
order to be able to have it be covered by insurance: "If you have a good clinician, she has to diagnose you with something that's fundable, and that's ridiculous” (B.T.). This puts providers and consumers of services in very difficult situations, sometimes choosing one diagnosis over the other based on insurance coverage. This participant speaks about finding herself in a double bind, having to choose between spending most of her salary on treatment, or possibly having to leave employment:

I spent two thirds of all of my money on my therapist, on my medication, on my psychiatrist. Because I knew that if I didn’t do that, what was the point of looking for work? I knew I would not be capable of working if I did not take care of myself. (M.J.)

The participants focus on the emerging roles of peer support specialists as they navigate the medical establishment and insurance systems. There is a heavy critique of these institutions' difficulties in measuring and valuing the services that peer specialists provide:

That's the problem in the treatment system. People working organically in the community with other people get better. Well, the system doesn't fund that, not because that doesn't work, but because the system doesn't have a way of measuring its effect. And it's the system’s fault for not developing a broader base. (C.F.)

Similarly, this participant speaks of providing a valuable service for which there is no recognition, in order to be able to account for it, she must apply a category that does not fit: 
How you get funded is by how much PEO data you have. But ... going to hang out with someone isn't really considered PEO data, cause you have to have some kind of outcome to it ... we use mostly is 6 and 7 , basically they're like "had a team meeting with someone" or "talked with someone on the phone about their team meeting", so it's all around a psychiatric thing. Whereas just going and having coffee and talk about how your cat is doing today isn’t PEO data. It isn't therapeutic enough, and it’s not valuable to do. (L.S.)

The institutional structure discriminates against the kinds of services that these participants offer and the ones they find to be most helpful. This discrimination harms them both as workers and as consumers of services. This participant speaks about the treatment system's lack of flexibility and unwillingness to let go of procedures that don't take into account people’s complex lives:

It's all in neat little packages, modularized, when really those people might be better served by the guy getting off his ass, out from his desk, getting out, getting down and dirty in the person's real life and understanding what's going on. Most of the problems they hear about in a clinical setting, ... if you outreach that person the chances of that go way down. But the system itself doesn’t want it, it wants procedures, credentials, diagnostics, they don't want to have the messiness. (C.F.) This participant speaks about the struggle to have peer services recognized by the traditional treatment institutions: 
I think OSH is finally hiring peer support specialists that are on staff, that's amazingly important because I think the only way, I think when it comes to funding and change people want to see numbers, they want to see data. ... I think it will take time for peers to be working in the field, working with people who are currently labeled as patients who are in the system, for them to be collecting data. Because right now it's like "you're the peer support specialist, we're so glad you're here, why don’t you go play checkers with somebody". (M.J.)

She illustrates the dismissal and patronizing that peers often face when trying to access the treatment system, and talks about navigating the process of research in order to gain acceptance into the institutions.

The participants resist the devalued status and discrimination they face by reclaiming their own value and expertise. They focus on becoming active participants in the decision-making process and policy decisions that affect their lives. This participant explains that she "just wrote a letter today to the governor's office to say 'I'm requesting a meeting with the governor on peer delivered services', the fact that I go meet with the governor and propose a statewide system, I love that!” (L.T.). The participants are active in policy creation, and generating change at an institutional level:

I helped create the office of consumer affairs, and it was an incredible opportunity to turn that place inside out in terms of organizing patients, changing policy, making it a more recovery-oriented facility and it was probably the best experience of my life to be there. (K.H.) 
This enthusiasm for participating in large-scale change is echoed by another participant: “I’m helping to make policy, to drive policy, and that's part of what I love to do with my work. I work at the state and national level on policy, and that's one of the most fun things I get to do” (L.T.). This participant does not have access to the same avenues for change that the previous ones did, and laments the lack of participation allotted for consumer/survivors:

A lot of it is set up by the legislature, and the institutions themselves that set stuff up too. And it’s not like they’ve asked consumers how they would like to do stuff, and then set stuff up how consumers want. (B.T.)

The participants are active in proposing the changes they wish to see, and they are proud of the movement's accomplishments and entry onto the political stage over the last decades. This participant is optimistic about the inclusion of peer specialists into the treatment system:

I think the hospital is a really exciting example of change right now, you have the consumer council within the hospital, you have patients or residents of the hospital rising up, going to the legislature, talking back to the PSRB ... changes are happening, and it’s very exciting. (L.T.) Being recognized as legitimate participants by the law provides an entry that has the potential to generate more change:

It was the first time ever in any kind of a law that people with mental illness had to serve on advisory boards in order for the plan to be legitimate. And it had to be demonstrated that people were involved in 
developing that plan, so every state was required to create an advisory board. (K.H.)

Having a seat on boards and councils allows participants a foothold toward making their voices heard, and reinforces their right to participate in policies that affect them: "Every state has kind of the DRO and all of them are required... they have to have these boards that ideally tell the DRO executive staff what they want, literally” (K.H.).

The participants' responses focus on what they would like to see change within the structures that affect them. Their proposals for improvement address multiple structures and institutions, including treatment facilities, educational systems and early intervention systems. This participant proposes a support system for people who wish to move away from medication: "there need to be supported titration programs, so that folks can have a real wraparound, people ... could have the supports to start pulling one thing back at a time, to figure out what's actually them vs. medication side effects” (C.R.). This participant talks her policy work on changing health outcomes:

One thing that I'm working on is creating a culture of wellness because of that statistic that I quoted earlier, people dying so early, and having comorbid diseases, the health disparity, that's one things that's very tangible that I can work on, tobacco cessation. (L.T.)

When considering their priorities for altering systems to improve the lives of people with psychiatric diagnoses, the participants would propose multiple strategies. When offered a chance to really consider what is necessary, not to be bound by the applicability of their solutions, their responses ranged from concrete and immediate to 
fantastical and improbable. Some participants focused on changing the "first responders,” or crisis response systems, finding them to be crucial in a recovery process:

I definitely think the people who are on the front lines need to be educated, especially when you're dealing with people who may be having their first experience with mental illness ... people's first response is to call 911 ... I think that just having a day of sensitivity training or having a required course in bedside manner, is not sufficient. (M.J.)

Similarly, this participant envisions a humane approach to community care that also is very powerful:

I wish there was a van that drove through town and the door opened and there were all these supermen that jumped out of the van that were from the peer movement, and said “we're here and we love you and we're gonna help you”. (K.H.)

In this excerpt, the participant envisions a more humane alternative to crisis intervention. . She emphasizes the role of peer providers, and invests them with greater capacities for acceptance, love and support in contrast with the descriptions of first responders that other participants have offered.

This participant illustrates the urgency of intervening at the level of first responders, citing how crucial this point can be:

I believe most people can and will recover from mental health problems. And to not have that support, especially when you're at the most critical first days can be really damaging. That's where I feel that I had some of 
the most damaging experiences, those first few days when I was at my most vulnerable and I was being treated like I was a caged animal. (M.J.)

Other participants focus their efforts on the kinds of messages people receive about psychiatric diagnoses, attempting to interrupt stereotypes: “There would be role models in the community of people who had madness ...

who were contributing ... it's still possible to contribute and to have a life and to be productive, I think being productive is a huge thing” (L.T.). This participant emphasizes the importance of a positive message during vulnerable times:

What I would change if I could would be, this is the magic wand part, never have anther person who is experiencing psychosis or mania or injury be told "you'll never work, it's always gonna be like this, you're always gonna need to be on meds. (C.R.)

The issue of dehumanized treatment comes up in the participants' proposals for change as they denounce the abuses that have been perpetrated and propose new models. This participant's response is quite strong in her wish to have those in power experience the abuses of the system as a hope for generating change and empathy: "I would take every psych resident and I would restrain them for an unknown period of time, and I would inject them with a medication with about as much information as they give their clients” (A.L.). This participant's response is more measured, but also calls for a radical cessation of the current model of care:

I would certainly abolish both state hospitals, the one they talk about building and the OSH, one thing I'm working on right now is to make it 
against the law to use seclusion and restraint in secure residential facilities.

Along the same line, this participant proposes dismantling the forensic hospital as well, and creating a more inclusive setting in its place:

I would do something really creative, I would make Salem where the hospital is some kind of central location for the state ad the region, where people can rally regroup, not in a locked setting, but be there in that environment, and go to the gymnasium and learn skills that they may never have learned, in an open environment, and help people have a giant wing of that be a computer center to teach people how to get on board with technology and some kind of an employment Mecca. (K.H.)

The fourth element in the Link and Phelan model focuses on the aspects of stigma that are often hardest to pinpoint. The subtlety of status loss is present in the context of psychiatric stigma as the participants both illustrate and resist their loss of value. The patterns of structural discrimination can be both covert and overt, and the participants address the way they map onto their life chances, such as life expectancy and access to resources. The participants attempt to change these aspects of stigma by denouncing the structural discrimination they face in areas such as work, insurance, treatment options, and service provision as peer specialists. Their responses also present us with a way of interrupting status loss and discrimination within psychiatric stigma by providing an example of participation in creating structural change, such as policies, laws, firstresponder training, treatment, and hospitalization. The following section focuses on the 
discussion of power imbalance, which Link and Phelan present as the underlying current necessary for catalyzing the four elements into forms of social stigma.

\section{Power}

Link and Phelan pose that power is central to the creation of stigma because it allows the other elements to be communicated and enacted in a broad social context. Although power operates at all levels of the stigma process, the concept of power also carries a more delimited meaning in referring to activity involved in a more explicit political context. Power involves possessing some means of enforcing or acting on differences, as well as of reinforcing the separation and status loss through control of social institutions. Link and Phelan propose that power is the aspect that allows stigma to have real-life consequences for target groups because it gives the stigmatizers control over the societal structures and institutions necessary to disseminate stereotypes and enact exclusion. The Link and Phelan conception of power as it operates in their stigma model is unidirectional, however, and does not address the power involved in challenging dominant structures and in resisting stigma.

This section centers on the conceptualization of power in the Link and Phelan model. I discuss the ways that the participants' responses map onto the model, but also how their conceptions of power dynamics go beyond the Link and Phelan model. By focusing on the role of resistance as an avenue of power in combating stigma, I hope to advance a more complex understanding of power dynamics in both creating and transforming stigmatization. Even though the Link and Phelan model intends to address only the creation of stigma, and not its transformation, I hope that we can learn from the 
front line agents who work to interrupt the process, honoring Lewin’s (1946) focus on learning about a phenomenon by trying to change it.

The section is organized along two overarching themes: oppression and resistance. In the oppression section I focus on some of the sites of exclusion and stigmatization that the participants describe. Some of the themes that emerged involved denial of credibility, which presents itself as personal invalidation, and operates at a system level as a loss of legitimacy. In the resistance section I focus on the strategies participants utilize to make their voices heard, some of the grassroots strategies employed in the consumer survivor movement, as well as internal struggles within the movement.

\section{A. Oppression.}

In this section I explore the ways that stigmatization and power imbalances play out within a context of psychiatric stigma. The responses illustrate many of the aspects of power imbalance that Link and Phelan put forward and help us understand systems of oppression that serve to stigmatize this particular population. I discuss here the ways that participants are pushed into passive roles, especially within a medical context. I also focus on issues of credibility, which were central to many participants as it relates to legitimacy within larger social structures and the weight their voices carry within them. This section explores the ways these participants speak about the disregard of their knowledge within the mental health system, issues of power and legitimacy involved in a conventional psychiatric relationship, and the dismissal of the peer services model within a conventional psychiatric paradigm. As one participant so eloquently expresses it, “part 
of being stigmatized is not being listened to--not making your own choices make any difference. (C.F.)”

The participants address the way that people and systems have attempted to push them into a passive patient role where they are meant to be the objects of policies they did not help to design. One participant succinctly describes this principle: "if you want to help people don't put them in a position where they feel helpless” (B.T.). Likewise, this person speaks about the importance of self-efficacy, and the ways that systems encourage passivity: "responsibility comes as you learn more about making your own choices, and when you take the ability for people to make their own choices away from them, they also lose their responsibility” (A.L.). In a similar vein, this participant points out the policies that reflect the exclusion of patients from decisions about their own care: "there was a law in Florida that people with mental illness could not get their own records from the hospital. They were not allowed to have their records, and I really wanted them” (K.H.). In more subtle cases, participants discuss situations where they are left out of decisions: "it's coming from professionals thinking that they know how to help people, and they're not asking people how best they can help them” (B.T.). In a similar vein, another participant discusses being left out of decisions and being treated as objects of programs instead of stakeholders:

they’re saying "oh gosh, we've identified smoking, they smoke too much. So lets so something, let's quit them smoking". And they do have some mental health consumers involved, but it's still not having a couple of consumers on a committee, it's not like finding out what in general what people think, and also what really helps most of the people. (S.K.) 
In situations where participants try to exercise autonomy it can be discounted as pathological:

It's like people in the system have traditionally wanted one of two things: either you're broken and so we're gonna tell you what to do, or you're fine and you get out. If you want some degree of autonomy, some selfdetermination, some say in what you're doing then that either means that you need to get out or it's a manifestation of your pathology. (L.S.) One participant discusses the way that successes can be co-opted. In gaining access as active participants in the treatment process, peer specialists can be relegated into a passive role with little authority:

The system has an equal amount of interest in including the opposition so that it's ineffective. Now you have all these agencies hiring peers. Well, those peers essentially become extensions of the clinical authority they already have, which is, if it was a real valued relationship they would have their own right to authority, in their life lived experience. (C.F.)

The participants discuss the difficulties in resisting this assigned role of passive patient, and address some of the ways that it can become internalized. This participant talks about the difficulty in recruiting peer specialists: "the survey said that people wanted peer services and greater wellness. But what I started realizing is that these people don't wanna do peer service, they wanna get peer service” (L.T.). One participant talks about the ways that a traditional patient role discourages choice:

If I don't really trust the changes inside me and I really view someone outside myself as the bastion of power and that this should be controlled 
by medication, then I'm going to take whatever you give me, like a disempowered thing. The people I've seen who are pretty successful in terms of managing really hard stuff, find some place in the middle where they are empowered and know that they can take or leave stuff, that are viewing what's happening inside them as not all one thing or the other. Totally, painfully aware of the fact that for so many of these decisions, there's not a right decision, there's not a win-win. (C.R.)

A frequently recurring theme in the responses was credibility, the veracity with which claims are received by others. There was intense focus on the ways participants' ideas and experiences are disregarded, and the ways that the content of stereotypes about people with psychiatric diagnoses pose a particularly useful tool for dismissing their ideas and demands. Within this overarching theme, there are sub-themes that bring more depth to the discussion, specifically in relation to invalidation and legitimacy. In the sub-theme of invalidation I discuss the ways that the participants' experiences are systematically dismissed and denied. The subtheme of legitimacy is concerned with the acceptance into larger structures that the activists and their claims have received as well as the authority that their voices carry.

The participants discuss difficulty in having their claims taken seriously, or having basic assertions carry weight. Medical care is complicated when health care professionals disregard reports of physical symptoms, as one participant states: “I’m going in with a physical problem, and I want to make sure that I'm not treated for a mental state” (L.T.). This participant speaks from her experience as an advocate as well 
as her own interactions with physicians. She speaks of the way that the diagnosis becomes her main identity to others and worries that it will affect her physical care.

In a similar way, another participant speaks about the way that doctors can focus mostly on the psychiatric diagnosis instead of the medical complaint:

While he's a really nice guy and he's never said anything remotely offensive to me ... that's gonna be my primary diagnosis to him, he's probably gonna ask me every time I see him "are you taking your medication?". Regardless if I go to see him for a runny nose or whatever, that's gonna be at the forefront of his mind, I truly believe that, as being the underlying problem. (M.J.)

This example illustrates some of the subtle forms of oppression and stigma, the label of psychiatric patient is hard to set aside, and underpins relationships with others even when it's not relevant.

The issues these participants bring up reflect Link and Phelan's element of power imbalance as a catalyst for stigma. They find that their credibility is questioned, their voices are not heard, and their experiential knowledge carries little value. This participant discusses the dismissal she has faced: "I feel like the hospital staff have a tendency to treat people like they're two years old, or they're stupid. And just because I have an illness doesn't mean that I'm an idiot” (B.T.). The experience of being infantilized and mistrusted is echoed by this participant

And as far as medical coverage and disclosing mental illness to providers there's definitely discrimination as far as prescribing, not being trusted with certain medications. If someone's mentally ill, you don't want to give 
them anything they can overdose on. ... something that they may misuse or sell. Again the criminality of just... all of a sudden you've lost the credibility, like you're not a trustworthy person. (M.J.)

These scenarios illustrate Link and Phelan's focus on power differentials as central to the creation of stigma. As consumer/survivors the participants interact with multiple professionals and care providers, and are often treated as a combination of incompetent, irresponsible and untrustworthy. These repeated interactions serve to undermine their agency and autonomy. In this scenario this participant's requests were brushed off as completely irrelevant:

At one point I walked up to the nurses' station to say that I wanted a hearing, I kept demanding "I want a hearing, I want a hearing" and they said "you have to put it in writing: so I demanded a piece of paper. They gave me one of those old brown paper towels and a crayon, and I wrote it there. All I wrote was "I want a hearing". I wrote it on top of the nurses station, they ended up grabbing the paper towel and balling it up and throwing it away like it was a piece of trash and I never got a hearing, and it was a really sick thing to do to someone. (K.H.)

This participant illustrates the ubiquity of dismissal:

It's really acceptable and very common for the culture to make fun, discredit, stigmatize and make jokes about people with mental illness. It's a pretty easy go-to. Even I and the people I work with, how common is it for all of us to use the adjective of crazy? It's really common, I do it at least 10 times a day (M.J.) 
This theme of credibility reflects the Link and Phelan stigma model, particularly in regards to the power dynamics involved in granting ideas credibility and legitimacy. This theme supports the element of power that the authors bring forth, by emphasizing the role that legitimacy and structures carry in the creation and perpetuation of stigma. In the next section I discuss the subtheme of invalidation and the power inherent in dismissing people’s points of views as unreal, or unacceptable.

In a process of invalidation, a person's experiences or perceptions are denied, dismissed, or discounted as unreal by another person. When invalidation occurs, events or interactions might be disregarded as unimportant, feelings and perceptions can be declared erroneous. The dissonance that this interaction can create is quite powerful, including feelings of confusion as the person tries to reconcile their own ideas with the ones being imposed by an outsider. When these experiences become chronic and people’s belief systems, thoughts and experiences are systematically contradicted by others the consequences can be grave. Having to constantly defend or re-evaluate one’s beliefs creates a serious drain that can accumulate over time into feelings of self-doubt and exhaustion.

Because of the stereotype that the mentally ill lack credibility, people with a psychiatric diagnosis are more susceptible to having their ideas and beliefs discounted. The process can be very demoralizing: if people feel dismissed, they can never be certain that discrimination was not a part of the interaction. Dealing with repetitive invalidation can make people doubtful of their own ideas and beliefs, making it hard to organize around change. 
One of the sources of invalidation can be the very therapeutic relationships that purport to heal. Having someone's judgment of one's experiences matter more than one's own interpretation and being told that one's ideas cannot be trusted can feed into doubting one's identity. This participant speaks about the difficulties in getting support: I felt like I was never taken seriously, I was kind of dismissed, or that there was a feeling of “you're being a little dramatic, or you're really amplifying your experience”. So I started to really doubt myself "am I making this up? am I being too dramatic?” and so of course I started to question, which I knew in my gut, that something is definitely off here that needs to be addressed (M.J.)

This example can be representative of many people's experiences, knowing that something is wrong and they need support, but not being able to get it. In these cases, a psychiatric diagnosis can be a source of validation:

When you really are in distress and somebody tells you that there's a name for what you're experiencing, there's a lot of relief, like you're not, this fear that we have about being crazy, whatever crazy means to people is real. But over time you get more comfortable with the name and the idea that there's actually a problem or that it's real and it's not in your head, even if it IS in your head (A.L.)

Feeling validated after a long period of being invalidated can be incredibly powerful. They are often described as relief, finally being understood, and a long-awaited confirmation that one is "not crazy". This participant speaks about receiving a psychiatric diagnosis: 
I finally feel like I’ve been validated: “OK it’s serious, it's a real thing”. And for me, as far as personal validation, I finally feel like I'm not just making this up, I have serious problems. And while some people might find that scary, and it is scary to know that you have things going on, my personal experience is, some things aren't always in my control or my awareness. So that is scary, but not as relieving as is to know "ok there is something legitimately going on here, there is a way I can help myself get better" but again, at a great cost. (M.J.)

The participant describes the tension between being invalidated by an outsider that defines who you are and being supported by an outsider that confirms what you've been thinking. After having one's concerns repeatedly dismissed as unimportant or erroneous, receiving confirmation that there was indeed cause for concern is a powerful feeling of validation. This complex reaction illustrates some of the contradictory feelings participants experience as they make their way through the mental health system. In some cases, what begins as support can quickly turns into suffocating control. As this participant explains,

It's really tricky, coming from that place where you want people to recognize and validate your problems. But then once they’ve addressed that, getting to go back and say “OK but I’m still a person, you're not the boss of me forever (M.J.).

When it comes to treatment, the participants speak about the way their preferences, ideas, and decisions are invalidated, while the therapist's point of view is imposed. As one participant states, “you're teaching people that they're sick and that other 
people know better” (C.R.). Within the medical model the expert's opinion is central, and the patient must acquiesce to their judgment, as this comment illustrates:

If a doctor tells you something, chances are unless you felt like you'd been misdiagnosed and you'd been through this intense experience of trying to be heard in the system, you just accept what's said. That's also part of our culture, doctors are authorities, police are authorities, and if you're deemed dangerous by a police officer, and you're taken in and you're deemed schizophrenic by a doctor, that's why I can see people thinking very easily “oh my god, I really am a crazy criminal.” (M.J.)

In the cases where the participants have tried to counter the outsider's imposed point of view, they run into more dismissal. Within the medical model the patients' opinions carry very little weight:

The psych hospitals, they're not too much into recovery, they're more into "take this pill, and you're here for however many days, and you're gonna take all these different groups" which I've never found to be helpful. I know they think they are, but they're coming at it from 'I'm thinking about how to fix you" rather than "tell me how to fix you (B.T.) This participant discusses interactions with therapists in which his point of view has been invalidated: “if you don't need the pill (I'm using pill to mean treatment, whatever that is) 'If you don't need the pill that I tell you then you must not be sick'. It can't be that maybe I need something else?” (L.S.). His attempt to negotiate the terms of treatment is considered such a challenge that the therapist threatens to relinquish support. 
In other cases, the consumer/survivors’ concerns are dismissed as irrational or unimportant. When discussing the cases of peers she has supported, one participant states:

That's a problem that people experience too. You hear that "stay on your meds, everything's ok if you're on your meds", and how disempowering that is. “That's really great, but I can’t get it up”. I mean that's not a winwin for me, that's not an answer (C.R.)

In this case a serious physical side effect is brushed off as irrelevant. In another case a participant's needs for support are belittled:

Say for instance somebody needing someone to go with them to have a pap smear ... she said, "there's nothing wrong with having somebody go with you, I take somebody along with me". But then you have other ones in the same agency that say "you should be able to do this by yourself... You pull yourself up by your own bootstraps”. (S.K.)

In this way a perfectly reasonable need for companionship is pathologized and taken as a sign of slow progress.

Sometimes the invalidation and dismissal happen because the consumer/survivor does not match the expected stereotype:

Basically there's this vision in people's heads that we're gonna come in with home made quilted vests, with our cats, and bags around us ... It really was a bit of a catch-22 for me, if you look at some of the first things that doctors will say when they dictate their notes ... how you look, how you speak, how you smell. Those are qualifying factors for how well you 
are, which is not only offensive to people who present well, but for people who don't have the means to not present well ... I kinda felt like I needed to go in naked with sharpies written all over my arms and talking about Jesus speaking to me before anyone would be like "oh, maybe something's going on". (M.J.)

In this case the stigma and stereotypes had been so pervasive that the participant was having trouble getting support because she didn't fit the expectations.

The subtle dissonance that invalidation can create can be particularly elusive, as this participant illustrates: "they have council meetings ... where they include people with mental illness ... and sometimes it feels like consumers are treated maybe a little differently than the professionals are” (B.T.). The cumulative effect of this management and discrimination is strong, yet difficult to measure.

Dealing with repetitive invalidation can make people doubtful of their own ideas and beliefs, making it hard to organize around change. This participant illustrates the overwhelming feeling that can come from seeing your beliefs supported and knowing that they are creating social change: "I remember reading that law, I know exactly where I was ... I cried when I read it because it was this floodgate of opening up an opportunity for people to serve (K.H.)”

A key theme related to power concerns loss of legitimacy, which is one effect of being denied credibility. The concept of legitimacy relates to the position of a group within a broader social system, and the way their voices carry authority. The subtheme of legitimacy comes up as the advocates face different levels of acceptance within social structures. The weight their voices carry can be limited by their participation within 
formal education, and their admission into institutions as care providers can be thwarted by their rejection of the dominant medical paradigm.

The participants repeatedly find their ideas being dismissed because of their identity as people with a psychiatric diagnosis, or because of their rejection of the dominant paradigm. Their credibility is questioned because of lack of formal education, and they find themselves routinely struggling to have their ideas valued. As one participant puts it, "people listen more to people with PhDs, or whatever initials behind their name” (S.K.). Yet another participant talks about the way consumer survivor narratives are received:

We hear a lot these days about Robert Whitaker, he's sort of our canary in the coal mine, go out and tell everybody what people have always been feeling and knowing, but have never been giving a quotable source. And now he's sort of like the authority on medication and mental health. ... it really does take just that, one person has those few letters behind their name, who are a credible source to say "ok listen what they’ve been saying all along is valid, and I will show you how it is”. (M.J.) This excerpt exemplifies the validity that is given to this physician as an author, and expresses the frustration that the participants have felt for years at not being heard. The lack of authority and credence that is given to their ideas leaves these participants feeling like they need a spokesperson, like they are not a 'quotable source". This participant talks about the resistant reception the same author received at the Alternatives mental health conference. His panel was cancelled, reinstated after prolonged requests from the participants, and then reformatted to include immediate rebuttal from a representative of 
a pharmaceutical company. This author faced some of the resistance that is presented to those who question the validity of the dominant paradigm. At another instance she speaks of the consumer survivor perspective by saying "not only are doctors not aware of it, because it's not something that they respect or validate, and it's kind of a threat as well to the medical system that people don't need to be on medication their whole life” (M.J.). This sentiment exemplifies the dismissal many advocates feel when attempting to have their ideas considered by those within the medical paradigm, in some cases becoming defensive or feeling threatened.

The conventional medical model relies on the expertise of a physician or psychiatrist, relegating those in their care to the role of compliant patient. When the legitimacy and authority of the psychiatrist is questioned, these participants speak about some of the pushback they receive, interpreting their resistance as a symptom of illness. This places consumer/survivor activists in a uniquely difficult situation, the very establishment they try to challenge has the power to officially dismiss their claims by declaring them to be pathological, and therefore irrelevant. This participant talks about the way he and others have been treated when they tried to renegotiate the relationship with a therapist:

They were subtly threatened with the removal of services. And there are lots of people in this movement who have had that same experience ... where as soon as someone begins to show that desire to have a proactive role in their recovery process then they're told, “either you're a patient and I'm the expert, you're sick and I'm your doctor, you're the one waiting to 
receive the pearls of wisdom and I'm going to be the great teacher that gives them to you, or you need to go somewhere else.” (L.S.)

In a broader arena, these advocates have been challenged not only in their ideas about appropriate treatment, but also in their role as peer specialists. This issue is echoed by many of the participants who find themselves pushed aside within the mental health paradigm. The dismissal they have received has in cases taken the form of withholding credit for work and ideas that the consumer survivor movement has put forth. As one participant explains,

In different places the peer movement has come up with targeted case management, trauma informed services, integrated settings, integrated medicine, sustainable medicine, all these things came out of the peer movement ... if we were Microsoft we would own most of the progressive movements within psychology as far as the advances in treatment. (C.F.) The lack of legitimacy that the consumer survivor movement holds makes it more vulnerable to being overrun, or having its ideas misappropriated. The kind of consideration that one medical professional might hold for another's work, might not carry over to the ideas that are put forth by mere patients. This other participant sees this exemplified in her experience

They do stuff frequently like for professionals they might have a thing where you can’t steal somebody else’s program but if a professional wants a program that a consumer run organization does then they kinda can do that without anybody really saying that's a bad thing, [...] it's just all these kind of weird things that they can do, or they feel that they can do without 
any consequences, and it's stuff that they would normally do amongst each other ... I don't believe that it's intentional, I think that it's their old thought process that it's ok to do this to a consumer, and it's not ok to do it to professionals. (B.T.)

Another aspect of the lack of legitimacy that peer services receive is the denial that the peers bring specialized and valuable knowledge to their interactions. The experiential knowledge that people accumulate through their passage through the medical system is often dismissed as inconsequential. The medical establishment has resisted giving legitimacy to that expertise. In this case, this participant discusses the difficulties in having those special skills receive monetary compensation:

We tried to get that at some point in the state, having it if you had peer experience and a credential it would give you an enhanced billing rate because you'd actually have those skills to draw on, if you were competent at what you were doing. (C.F.)

Within the dominant medical paradigm, the opinions of experts and professionals carry more weight than the experiential knowledge of patients. In a broader context this idea of expert authority is repeated by what is considered credible and valuable knowledge by scientific and political systems. The participants discuss how difficult is it to gain entry into larger structures because their knowledge has not been validated by the existing medical and scientific community. This participant explains:

They don't want to document. They're the controllers at the research level, so they're not going to go and research and say "Wow, this is really helping more than what we've thought... has helped for years and what are 
we gonna do if these things help more?” and the pharmaceutical industries are like "hey no, you can’t do that" and so they gotta keep proving that what they've been doing for years is better. So they're not gonna do these big large studies, not the ones that count. The big authorities, the money people and all that, they're not gonna do too many real scientific studies about what really helps. (S.K.)

In this excerpt, the participant discusses the obstacles stand in the way of validating peer services through the medical and scientific paradigm. Likewise, this other participant talks about what it takes to be accepted within that paradigm:

Right now I think that alternative plans, holistic, and peer based are kind of a luxury, and hopefully that would change ... I think it's gonna take a long period of time where they're gonna have proven results that they can put on some pie chart at a conference and show to doctors and say "look, it works.” (M.J.)

The medical model has difficulty measuring the worth of the accumulated knowledge and experience that peer providers hold. The expertise that consumer/survivors have gained by learning how to manage their lives, how to navigate the medical establishment and the social support system has often been deemed irrelevant by the medical model.

In many cases, participants speak of being placated, included in the system at superficial levels, receiving lip service as a way of appeasing their requests but without receiving real power. These situations reflect a lack of authority and legitimacy, a way of being brought in without generating real change. As one participant explains it, this is “involving people at a level that subtly degrades them even with the inclusion, because 
really those people's abilities are not recognized” (C.F.). This sentiment is echoed by another participant:

I feel like because there's been so much progression in the movement that people are kind of saying "well at some point you have to listen. If people are really causing a stink about this, let's just do something to placate that, let's just hire some peer support specialists and good for us”, it's kind of like having a diversity hire, that's basically what it's like. (M.J.) These participants illustrate the frustration of being included nominally, while at the same time excluded from the higher status positions that have decision-making power. Another participant reflects on the roles that peer specialists have been relegated to:

Instead it’s like 'ok, we'll let you guys participate, at the bottom here. You guys go get them groceries, or take them to the drop in center, or go take them on an outing, but the real business of treating people, the serious business of medicine, that's really not left to...' that's a parochialized role. (L.S.)

These situations of superficial involvement imply that the role of peer specialists does not hold the esteem and legitimacy that a professional role carries. The knowledge and skills that peer support specialists bring to the table do not have sufficient value to be granted a position of more authority. In this excerpt, the participant speaks about the inability of the system to differentiate between the skills one peer brings to an encounter, and those of another:

You can’t standardize it because you have these HR policies, and then one peer looks about the same as the other. And there's a difference. The 
people who are really good at it can make you know why there’s a category for peers. People that aren’t very good, they make you wonder why they should even bother to fill the positions. (C.F.)

This other participant speaks about the efforts to standardize peer services and provide it with a mantle of legitimacy through a certification system that grows ever more rigorous and involved:

The people who say that you need to have this much certification, if they asked all of the peers, they wouldn’t say “yeah, you need to have all these certifications in order to be called a peer support person”. No, it’s coming more from up above, and then people are saying "we can see that, we'll go along with that, that would be cool, to have this certification". But to me it's like "I can do what you do, I know what I need and I know how to empower people and I’ve been doing it a long time, and I know that other people know what's best for them" and so I can ask them "what helps you?" I can empower them. (S.K.)

In these cases, the advocates critique the existing treatment system for not being able to recognize and value the experiences that a skilled peer specialist can bring. In one scenario they are discounted because they are difficult to measure and in another the focus on formalization pushes out the peers with longest trajectory.

The advocates face a difficult prospect in challenging the dominant paradigm. The medical model is backed by the legal, scientific and political system, making it an uphill battle in generating change. The authority and legitimacy conferred to those who design and participate in the system create a challenge for consumer/survivors trying to get 
heard. These systems of oppression operate to maintain a power imbalance.

Consumer/survivors are systematically silenced through the passive patient role assigned to them, and the structures that serve to keep it in place. The stereotypes that support this stigmatization act as barriers to credibility, fueling disbelief, invalidation, and lack of legitimacy. In the following section I discuss issues of voice and resistance as the participants discuss finding a sense of individual agency and participating in grassroots change.

\section{B. Resistance.}

The theme of voice and grassroots resistance was pivotal in the activists' responses. The advocates spoke at length about the ways that they moved away from passivity to become active defendants of their own interests as well as those of others in a broader political sphere. In this section I discuss the ways that the advocates rejected the patient role and became more active in their treatment. The participants focus on resistance — not just as individuals affected by stigmatization but as activists building a social movement. I address some of the ways the participants discuss power and struggle within the movement. There is great emphasis placed on grassroots power, and the participants draw inspiration from the civil rights movement, among other emancipatory movements. I also discuss some movement strategies as well as conflicts within the movement around issues of hierarchy and conceptualizations of madness.

The participants offered their own stories of moving from individual passivity to activity, of becoming active participants in their recovery and the consumer/survivor movement. They explore the way these changes affected them, as well as other people 
they have supported as peer specialists. This participant addresses how the way that support is structured can play a large part in promoting a passive role. The lack of choice and autonomy makes it difficult to even conceive of taking an active role:

Many people with serious mental health issues really don't believe they have anything they can give anyone else. We're given to for many things: we might have our housing given to us, food vouchers, etc. We're called consumers because we consume and consume and consume, so to be a provider... wow... what a shock! (L.T.)

Another participant also describes the difficulty involved in resisting disempowering messages and transitioning into taking control:

We've been taught to be compliant. We've been taught that we don't have an opinion, that we don't matter, that what we say doesn't matter. We are taught that things are gonna be done to us, and that if we don't cooperate then we're going to have bad things happen to us. Then we get in this little box, and kinda just stay there all the time. So then it's like a real powerful thing, when you see somebody come out of that box. (S.K.)

Another participant exemplifies an active role by promoting the structures to support others on a similar path:

I was sitting there looking around, and for the most part people were not particularly empowered, as far as I could see. But I could just imagine, I see change coming over, I think it's gonna happen, I think I'm gonna create a program, or combination of programs, and people are going to start taking little incremental steps outside the roles that they're in. (L.T.) 
The participants emphasize the importance of taking charge of their care. They push for a recovery model based on personal choice, resisting the power differential inherent in a therapeutic relationship in order to negotiate treatment. One participant talks about the process of negotiating a relationship with a new provider:

When I found the person that I thought I wanted to work with I sent her a whole email. I said "listen, this is my experience, this is what they're telling me I have, I don't believe them, I had a manic period that was induced by Effexor, do you think you would be willing to work with me?", she says "I think I we can work together on this". (C.R.)

This participant discusses a recovery program that puts the consumer at the center of the decision-making process, and accounts for providing people the support needed to make decisions:

Person-centered planning is a technology for the power to participate in the design of their own treatment plan. And I mean in every literal sense, to where the person actually signs off or even might draft that plan. And for people who may not be able to do that there's an opportunity for peers to help guide an individual in the development of such a plan. (K.H.) This participant extrapolates the importance of autonomy on an individual level to a proposal for broader social change: "I think the whole idea of saying 'I want to create my road to recovery, and this is what I need to get there' is at a micro level what I'd like to see more of at a macro level” (A.P.).

The theme of voice follows a similar pattern to the excerpt above, participants speaking about the connection between individual consciousness raising, and using a 
newfound voice to foster a movement for social change. This participant discusses the processes she has observed in herself and others:

I gotta go tell my friends, I gotta let them know that this is really cool, and that this is really powerful, and that I'm growing, and I'm getting to be this person that can speak in front of people, I'm getting to be this person that can tell a counselor "no I don’t think that will work for me". I'm getting to be this person that can say no ... That's being powerful, that's the inside power. And I think probably that everything that started at the grassroots level and that has lasted, then that has been able to make change. (S.K.)

She goes on to discuss how people become connected to a social movement and resist traditional power hierarchies, focusing on the bottom-up power of social movements: Most of those people that are going to these agencies ... they're learning that "I’ve got some power, I’m gonna go over here, they're advertising this committee, or my counselor told me about" and they start becoming involved ... And it's powerful to see other people get their power. And they are getting their power even though these other people up here are the ones that have the key to what happens. Then there's these people down here, that are really getting pretty powerful. And actually their power, our power, is really power because of where we've come from and where we've moved to. (S.K.)

In this response, the participant introduces the concept of personal power as a source of resistance, going beyond the conceptualization of power that Link and Phelan presented 
in their model. Another participant addresses the connection between personal voice and systemic change:

I see it in a grand way as an opportunity for people to articulate what they want and need, as a way of telling the system that this is what folks want. And it would be hard pressed for a public service system not to kind of adapt to the voices of the people that are being served...person-centered puts the pen and the paper in the hands of the clients, it's where I come from in terms of patient choice and self determination and then broadly it’s an opportunity for people to “speak to the system”. (K.H.)

The participants also discuss a relatively new avenue for making their voices heard-the formal inclusion of consumer/survivors into policy committees. One participant discusses the advisory boards that help to guide government organizations: "the boards, just by virtue of them existing, actually help show those agencies that people can serve and contribute, people can be part of a plan that a state has to adhere to in order to get funding” (K.H.). This response addresses the recognition inherent in having consumer/survivor opinions carry enough weight to affect funding decisions. Another participant worries that even though consumer/survivors are included in committees, their voices might not carry enough weight, but still finds the balance favorable: "years ago they wouldn't even have a mental health consumer on any state committee, and now there's some on state committees. Sometimes they're not listened to, but sometimes what they say makes a difference” (S.K.). 
Possibly because of their experiences with exclusion and silencing, the participants emphasize their philosophy of valuing other voices. This participant speaks about learning to value his client's perspective from his mentor:

He said "what can we do to have you feel that you are obtaining the highest level of quality of life you can experience?". That is the attitude that I work toward, and that I hope to see become the hallmark of the consumer/survivor/expatient movement. (L.S.)

With this focus on valuing voice, the participants are resisting top-down hierarchies and making room for voices that often are not heard. In addition, they are helping to enact a different paradigm and learning from the experience of putting change into practice: “we're trying to see that we're all in the same boat, nobody's separate, nobody has more power than the other, every voice is important, every voice is heard, everyone has choice” (S.K.). She goes on to talk about designing a study in which the participants’ opinions were given a powerful role, and the ways they tried to honor their expertise:

We had a center do a study and we had these survey questions that we designed, us trauma survivors... we asked them things like “did anybody help you? how did they help, who helped, what hurt you the most?” and then the biggest thing was, "what do you recommend for people who help trauma survivors”...we went further and showed what things helped those people, what they thought helped, not having somebody say, "we think this would help these people”... Instead, it's like “you guys are the experts, what do you think would help?” (S.K.) 
The theme of resistance helped guide many of the participants' responses. This was enacted through discussion of their rejection of a devalued status, valuing consumer/survivor knowledge, demanding participation within the policies and institutions that affect their lives, rejecting a traditional patient or provider role, and emphasizing bottom-up power. Their support of a grassroots movement illustrates a power that speaks back, moving away from the unilateral power that Link and Phelan propose. The process of social change that they have helped create helps us focus on how we can understand a phenomenon by trying to change it.

The participants emphasize the importance of openness and acceptance in their work for social change. This participant illustrates this philosophy of resistance of hierarchies: "I’ve worked with several different movements ... what I've found is the mental health movement is by far the most innovative and open and receptive to new ideas movement out there ... more able to understand diversity” (A.P.). In a similar vein, this participant discusses the difficulties the movement has faced in making their voices heard within some institutional contexts:

It's just hard sometimes. The good thing is that some of the old guard is moving out and there's new people coming in and they have different ideas of how things operate and they're more willing to listen and they're not so closed minded about how they're going to deal with people. (B.T.) In discussing their values, the participants put a great deal of emphasis on the power of grassroots movements, and the importance of making sure everyone is heard. In this way, they are enacting a resistance of the exclusion and devalued status that Link and Phelan propose are the basis of stigma. Their focus on the power of resistance 
emphasizes the central role that the targets of stigma play in overturning it. This participant poses that the basis of any movement has to be the voice of the people who experience the stigma:

In order for this kind of thing to work, for people to be heard and respected, there really does need to be, I think as far as any movement ever, it has to come from the people who are experiencing the treatment ... hypothesizing about it does no one any service whatsoever. I'm hoping maybe in ten to twenty years that there is a more progressive, openminded model of what the standard of mental health treatment is. (M.J.) Another participant celebrates the accomplishments that the movement has made through the slow process of grassroots organizing:

We're having our little low consumer groups who are getting cities organized, and then we're getting the state organizing consumers, different groups around the state. There's a national coalition and so eventually then we may be listened to. We may become more powerful and be able to have somebody see that “we can’t do anything to destroy their power, they've been around, they're still here, and maybe we should listen to them”. (S.K.)

The movement's persistence and trajectory has been a source of pride and inspiration to the participants. There is a lot of focus on the growth of the movement and the inclusion of their perspective into broader structures: "It's growing and there's more people who are in agencies that are powerful, that are controlling funding or that have a 
little bit more power than others, that are saying 'hey, let's listen”” (S.K.). This participant talks about the slow gains the movement is making:

they are seeing how peer support work is not just in any one hospital in the state or in one area of the country ... for it to be just common practice will definitely take some time. I think it will take people slowly working within the system and giving people results that they can actually see, "well maybe it's actually working" for it to be widely accepted. (M.J.)

A focus on grassroots growth pushes the consumer survivor movement to place value on the smaller voices, the opinions of their base, not just figures of authority. This participant discusses the slow change in having big institutions shift toward recognizing the small voices of consumers:

the system is going to have to shift toward the development of those services. If $\ldots$ a thousand people want acupuncture $\ldots$ that pushes the system to say "wow we have all these people saying that I can come and share these benefits with them, we might need to do that because all these people are saying that that's been helpful”. (K.H.)

Likewise, one participant talks about an author who supports a non-medical approach, and emphasizes the inspiration she receives from having his voice carry weight despite having a limited trajectory and presenting an uncommon opinion:

Just a guy who researched and put out a book ... I think that even is more threatening than if a big name were to come out and say "here's what I think". Here's this guy who really started in a grassroots way doing his 
own stuff ... and he's being heard. For us it's really awesome, for people who self-identify, that's really powerful for us. (M.J.)

The participants also draw inspiration from comparisons and connections to other social movements and other stigmatized identities. Multiple participants spoke about the civil rights movement as a guiding example: "I grew up during the years where the civil rights movement was very strong and I witnessed incredible discrimination towards African-Americans and that really has had a huge impact on me” (L.T.). This other participant describes some of the similarities between groups when she talks about an event where "there was an African-American man, and he said 'you mean there are other people who are as afraid of the police as I am?"” (A.L.). One participant supports Link and Phelan's proposal that power imbalance is central to the maintenance of stigma, and notices a similarity between the civil rights movement and the consumer survivor movement:

That's the thing that I've always seen about slavery and its being able to last, was the power imbalance ... And when you've got more people thinking about the power imbalance like some of the civil rights leaders, like Martin Luther King jr., it’s the same type of thing. (S.K.)

Likewise, this participant addresses the trajectory of the civil rights movement as a comparison point for where the consumer survivor movement can go:

When you think of African-Americans and other ethnic groups who've struggled for civil rights, they've been able to move from weakly constructed up to here where they get more advantage. I wouldn't say they're as advantaged as the white people still, but there's more ... people 
really have a hard time letting people move out of this weak construction.

In this case, the participant makes comparisons with other movements, speaking about reclaiming the terms that have been used to stigmatize, and considering the use of that strategy for the consumer survivor movement:

It's not necessarily that the word client is a bad word, it's how it's been used in the past as demeaning towards people. People refer to use consumer or advocate because it's more empowering. But I come to the idea that a person can take back those negative words, like gay or wetback. So you take those words back from the person that's using them in a negative way to make them empowering words, but it’s hard because a lot of people don't want to do that. (B.T.)

The intersection of multiple stigmatized identities was discussed by various participants as they made sense of the difficulty of working against systems of consolidated power. When discussing structural discrimination, this participant focused on the shared oppression between several categories: "I think that that's the key behind the whole thing, who gets what types of services, it doesn't have to be just mental health it could be racial, it could be gender ... there's an imbalance in power” (S.K.). This participant discusses the difficulty of an intersection between a psychiatric diagnosis and being gay, citing exclusion and discrimination as a result of it:

Being gay and having a mental illness is like levels of stigma ...it's hard for people to come out of the closet about being gay with a mental illness because there's a part of our society where being gay IS a mental 
illness ...there are clinicians and doctors who make you feel bad if you tell them you're gay, or they're not accepting of your partner. ...it's just really difficult to be something plus something. (B.T.)

In a similar vein, another participant recognizes that people who carry multiple stigmatized identities have a heavy load, and from her position of relative privilege it is hard to comprehend all of their disadvantages:

I know that even though I have had this huge stigmatizing label on myself of schizophrenia I still grew up with incredible privilege so there's all different levels and layers. I know that people of color that also are carrying the label of mental illness are really carrying an incredibly heavy load, and I don't know what that's like ... so, some of my answers are probably too easy, because it's easier for me than it is for some people. (L.T.)

One participant talks about the sexism she has encountered even within the consumer survivor movement, and the reluctant acceptance she has received:

For a long time I'd see women coming to the movement and they'd leave. And I was either foolish enough or dumb enough, I just ended up staying around and didn't go away. It really was a boys club here as far as who the leaders were and they didn't know what to do with me ....all of a sudden found myself at the boys table and being accepted as one of the boys, I'm like “what happened? how this did this happen?” and I don’t know if it was because I was there for so long that I became kind of part of it. And it freaked me out at first, I'm not sure I want to be here. (A.L.) 
An important theme among the responses was the trajectory of the consumer survivor movement and its struggles to achieve legitimacy, as well as the movement's milestones and achievements. The participants also reflect on the value of diverse strategies as forms of resistance and their value in generating social change. This participant illustrates the difficulty in redefining an identity when each of the terms can be so charged with a painful history:

Even just in labels, one of the things that we have trouble with, among us who are in the peer movement is what to label ourselves. And a lot of that comes from what the others in power or in organizations that have said we're broken, it comes from them, so some of us are adverse to certain terms being used, and yet we don't know what is a good one ... "It's too long to say mental health consumer, psychiatric survivor, expatient movement", so you get, "well what are we? what do we want to call ourselves?" and then there is no one word that we've been able to find. (S.K.)

Another participant reflects on the roles that different factions take within the movement, and the way that affects the process of social change:

I always find it good to have people who are on the extremes ... a moderate voice can say the same thing that an extreme voice says, but because they're not so extreme it doesn't seem extreme. Then everybody goes along with it. ... you can always say “If you don’t agree with me then Mindfreedom's gonna come here and you're gonna have a real problem, so which would you rather deal with me or Mindfreedom?" (B.T.) 
That response reflects the role that radical movements often carry within society, that of pushing the envelope in a direction that seems unreachable, and helping move society a few steps toward that goal.

The internal conflicts and differences of opinions within the movement were discussed by all of the participants. The process of negotiating priorities, identities, definitions and even clashing worldviews is a conflict that has been shared across most progressive social movements, as they try to make room for everyone's voice. The conflicts in this movement address the difficulties in creating broad social change, and center around hierarchies of diagnosis, decision-making around priorities and strategies, and differences of opinion regarding the medical paradigm of mental illness.

The participants discuss patterns of exclusion that are present within the movement, namely around who can be a part of the movement. The factor of exclusion is centered on the severity of diagnosis: "there's also a hierarchy about what kind of mental illness you have, and people can be deemed to be even crazy within the mental health movement, which is unfortunate” (A.L.). At another point, she explains the way that division presents itself:

I think another way that separation happens in our movement is the hierarchy that exists. If you have been force hospitalized and you've had seclusion and restraint, you're at the top of the hierarchy... And if you've had one hospitalization you've taken maybe antidepressants for year, and you do private therapy, you're at the bottom of the hierarchy. (A.L.) This participant discusses her original feelings of exclusion, based on a supposed lack of understanding: 
I used to be more radical in my thinking because I used to think that unless you were involuntarily treated, and locked up and committed against your will that you couldn't really call yourself a client or a consumer or a survivor. I was really narrow about that. ... Unless you've lost your liberty.... I feel like unless you really experience those things that come along with labels, it would disturb me when people would say I'm this, but not really get what that was about. (K.H.)

Another participant discusses a similar stance, and a confrontation with one of its supporters around issues of safe space:

Oh "you're not crazy enough" I’ve never heard somebody be bold enough to just put up what they were saying but I've heard people say that without using those words ... "you haven’t had enough suffering" ... and I was really getting frustrated so finally I just turned to him and I go "where do you keep these yardsticks?" ... it’s more upsetting because it’s somebody that you think is on your team, and all of a sudden you see them start popping people around you. And you're like “what the hell are you doing? These people are supposed to feel safe here!” (L.S.) The push for broader inclusion is based on ideas of unity and support for the movement. One participant discusses how she changed her mind on the issue, in part based on a rational decision for the benefit of the movement: "over time I thought 'well, if somebody what's to call themselves any one of those terms, we need people in this movement' so the more the merrier” (K.H.). Likewise, this participants chooses to emphasize similarity and inclusion: 
If you really want to self identify, join us. I don't see the need for a hierarchy. I think that there is sometimes a qualitative difference about the experiences that people have and I think that sometimes there's lack of understanding about those qualitative differences, but I don't think it's something that we should put a hierarchical order on our experience.

\section{(A.L.)}

Other conflicts are discussed more generally, with shared frustrations over infighting and disagreements. One participant recognizes that internal struggles are typical within a movement: "every movement at some point will eat it’s own. I hate that expression, but I hear it all the time, and that at least tells me that there are people who feel like they're being eaten” (L.S.). Later, the same participant expands on the exclusion he sees in the movement:

You get people who enter into this process ... of defining this group and then for some reason that becomes their mission, that becomes their life's work. And what they do is continue to narrow the opening in the funnel until fewer and fewer pieces of sand work their way through that. (L.S.) These issues of separation and exclusion mirror the stigma process that Link and Phelan propose, repeating some of the patterns that have occurred directly to the participant. This participant illustrates this repetition within the movement of patterns of oppression:

And what's interesting too is how they use power within their group. What you hear a lot of people getting burnt out on is when they do what's been done to them in the system. Peer run organizations have fallen apart because of some of those dynamics, and we traumatize people and I think 
it's partly what was done to us ... I watch how people treat people in this movement (A.L.)

Some of the conflicts are described as caustic and draining, while others center on differences of opinion about what should be a priority, and what is superfluous. This participant talks about feeling distance from OCSC and being worn down by the conflicts:

I wish that we would as a movement get off of some of the personal nitpicking and so sometimes I feel out of sorts with OCSC. People are very, not narrow minded, I think people are where they want to be. But I tend to be thinking about the bigger picture, and that tends to get pulled down by some of the nitpicky types of stuff. (K.H.)

Later she reflects on the repetition of larger patterns that promote stigmatization: "I also wish that we didn't tear each other down as much ... I think we do contribute to discrimination, ironically enough when we do that, it’s like a vicious cycle. (K.H.)” Another participant discusses the intensity of the conflicts and appeals to authority as a way of controlling the disagreements:

You've seen the emails recently...? The vitriol in that is just, you may have noticed that I haven’t said anything in any of those. But I have been sending emails to the board of OCSC saying "you guys need to step up, this is outrageous, this kind of crap can't be, you can't have people calling names, or throwing around wild accusations about members of this coalition that go unaddressed.” (L.S.) 
There are struggles within the movement regarding conceptions of mental illness versus human diversity, and the worldview that guides their understanding of madness. This participant addresses the passion involved in these disagreements: In the consumer survivor expatient movement this is a hot topic. it's a topic that I've seen it's caused people to leave organizations, to refuse to have any type of contact with people. and ... even will leave sate meetings because the other person shows up and it's because they think, at least, that they're in opposition to each other on this topic. (L.S.)

There is strong disagreement about the role of psychopharmaceuticals, the push for the inclusion of alternative treatments has sometimes resulted in exclusion of medication:

The people in our movement ... that if somebody says "I take medication because it allows me to function better so I can be more successful in my life" then they’re like "you're just using a crutch, and you might as well be using crack cocaine or something to get you through your day. It's the same thing because you're just taking a drug and it's not serving any purpose" (L.S.)

Another participant echoes the charged issue of pharmaceutical treatment: There's a very strong movement against psychiatric medications ... sometimes people who are fueling that really are out of touch with what it's like to have these issues, they can say the theoretical way that other people should be able to deal with their issues without using pychotropic pharmaceuticals, or they can say "this person did it, or I did it, so it must be possible for everyone” and I find that very problematic, I feel that has 
kind of like a reverse stigmatization ... our movement is creating divisions and levels of either wellness or saneness or madness that are exclusive and that don’t allow for variation (L.S.)

These responses illustrate that despite ideals of inclusion and diversity, there are patterns of exclusion and stigmatization within the movement. This participant discusses another controversial topic regarding forced treatment:

I was "picked up" by the police in the middle of this busy street and I have to admit that if that didn't happen and I was then committed, I don't know what would have happened, even if I wasn't hit by a car where would I have gone? ... I often run into challenges with my peers because there is no other answer except to say I'm glad that that happened. I'm not glad with what happened right after I was detained, it was a brutal horrific experience and I never would have wanted that to happen, or to anyone else. But that moment of being extricated from a dangerous situation, I don't know what else would have occurred. So I often run into frustrations with my peers about that issue. (K.H.)

This participant feels that there is not enough room for her point of view within the movement. Since part of what she proposes aligns with the dominant treatment paradigm she feels that it is not well received. Her story illustrates ambivalence about the need for forced treatment in extreme cases. She presents a critique of the consequences of being forced into treatment, but at the same time values the need for safety and protection in times of severe crisis. This point of view generates resistance from her peers because of 
the history of oppression that consumer/survivors have suffered under the guise of protection.

In the section on power imbalances there are a number of themes that support the Link and Phelan proposal that power plays an integral part in creating stigma. The participants illustrate the power differentials they face in a context of psychiatric diagnosis. Issues of credibility, legitimacy and invalidation serve to silence the participants, acting as obstacles in their push for social change. However, the participants go beyond Link and Phelan’s unidirectional conception of power to focus on their grassroots strategies of resistance. In this way, the participants take control of their circumstances, and coalesce to create a strong movement. The priorities and strategies of the movement illustrate for us what bottom-up power can look like in a context of psychiatric stigma. Yet even as the participants struggle to resist exclusion and stereotyping, they seem to repeat some of the same patterns among themselves. This complex interaction of power dynamics serves to expand the conception of power that Link and Phelan propose.

The priorities and strategies of the movement illustrate what bottom-up power can look like in a context of psychiatric stigma. Yet even as the participants struggle to resist exclusion and stereotyping, they seem to repeat some of the same patterns among themselves. This complex interaction of power dynamics serves to expand the conception of power that Link and Phelan propose. 


\section{Chapter 5: Discussion}

"When psychiatric patients internalize the discrediting, there is nothing to say: they are silenced. When they talk about the discrediting, they are resisting it” (L. J. Morrison, 2005, p. 114).

\section{Overview}

In this chapter I discuss the major themes from the interviews and the ways they inform the Link and Phelan model of stigma. In particular I address the sites of agreement between the model and the responses, illustrating the applicability of the model to a context of psychiatric stigma. I also focus on the specific themes that may be enlisted to expand the model for this population, in particular how participants' activism can inform anti-stigma work. While the Link and Phelan model is a conceptualization of the processes of stigma creation and maintenance, we can learn about the phenomenon from those who have engaged in strategies for resisting stigma. Of particular interest is the participants' broad conception of power-one that is more complex than the unidirectional approach that Link and Phelan utilize. This study seeks to understand how a consumer/survivor activist perspective can inform the Link and Phelan model of stigma.

\section{Limitations of the Study and Future Research}

One of the limitations of this study centers on the narrow geographical region from which participants were drawn. Their shared participation within a single coalition also makes the perspective they offer very specialized. While a sample size of ten participants is acceptable for the methodology in this dissertation, the applied value of a 
study of this size must be addressed. However, the goal of the study was not generalizability, but to purposefully sample key informants who were knowledgeable about a specific set of phenomena.

Instead of generalizability, this study seeks to address what Lincoln and Guba (1985) term transferability. By providing detailed descriptions of the context and procedures of this study, I hope to provide enough information for other researchers to determine whether my conclusions can be applied to other settings, situations and populations. Lincoln and Guba (1985) propose that in order for a study to be transferable, the reader must have enough information about both the context of the study and that of the field of application to judge the degree of fit. I have followed Graneheim and Lundman's (2004) recommendation in providing extensive description of the context, selection, and characteristics of the participants, as well as of the processes involved in data collection and analysis. (For a more complete context of the participants' words in the interviews, see a full interview transcript in Appendix C.) In imagining the context of potential readers, it is likely that they would be working on discrimination or stigma, perhaps within a context of psychiatric disability. A potential application for the results of this project might involve anti-stigma work, whether if be a public campaign or a policy and legislative change.

This study's focus on a consumer/survivor perspective limits the range of responses since it excludes the perspective of other stakeholders. While it is valuable to consider a minority perspective that has mostly been excluded from the conversation on stigma interruption, it is important to note that other actors hold valuable knowledge not taken into account in this research project. The perspectives of legislators, hospital staff 
and administrators, social scientists, and policy designers would also provide perspectives from which to inform the Link and Phelan model.

The selection criteria for the participants also excluded a significant portion of consumer/survivor activists. Academic studies based on interview data presuppose capacities for rational discourse and patterns of reasoning that conform to conventional models of reasoning. There are many individuals with psychiatric labels barred from participating because their mode of communication did not fit these parameters. Because of this limitation, the study excludes some perspectives on anti-stigma strategies. For example, there may be non-verbal exchanges that are important to strategies of survival and resistance that are not readily articulated. There is a risk then that this study replicates the very patterns of exclusion that it seeks to change. Future researchers might wish to explore methods of including those whose perspectives might not be easily conveyed in an interview format. It would be beneficial to engage the expertise of consumer/survivors in designing the research methodology to involve a broader range of psychiatric survivors.

The selection criteria may have also narrowed the range of responses. In order to speculate on how other perspectives may have influenced my findings, I consider here the role of social locations on participant responses. By drawing on activists with extensive history in this field, I sought out people with experience in articulating their point of view, but left out the perspectives of those who are relatively new to the movement. Individuals who are joining the consumer/survivor movement may bring important insights about the process of stigma.Their perspectives may be less scripted since they may be less influenced by the organizations and the coalition. Youth who are new to the 
movement might focus on different aspects of stigma than activists with a longer trajectory. For example, young activists might be interested in addressing the role of schools in participating in labeling, the first element of the Link and Phelan model, since they might have faced an early diagnosis. That perspective would contrast with the participants of this study, who focused more on the importance of language and terminology. For young activists the focus on terminology may not be as compelling. The young activists might also focus on the second element, negative stereotyping, emphasizing the importance of moving on from a perspective of chronicity. Being labeled as chronically ill might be particularly sensitive to younger activists since they might worry about a label that will follow them for the rest of their lives, or they might be more vulnerable to a discourse that implies that their hopes for their future might be thwarted.

The study also is limited through the omission of the perspectives of individuals under the jurisdiction of the forensic psychiatric system. Psychiatric patients confined to an institution might be more heavily involved than my participants in the issue of separation from community, the third element of the Link and Phelan model. Their priority might be the role of criminalization in stigma, preferring to focus on interrupting stigmatizing discourses that emphasize dangerousness. This population might also address the role that stigma plays in the creation of residential treatment facilities (RTFs), since the lack of RTF beds keeps many of them in a more restrictive setting than they have a right to access. This would contrast with the perspectives found in this study on issues of separation, which were centered on the dehumanizing practices of institutions. 
Exploration of social class and other differences along dimensions of oppression was particularly limited in this study. Because of the selection criteria, the participants were mostly middle class with stable jobs, and most had high school or university degrees. While income and level of education were not direct questions in the interviews, many participants included information about employment, level of education, and living situations in their responses, allowing me to infer their class standing. The sampling left out the large number of homeless people with psychiatric diagnoses, or even those living below the poverty line. In addition, very little of the data directly addressed class struggles beyond issues of access to treatment. Future studies might focus on dynamics related to social class to explore different patterns of stigmatization.

If the sample for this project had included individuals living at or below the poverty line emphasis might be placed on the role that stigma plays in accessing basic material needs. These participants might focus on the fourth element of the Link and Phelan model by addressing the stigma and discrimination involved in locating adequate housing, in contrast with the participants of this study, who emphasized inequality in life opportunities. Persons without a high school or college education might be more focused on creating immediate changes that alleviate economic hardship. Their focus might center on the obstacle that stigma presents in employment, when the second element of stereotyping effectively blocks people who are easily identified as suffering from a psychiatric disorder. This population might be more focused on intervening on structures and institutions at the employment level. Those without employment or who are living at the poverty line are more vulnerable to interacting with institutions and law enforcement 
so their focus might be centered on better police training addressing the fourth element of structural discrimination as well as the second element of stereotyping.

Also omitted from of this sample were the perspectives of more radical factions of the consumer survivor movement.. Since all of the participants of this study are invested in participating in the system and are working toward incremental reformist change, the more radical positions — for example, those identified with "mad pride”-- may have been excluded. Mad pride includes rejecting a range of normative assumptions, including any participation in the current system. If the radical perspective had been more represented $\mathrm{n}$ this study, there might have been more critiques of peer programs and changes that center on reform. The responses on separation, the third element of the Link and Phelan model, might also have been more complex. Depending on how much participants identify with or want to be part of the dominant culture, there might have been more expressed ambivalence about the identity of the outsider.

Based on Lewin’s (1946) injunction to learn from a phenomenon by trying to change it, this study sought to learn about stigma from those engaged in anti-stigma work. However, the Link and Phelan model was designed to explicate the process of stigma creation rather than stigma resistance. Because of this focus, applying the model to a context of stigma resistance goes beyond the original scope of the model.

\section{Findings and Interpretations}

This dissertation seeks to explore how a consumer/survivor activist perspective can inform the Link and Phelan model of stigma. This model proposes that stigma occurs when labeling, negative stereotyping, separation, and status loss and discrimination co- 
occur within a context of unequal power. Since the model was developed to explain the formation of stigma more generally, the application of this model to psychiatric stigma offers potential insights on its usefulness in this applied area. The responses from activists can help to illustrate whether the Link and Phelan model provides a useful framework from which to understand the particular processes involved in the creation of psychiatric stigma.

The Link and Phelan model was intended to illustrate the processes of stigma creation and maintenance, rather than stigma resistance or processes of change. This dissertation takes up Lewin’s (1946) challenge of trying to understand a phenomenon by altering it, and seeks to explore the perspective of those who actively try to change stigma. This study addresses how the model is relevant when discussing change and implementation, not just in a theoretical understanding of process. The strategies of resistance that the participants focus on speak to the applicability of the model for interrupting stigma.

The findings are organized to correspond with each of the elements of the model in order to allow for comparisons between the model and the responses, and the discussion follows a similar order. Overall, there was a strong fit between the process of stigmatization as is described by Link and Phelan, and the participants' experience in the field. The activist strategies of resistance serve to inform the model and illustrate some avenues for implementation. 


\section{Labeling.}

In regards to the first element of labeling, the participants explored the implications of language and diagnosis. There is a strong match between the model and the participant responses in calling attention to the person who assigns the label. Link and Phelan propose this first element as a way of shifting the focus from the target of stigma that is present in multiple conceptions of stigma, onto the person doing the labeling, who is often rendered invisible in discussions of stigma. By making the labeler visible, they intend to allow the possibility of questioning and critiquing the process of labeling. These two aspects were strongly supported by the participants' responses in repeatedly moving the focus to the person assigning labels, and challenging the labeling process as a strategy of resistance. This aligns with the move toward utilizing discrimination as a more appropriate term than stigma since it focuses on the person affixing the label (P. W. Corrigan \& Penn, 1997; Sayce, 1998).

Morrison (2005) proposes that labeling in the consumer/survivor/ex-patient movement relates "less to the positive or negative definition of their identity, than to the right of others to define their identity in the first place. ... It is an ultimate politics of identity, where they are demanding the power to be a part of the identity discussion” (p. 171). The responses of participants in this study center on the right to participate in discussions about identity, language and labeling. The participants identify the activist strategy of reclaiming the right to choose their own definition.

The discussion critiquing the diagnostic and labeling process aligns with Foucault’s (1988) analysis of the boundary between normality and pathology. A historical analysis shows us that this line has moved drastically throughout the centuries, 
indicating that the definition of sanity has been fluid and changing (Foucault, 1988). Foucault poses that the dividing line between normality and pathology must be examined and questioned in order to determine the role of madness in a society. He focuses on who has the power to determine where the division between normalcy and madness is drawn, and how that role has changed hands over time. The participants' responses also question the legitimacy of psychiatry as the arbiter of normalcy, calling attention to the diagnostic process in order to render it visible and make it susceptible to critique. Foucault's (1988) discourse on different conceptions of madness allows us to conceive alternatives to the current, normative view; while pushing us to understand these changes as non-neutral and political.

The responses identify the importance of utilizing a language that emphasizes humanity instead of pathology. In addition, the participants resist labeling by insisting on separating personhood from diagnosis, choosing adjectives instead of nouns. This strategy is in line with Haslam's research on the connection between essentialist beliefs and prejudice (N. Haslam, 2000; Nick Haslam \& Ernst, 2002; N. Haslam et al., 2002). The participants interrupted the process of differentiation by promoting a discussion of similarity, and focusing on a continuum of shared experience. By utilizing this strategy, they are resisting the emphasis on difference that can reduce a group to essentialized characteristics.

\section{Stereotyping.}

The participant's responses illustrate the element of negative stereotyping within the Link and Phelan model. The participants discuss the ways they encounter 
stereotyping in multiple settings, whether in a personal interaction, or within broader contexts such as media and the health care system. The participants point out the ubiquity of stereotypes, explaining that their pervasiveness makes them very difficult to interrupt. Crocker, Major and Steele (1998) also discuss pervasiveness as an important factor in stigmatization. The authors argue that the stereotypes that address the most severely stigmatized identities may become so ubiquitous as to be accepted as facts. The authors propose that the acceptance of stereotypes as facts results in widespread devaluation that affects the lives of stigmatized people in ways that are often difficult to determine. In the responses, the participants placed a strong emphasis in challenging myths and rejecting negative representations. The participants shifted discussion of stereotypes to issues of human diversity and the right to be different without being cast aside.

The strategies of resistance to stereotyping focused on a critique of the illness discourse and its premise of deficiency. These strategies are in line with Riessman's (2000) research on stigma resistance that focuses on the refusal to internalize deviant labels (resistant thinking) as a central strategy. Five of the participants addressed mad pride, and discussed the value of madness in their lives and for society at large. A consumer/survivor perspective is an interesting point from which to assess the Link and Phelan model because the participants attempt to interrupt the process of negative stereotyping by moving away from a disease model and embracing the positive aspects of their madness. Morrison (2005) discusses “claiming, redefining and celebrating deviant identity” (p.165) as one of the central strategies of the consumer survivor movement. This perspective is particularly interesting for the interruption of stigma because it 
deviates from a more standard approach of accepting the negativity inherent in an illness discourse. As one participant indicates, traditional anti-stigma approaches can focus on pity instead of human rights and celebration. This approach is consistent with the research that critiques the "illness like any other" approach to anti stigma work, which can have the unintended consequence of increasing "prejudice, fear, and desire for distance” (J. Read et al., 2006, p. 303). The participants rejected the implied chronicity often associated with the mental illness discourse and emphasized the importance of hope in a process of recovery.

\section{Separation.}

The participants address the third element in the model, separation, in the context of psychiatric stigma by calling attention to sites of exclusion. The responses illustrated the separation from the broader community, and discussed the policies that are utilized to enact social distance. The participants propose that fear fuels the community impetus for separation, a result of stereotyped representations of mental illness. There was also focus on the exclusion of peer specialists and the consumer/survivor movement, as well as the distance inherent in a traditional therapeutic relationship. The participants denounce dehumanizing practices that contribute to objectification and mistreatment.

The management of disclosure is central as the participants analyze the social costs that come from a public stigma. Since a psychiatric disability is not necessarily directly observable, the participants discuss the issues that surround practices of secrecy and disclosure. Goffman’s (1963) work discusses the troubles of discreditable individuals, who must focus on managing information in preparation or avoidance of 
disclosure. The participants’ responses illustrate the considerations involved in disclosure, since it can mark the beginning of exclusion for many of them. Buseh and Stevens (2006) also discuss this strategy of resistance as selective disclosure in their work with people living with HIV and AIDS.

In addition to denouncing practices of separation, a central point of resistance was the focus on struggling for inclusion. The participants discuss their strategies for inclusion as peer specialists, within policy decisions, and as valuable members of society. The participants addressed and celebrated the progress that the movement has made in becoming a part of policy discussion, their inclusion in committees, boards and employment. Inclusion was a central aspect of the proposals that the participants brought for creating social change. The participants discussed their goals for dismantling institutions that foster separation, and focused on the value of inclusion and connectedness.

\section{Status loss and discrimination.}

Regarding the fourth element, status loss and discrimination, the participants illustrate its applicability to the context of psychiatric stigma. The responses evince a deep trench of inequality, and the most compelling example the participants can offer is a 25 year decrease in life expectation for people with a psychiatric diagnosis. There is extended discussion about multiple social institutions that serve to discriminate against people with psychiatric diagnoses, including laws, law enforcement, employment, housing and schooling. The participants spend a significant amount of time discussing the discrimination they face within the insurance and health care systems. They discuss the 
lack of access to treatment, as well as the difficulties they face in being accepted as providers.

The participants discuss their strategies in interrupting the process of status loss and discrimination through calling attention to inequality as well as attempting to transform the structures that affect them. The responses illustrate the work that these participants do as activists as well as some of the larger successes of the consumer/survivor movement. The strategies of resistance include demanding participation in decision making, participating in policy discussions, recommending changes to providers like first responders and demanding drastic changes to standards of treatment and hospitalization.

\section{Power.}

Link and Phelan pose that a context of power imbalance is necessary in order for the 4 elements of the model to become a stigma. Power acts as the underlying current for stigma creation, acting on all the elements that the authors propose. As such, it is not possible to untangle power from the other elements or to conceptualize it as a discrete category. All elements of the model interact, sometimes making it impossible to tease out where one begins and the other ends. For ease of readability I have organized the findings and discussion sections of this dissertation according to the elements of the stigma model, even though there is considerable overlap among the elements. This challenge becomes most difficult regarding power imbalance: it is not even a separate element, but an underlying current that affects all the elements. I address this in order to clarify some of the organizational decisions I've made, but also to draw attention to the fact that top- 
down power and the power of resistance have been addressed throughout all of the sections. In this particular section, I discuss some of the themes related to power inequality that were less connected to the four elements of the model.

The discussion of power within the Link and Phelan stigma model has garnered attention within the field of stigma. A better understanding of the role that power plays in creating stigma can help us address some of the mechanisms that perpetuate it and make it difficult to disrupt. The focus on the structural supports that make stigma possible is the most innovative aspect of their model, and one of their major contributions. Many conceptualizations of stigma have focused on an individual or micro-interaction understanding of the process without adequately addressing the interaction with structural systems. This theoretical development has earned the model praise from authors who consider power to be a crucial element that had been overlooked in earlier studies of stigma (Rutledge, Abell, Padmore, \& McCann, 2009; Reutter, Stewart, Veenstra, Love, Raphael, \& Makwarimba, 2009; Maman, Abler, Parker, Lane, Chirowodza, Ntogwisangu, et al., 2009; Parker, \& Aggleton, 2003; Green, Davis, Karshmer, Marsh, \& Straight, 2005).

Link and Phelan's discussion of power is centered on the political, cultural and structural power necessary to enact significant societal consequences because of a stigmatized identity. Their focus on power is unidirectional and top down. They propose that a group without power cannot stigmatize a dominant group because they do not control the social institutions required for the stigma to take effect. Their discussion of power seems to dichotomize groups into powerful/powerless, dominant/subordinate. 
These dichotomies can oversimplify intricate interactions without considering the power of resistance or the complexity of intersecting identities.

I draw on Prilleltensky’s (2008) conceptualization of power to guide my critique of the Link and Phelan model. He poses that "power refers to the ability and opportunity to fulfill or obstruct personal, relational, or collective needs” (p. 121). He emphasizes individual agency, the volitional activity necessary to enact change, as the ability to fulfill needs. After addressing the individual level, he proposes that opportunity is governed by social and historical circumstances, structures and external determinants. His approach to power is centered on the interaction between agency and contextual dynamics. Prilleltensky (2008) poses that there are three types of power: "power to strive for wellness, power to oppress, and power to resist oppression and pursue liberation” (p. 121). Under his conceptualization, the type of power that Link and Phelan propose would correspond with the power to oppress. However, Prilleltensky’s two other types of power—striving for wellness and resisting oppression-are also in line with what the participants are illustrating.

This dissertation addresses the role of resistance as an avenue of power and proposes a more complex understanding of power in the context of psychiatric stigma. The discussion of power centers on the strategies that the participants wield as they seek to resist and change the status quo. In this section of the discussion, I focus on the challenges that the participants describe, and the ways they take up power to resist the existing power structures. The participants' perspectives serve to expand the model by shifting the conceptualization of target populations from passive and dependent to include agency and resistance. 


\section{A. Oppression.}

The participants illustrate some of the most important themes regarding stigmatization in the context of psychiatric stigma. They analyze and describe the oppressive power that pushes them into a passive role, and even as they strive to speak back when their voices are silenced and discredited. There is a strong emphasis on the difficulty in overcoming the passive patient role, the participants address how stigmatizing messages become internalized.

Prilleltensky (2008) calls attention to the psychological aspects of oppression, when dominant groups impart "in the subordinated persons or groups self-deprecating views about themselves. It is only when the latter can attain a certain degree of conscientization that resistance can begin” (p. 127). In this way, he discusses how internalized oppression becomes a mechanism of social control that acts as an obstacle to resistance and liberation, needing to be overcome through awareness in order to push for social change. The participants' responses illustrate the structural pressure they face to internalize the psychiatric paradigm: being forced to accept a label in order to receive support, being told that questioning the symptom can be a sign of pathology, or even facing threats of removal of services when they challenge a course of treatment.

An overarching theme in the responses regarding the conception of power was the issue of credibility. In the context of psychiatric stigma, the participants illustrate that a consistent strategy of power imbalance has been used to discredit their voices. Goffman (1963) discusses the ways that stigmas are used to discredit individuals, to diminish their value and social worth; whether it be with discredited individuals (those with a visible stigma) or discreditable (those with unknown stigmas). As Morrison (2005) proposes, 
one way to discredit a movement is to discredit its members, and she discusses how this comes into effect for other members of the $\mathrm{c} / \mathrm{s} / \mathrm{x}$ movement/: "The heroic narrative describes the transformation from ordinary human being to mental patient, with the realization that the psychiatric label destroys the credibility one may still expect to have in human interaction” (p.163).

Being discredited is not uncommon for marginalized groups or for social movements resisting a powerful structure. However, the scenario is different when it comes to psychiatric diagnoses. In this case, the very content of the stereotypes can provide the rationale for dismissing the participants’ claims. Following stereotypes and social attitudes would imply that people with psychiatric diagnoses cannot be trusted, that they do not have control and cannot make valid decisions. In a study about social perceptions of people with schizophrenia, Angermeyer and Matschinger (1995) found that "people with schizophrenia are perceived to be unpredictable, aggressive, dangerous, unreasonable, little intelligent, lacking in self-control” (as cited in Beate Schulze \& Angermeyer, 2003, p. 300). The social attitudes regarding people with psychiatric diagnoses imply that they are less rational, less believable, and even "less trustworthy, intelligent, and competent” (Link, Struening, Neese-Todd, Asmussen, \& Phelan, 2002, p. 203). These beliefs are a strong base from which to infantilize, belittle and placate people with a psychiatric diagnosis.

When considering the connection between individual experiences and a larger movement, Morrison (2005) states that "the claim to a voice (diverse voices) is necessary in order for larger claims to gain credence. When the voice is discredited from the beginning, claims are easily dismissed if they are heard at all” (p. 171). This disbelief 
expresses itself in many aspects of the participants' lives. Since they are sometimes not considered credible witnesses, crimes against them may go unprosecuted or never even reported (Sayce, 2003b).

Within the theme of credibility, the subtheme of invalidation addressed some of the personal interactions that the participants face. Invalidation serves in this case as a way to silence the claims of the participants. Fernando (2006) speaks about this vulnerability: “to designate someone as a 'schizophrenic' or 'psychotic' invalidates everything they do or say - designates them as ‘alien’ to society” (p. 25). Invalidation can be a strong undercurrent of people’s lives.

Morrison (2005) discusses the expectation that an external person (e.g, psychiatrist) has the power to dismiss or give value to a person's beliefs as well as define their identity through diagnosis. This framework makes the therapeutic relationship a vulnerable space for invalidation, as was presented in the participants accounts. In her work with consumer/survivor activists, Morrison finds a similar theme of "harm being compounded by a disregard for their efforts to define the experience, to negotiate the terms of treatment, or to leave the situation. Their sense of betrayal (if trust was achieved) and their disappointment that their own experiential knowledge of the situation can be so discredited is a powerful aspect of the accounts” (p. 103).

The participants discussed the obstacles involved in resisting their therapists' point of view and insisting on their own. In some cases challenging therapeutic authority was seen as a sign that their illness was worsening. This invalidation requires that the patient relinquish their own understandings of their condition and to adopt the perspective of another person. As Morrison states, “according to the psychiatric narrative, success in 
treatment is often measured by 'gaining insight', which involves accepting psychiatry's explanatory model of one's problem” (p. 112).

The challenge to credibility acted at a broader level as an obstacle to legitimacy, gaining acceptance in formal institutional structures. Chamberlin and Rogers (1990) explain that one of the important goals of the consumer/survivor/expatient movement "is to play a part in devising mental health policy, rather than to be merely the passive objects of policies designed by others” (p. 1241). However, the participants address the difficulties presented by a lack of voice or legitimacy within institutions, making it an uphill battle to be able to generate structural change. Morrison (2005) proposes that this immersion into authoritative structures is hindered by "the practices of social control used against discreditable and discredited individuals are enlarged into practices that silence, disregard or discredit dissenting voices in the public arena” (p. 162).

\section{B. Resistance.}

Although this study is centered on the power of resistance to oppression, making it the central point of focus, I do not wish to imply that the power of resistance carries the same force as the structural, oppressive power that gives rise to resistance. In conceptualizing power, it is important to address the mechanisms through which dominant groups hold the capacity to define the very structures and ideas through which resistance takes place. The processes of internalized oppression marks the way that the oppressed can resist.

The power of resistance is necessarily conditioned by the structures of oppression, making resistance a reaction to existing systems of domination. Foucault (1978) 
emphasizes that "where there is power, there is resistance, and yet, or rather consequently, this resistance is never in a position of exteriority in relation to power" (p. 95). Because resistance is responding to an existing structure, its scope is constrained by the shape of the dominant structure.

Steven Lukes (2005) conceives of power as consisting of three facets: visible, hidden and invisible. In his conception, visible power consists of formal structures that center on decision-making, such as government, legislature or committees. Hidden power addresses the issue of who is not being heard by calling attention to the power involved in keeping topics out of discussion or off the agenda in decision-making bodies. Invisible power is focused on the internal acceptance of the status quo by those with relatively little power, making them in cases unaware of their own interests. I address this invisible power in order to contextualize the power of resistance that guides this dissertation.

The process that Lukes (2005) describes as invisible power has been addressed by a number of theorists. The way that relatively powerless groups adopt the dominant ideologies and comply unconsciously with dominant interests is connected to Marx's focus on false consciousness and Freire's (2000) discussion of the internalization of oppression. Or as Adrienne Rich (2011) so eloquently describes it, "When those who have the power to name and to socially construct reality choose not to see you ... describe the world and you are not in it, there is a moment of psychic disequilibrium, as if you looked in the mirror and saw nothing” (p. 218).

Link and Phelan address the need for structural power in creating stigma by focusing on the institutions that control public discourse, such as media, religion and education. They pose that stigma cannot be flipped, that people who do not control these 
powerful mechanisms for communication cannot convey their interests and enforce the social costs of stigma in the way that those who control visible power can.

I emphasize this inequality between the power of resistance and structural power in order to bring a more dynamic model to the study of stigma and to situate the phenomenon in a more complex framework. By definition, resistance does not control the mechanisms that administer invisible power. As a result, resistance is necessarily shaped by the tools of the oppressor, much as in the way Fanon (1967) describes how being colonized constructs one’s subjectivity.

The act of rendering oppression visible can serve as an initial step in overthrowing it. The participants discuss the ways they take up their own voices first to denounce the mistreatment and exclusion they have faced, then to raise consciousness as part of a group and a social movement. The responses explore the processes some of the participants faced when joining a larger movement and finding means of resisting through alliances with others. In describing this process the participants present conceptions of power that go beyond Link and Phelan’s top-down approach. They celebrate the personal power and transformation that comes from consciousness-raising and taking an active role in one’s own treatment.

The participants discuss the process of taking up power, and the grassroots strategies that guide their movement. A lot of their focus is placed on demanding participation in decision-making, whether it be in policy boards, or in treatment facilities. The responses indicate that in addition to critiquing the existing laws and standards, the participants are taking an active role in creating new definitions. There is also an intent to connect to other social change movements, multiple participants draw inspiration and 
make comparisons with the civil rights movement, while a couple of them discuss issues of intersecting identities. These references stem from a tradition within the movement, the consumer survivor movement has drawn support and inspiration from the civil rights movements of the era, mainly the women’s movement, the gay rights movement and the black civil rights movement (J. Campbell, 2005).

The participants propose that valuing all perspectives, even ones that have been granted very little legitimacy in the dominant society, serves as one of the foundational aspects of their work within the consumer survivor movement. This includes being vigilant to avoid silencing other perspectives, taking conscious action to bring other voices in. In this way, they are attempting to reject the mechanisms that have been used to control them, such as silencing and coercion. Morrison (2005) discusses the complex situations these goals can create, "Recognition of difference and respect for dissent is at the core of the movement. Quite possibly it has also kept the movement from achieving some of its goals, which can become contradictory and prevent a cohesive approach” (p. 159).

One of the difficult dynamics associated with challenging dominant structures of power is that marginalized groups may replicate the structures they seek to change. Some participants address the internal conflicts within the movement, discussing the ways they have been silenced or rejected. The responses indicate that there are continual struggles within the movement in regards to terminology, definitions and conceptions of mental health. This aligns with Swarbrick’s (2009) assessment of dual factions within the consumer-survivor movement, radical psychiatric survivors (sometimes called expatients, and ex-inmates), and moderate mental health consumers. The groups face 
controversy particularly around issues that align with a traditional medical model, such as psychopharmaceuticals and forced treatment. The ambivalence felt by some regarding a medical paradigm is resisted by others, and in some cases silenced.

The role of power in stigma creation and resistance is complex and dynamic. It is neither top-down, nor bottom up, but multifaceted. While political and structural power might be easier to recognize as power, the power of resistance is profound. The fact that the participants draw inspiration from previous social movements that have made significant gains demonstrates the value they place on grassroots resistance and what it can achieve. The challenges inherent in being inclusive despite significant internal differences demonstrate that they are attempting to wield a different kind of power. The shortcomings they present in enacting acceptance also illustrate the complex roles that power can take, and the challenges involved in creating social change. All of these strategies and lessons help to inform the Link and Phelan model of stigma, in particular, their conception of power.

\section{Summary of contribution.}

The findings of this study can serve to inform the field of psychiatric stigma by exploring the working model of activists in this field — a neglected area of inquiry — as a framework for the re-conceptualization of stigma. This dissertation applies the Link and Phelan model in a specific context, psychiatric stigma, and informs the model by exploring the fit in this particular field. The themes that emerged from the data can help expand the Link and Phelan model by illustrating what stigmatization looks like in the field of psychiatric stigma. By having a better understanding of the patterns of 
stigmatization for this population, activists, academics, practitioners, and policymakers can make better decisions about how to interrupt the process. In this project I sought to discover how anti-stigma efforts in the field correspond to what the authors propose theoretically, and to establish the relevance of the model for discussing change and implementation. I also explored how the different elements of the model are taken up by participants, as well as which emergent themes were not addressed in the model.

Of particular interest are themes that were unexpected-emergent motifs that go beyond the direct application of the Link and Phelan model. One unanticipated finding centered on the positive value attached to diagnosis by some of the participants, which acts as a source of validation as well as a connection to a community of sufferers. While this minority position was only held by two of the participants, it represents one perspective within the diversity of positions among anti-stigma activists. Recognizing the relief and validation that may be associated with a psychiatric diagnosis may be an important strategy in welcoming some consumer/survivors into anti-stigma work.

Also unexpected was the participant's rejection of the term "stigma”, which presents an interesting challenge to the model. Some of the participants rejected the term stigma because of its focus on the targeted groups instead of the perpetrators, while others critiqued the term because of its individualistic focus. In this way, the participants' critiques match with the critiques that Link and Phelan present. In this case, even though the content of what was being discussed converged, the terminology generated significant resistance and would need to be addressed in order in working with a stigma model.

In addition to a rejection of the term stigma, and the positive associations with diagnosis, the recurring focus on a common core of humanity that overrides differences 
was unanticipated. The participants emphasize the potential of all people for experiencing a mental crisis that overwhelms available psychological and social resources, and for consequently receiving a psychiatric label. This theme underscores the importance of reducing social distance as well as a departure from medical conceptions of psychopathology. The discussion of a hierarchy of suffering speaks to some of the internal struggles within the movement, and the difficulty in defining identity for a group that has been consistently marginalized. The weight that issues of credibility carry for this population registers their sense of being repeatedly silenced. Sensitivity to the issue of credibility can serve as a guideline for designing future interventions, and focusing on strategies for social change. For example, lending credibility and value to the lived experience of people with psychiatric diagnoses might be incorporated into an antistigma campaign by making a consumer/survivor perspective central to messaging, instead of relying on expert medical opinions.

This dissertation expands the Link and Phelan model by bringing greater complexity to the conception of power in the dynamics of stigma. I have discussed some of the ways that marginalized people take up their own power to resist their stigmatization. Of particular importance here are the limitations of conceptualizing power as unidirectional and top-down.

Knowing more about the work carried out by those most affected by a social problem provides vital insights that might not be available to outsiders to this group or to this social movement. The participants I have worked with combine the experience of living with stigma while at the same time trying to resist and change this form of oppression. Exploring the work of the OCSC represents a unique source of on-the-ground 
expertise that is valuable for re-considering scientifically grounded theoretical models. In attempting to understand a phenomenon, research is best informed by those actively engaged in changing the phenomenon.

The picture of anti-stigma campaigns that this dissertation attempts to present is potentially useful for an array of actors. The coalition and its members benefit from having a rich description of their own and their peers’ perspectives. The information might allow them to reflect on their discursive practices and serve as a tool for communicating with others about their priorities. Coalition members might utilize some of the central themes to converse with other members to map points of convergence and areas of tension, allowing them to come closer to the unified front they hope to achieve while preserving areas of difference. For example, one theme that emerged concerned internal conflicts over which members experiences are more valuable in critiquing the medical model. Coalition members might use this theme as the starting point for a discussion of commonality and difference.

Academics may wish to explore the applicability of the Link and Phelan model to other stigma contexts. This research project has explored the range of strategies of resistance in the context of psychiatric stigma. Considering the active resistance of various stigmatized groups can lead to more dynamic models and richer forms of theorizing. For example, participants' emphasis on processes of legitimacy and credibility should indicate to researchers the importance of involving people with psychiatric diagnoses directly in research and intervention designs.

Within community psychology, this dissertation presents a useful perspective because of its close investigation of the Link and Phelan model. This stigma model has a 
particular affinity with community psychology because they both emphasize that human experience--both at the individual and small group level--must be framed within a broader societal context. While Brett Kloos (2005) explored the overlap of values that community psychology shares with consumer survivor initiatives, I propose that the principles of community psychology also overlap with the Link and Phelan model, making it a particularly rich model for analyzing stigma. The model is compatible with the principle of ecology within community psychology because of its focus on the structural factors that foster stigma. Kloos also emphasizes the role of community psychology in the critical analysis of oppression and power differentials, a point that is reflected in the Link and Phelan model of stigma. This dissertation's analysis of power imbalances and resistance to the mechanisms of stigmatization expands community psychology’s understanding of stigma.

The findings of this study will also be valuable to policy makers and intervention designers. Anti-stigma efforts can apply some of the conclusions of this study by focusing on the discourse of diversity and the similarity of shared human experience that the participants bring forward. For example, an anti-stigma campaign might draw on my findings in the area of stereotyping in crafting a message that focused on the strengths of people with a psychiatric diagnosis and their contributions to society, rather than a discourse centered on mental illness and deficits. The focus on positive values associated with a mental condition may serve as an antidote to pathologizing approaches that evoke pity or paternalism in these participants.

Clinical service providers might apply some of the lessons of this study by being more aware of their capacity to reproduce patterns of oppression with their clients. In 
particular, the emphasis that participants place on having their knowledge valued and their experiences validated can serve as a point of reflection for service providers. The participants discuss the strain that invalidation puts on them, having their experiences repeatedly dismissed or denied. In validating clients' perspectives, it is not necessary that providers confirm the factual veracity of a client's account but they can focus on the emotional content of it. Haaken (1998) speaks about the way that individuals use symbols and images that often are metaphors for experiences that are hard to put into words. In this way madness can be understood as a communicative system, a language that conveys meaning. The participants' emphasis on the importance of validation makes it clear that they are repeatedly encountering dismissal in interactions with treatment providers. Clinicians can respond to this theme in the responses by listening actively for value and meaning in all their interactions with consumer survivors.

In order to address the structural obstacles that Link and Phelan emphasize, it is important to intervene at the legislative and institutional levels as well. As Link and Phelan caution, stigma is supported by multiple mechanisms, and interventions that only address one or two elements are bound to fail, as other mechanisms step in to maintain the status quo. By pointing out the role that power inequities play in the creation of stigma, Link and Phelan help us understand the vested interest in maintaining discrimination. At the same time, they provide a series of sites for generating change. Incremental changes can add up to lasting change for people diagnosed with mental disorders. A more contextualized and structural perspective on stigma might facilitate the kind of change that goes beyond the eradication of psychiatric stigma to social change based on recognition and valuing of differences. Ideally, this study makes a 
small contribution toward pushing for social justice and human rights for those marginalized by the dominant conceptions of normalcy and sanity. 


\section{References}

Aderibigbe, Y. A. (1997). Deinstitutionalization and criminalization: tinkering in the interstices. Forensic Science International, 85(2), 127-134.

Alvarado, J. (2007). Easy for You to say! Evaluating HIV prevention considering latinas and access to power. Unpublished Master's thesis in Women's Studies. San Diego State University.

Angermeyer, M. C., \& Matschinger, H. (2003). Public beliefs about schizophrenia and depression: Similarities and differences. Social Psychiatry and Psychiatric Epidemiology, 38(9), 526-534.

Angermeyer, M. C., \& Matschinger, H. (2005). Causal beliefs and attitudes to people with schizophrenia. Trend analysis based on data from two population surveys in Germany. The British Journal of Psychiatry, 186, 331-334.

Angermeyer, M. C., \& Matschinger, H. (2005). Labeling--stereotype--discrimination: An investigation of the stigma process. Social Psychiatry and Psychiatric Epidemiology, 40(5), 391-395.

Baumann, A. E. (2007). Stigmatization, social distance and exclusion because of mental illness: The individual with mental illness as a 'stranger'. International Review of Psychiatry, 19(2), 131-135.

Boyle, J. S., Hodnicki, D. R., \& Ferrell, J. A. (1999). Patterns of Resistance: African American Mothers and Adult Children With HIV Illness. Scholarly Inquiry for Nursing Practice, 13(2), 111-134. 
Braun, V., \& Clarke, V. (2006). Using thematic analysis in psychology. Qualitative Research in Psychology, 3(2), 77-101.

Brohan, E., Slade, M., Clement, S., \& Thornicroft, G. Experiences of mental illness stigma, prejudice and discrimination: a review of measures. BMC Health Services Research, 10.

Burr, V. (1995). An introduction to social constructionism: Routledge.

Buseh, A., \& Stevens, P. (2006). Constrained But Not Determined by Stigma: Resistance by African American Women Living with HIV. Women \& Health, 44(3), 1-18.

Campbell, C., \& Deacon, H. (2006). Unravelling the contexts of stigma: from internalisation to resistance to change. Journal of Community \& Applied Social Psychology, 16(6), 411-417.

Campbell, J. (2005). The historical and philosophical development of peer-run support programs. In S. Clay (Ed.), On our own, together: Peer programs for people with mental illness. Nashville: Vanderbilt University Press.

Carlson, L. S., Rapp, C. A., \& McDiarmid, D. (2001). Hiring consumer-providers: Barriers and alternative solutions. Community Mental Health Journal, 37(3), 199213.

Chamberlin, J. (1990). The Ex-Patients' movement: Where we've been and where we're going. The Journal of Mind and Behavior, 11(3), 323-336.

Chamberlin, J. (1995). Rehabilitating ourselves: The psychiatric survivor movement. International Journal of Mental Health, 24(1), 39-46. 
Chamberlin, J., \& Rogers, J. A. (1990). Planning a Community-Based Mental Health System: Perspective of Service Recipients. American Psychologist, 45(11), $1241-1244$

Christians, C. G. (2000). Ethics and politics in qualitative research. In N. K. Denzin \& Y. S. Lincoln (Eds.), Handbook of qualitative research. Thousand Oaks, Calif.: Sage Publications.

Coalition, O. M. H. C. a. P. S. (2008). Bylaws of the Oregon Mental Health Consumer and Psychiatric Survivor Coalition. from http://www.mindfreedom.org/as/actarchives/us/or/ocsC

Conrad, P., \& Schneider, J. W. (1980). Deviance and medicalization : From badness to sickness. St. Louis: Mosby.

Corrigan, P. (2000). Mental Health Stigma as Social Attribution: Implications for Research Methods and Attitude Change. Clinical Psychology: Science and Practice, 7(1), 48-67.

Corrigan, P., Markowitz, F. E., Watson, A., Rowan, D., \& Kubiak, M. A. (2003). An attribution model of public discrimination towards persons with mental illness. Journal of Health and Social Behavior, 44(2), 162-179.

Corrigan, P. W. (2007). How clinical diagnosis might exacerbate the stigma of mental illness. Social Work, 52(1), 31-39.

Corrigan, P. W., \& O'Shaughnessy, J. R. (2007). Changing mental illness stigma as it exists in the real world. Australian Psychologist, 42(2), 90-97.

Corrigan, P. W., \& Penn, D. (1997). Disease and discrimination: Two paradigms that describe severe mental illness. Journal of Mental Health, 6(4), 355 - 366. 
Corrigan, P. W., \& Penn, D. L. (1999). Lessons from social psychology on discrediting psychiatric stigma. The American psychologist, 54(9), 765-776.

Corrigan, P. W., River, L. P., Lundin, R. K., Penn, D. L., Uphoff-Wasowski, K., Campion, J., et al. (2001). Three strategies for changing attributions about severe mental illness. Schizophrenia Bulletin, 27(2), 187-195.

Corrigan, P. W., Watson, A. C., Byrne, P., \& Davis, K. E. (2005). Mental illness stigma: Problem of public health or social justice? Social Work, 50(4), 363-368.

Crisp, A. H., Gelder, M. G., Rix, S., Meltzer, H. I., \& Rowlands, O. J. (2000). Stigmatisation of people with mental illnesses. The British Journal of Psychiatry, 177(1), 4-7.

Crocker, J., Major, B., \& Steele, C. (1998). Social stigma. In D. T. Gilbert \& S. T. Fiske (Eds.), The Handbook of Social Psychology (Vol. 2, pp. 504-553). Boston, MA: McGraw-Hill.

Cutcliffe, J. R., \& Hannigan, B. (2001). Mass media, monsters and mental health clients: the need for increased lobbying. Journal of Psychiatric \& Mental Health Nursing, 8(4), 315-321.

Deacon, B. J., \& Baird, G. L. (2009). The chemical imbalance explanation of depression: Reducing blame at what cost? Journal of Social and Clinical Psychology, 28(4), 415-435.

Dietrich, S., Heider, D., Matschinger, H., \& Angermeyer, M. C. (2006). Influence of newspaper reporting on adolescents' attitudes toward people with mental illness. Soc Psychiatry Psychiatr Epidemiol, 41, 318 - 322. 
Dietrich, S., Matschinger, H., \& Angermeyer, M. C. (2006). The Relationship between Biogenetic Causal Explanations and Social Distance toward People with Mental Disorders: Results from a Population Survey in Germany. International Journal of Social Psychiatry, 52(2), 166-174.

Dixon, J., Gordon, C., \& Khomusi, T. (1995). Sexual symmetry in psychiatric diagnosis. Social Problems, 42(3), 429-448.

Estroff, S. E., Lachicotte, W. S., Illingworth, L. C., \& Johnston, A. (1991). Everybody's Got a Little Mental Illness: Accounts of Illness and Self among People with Severe, Persistent Mental Illnesses. Medical Anthropology Quarterly, 5(4), 331369.

Fakhoury, W., \& Priebe, S. (2007). Deinstitutionalization and reinstitutionalization: major changes in the provision of mental healthcare. 6(8), 313-316.

Fanon, F. (1967). Black skin, white masks. New York: Grove Press.

Fernando, S. (2006). Stigma, racism and power. Aotearoa Ethnic Network Journal, 1(1), 24-28.

Fine, M., \& Vanderslice, V. (1992). Qualitative activist research: Reflections on methods and politics. In F. Bryant \& J. Edwards (Eds.), Methodological issues in applied social psychology: Social psychological applications to social issues (pp. 199218). New York Plenum Press.

Fisher, D. B. (1994). A new vision of healing as constructed by people with psychiatric disabilities working as mental health providers. Psychosocial Rehabilitation Journal, 17(3), 67-81.

Foucault, M. (1978). The history of sexuality. New York: Pantheon Books. 
Foucault, M. (1988). Madness and Civilization. New York: Vintage Books.

Freire, P. (2000). Pedagogy of the oppressed. New York: Continuum.

Frese, F. J., \& Davis, W. W. (1997). The consumer-survivor movement, recovery, and consumer professionals. Professional Psychology, Research and Practice., 28(3), 243-245.

Gaebel, W., Zaske, H., \& Baumann, A. E. (2006). The relationship between mental illness severity and stigma. Acta Psychiatrica Scandinavica, 113, 41-45.

Galatzer-Levy, I. R., \& Galatzer-Levy, R. M. (2007). The revolution in psychiatric diagnosis: Problems at the foundations. Perspectives in Biology and Medicine, 50(2), 161-180.

Goffman, E. (1963). Stigma: Notes on the Management of Spoiled Identity. . Englewood Cliffs, NJ: Prentice Hall.

Golding, S. L., Becker, E., Sherman, S., \& Rappaport, J. (1975). The Behavioral Expectations Scale: Assessment of expectations for interaction with the mentally ill. Journal of Consulting \& Clinical Psychology, 43(1), 109.

Goudge, J., Manderson, L., Ngoma, B., \& Schneider, H. (2009). Stigma, identity and resistance among people living with HIV in South Africa. Journal of Social Aspects of HIV/AIDS, 6(3), 94-104.

Graneheim, U. H., \& Lundman, B. (2004). Qualitative content analysis in nursing research: concepts, procedures and measures to achieve trustworthiness. Nurse education today, 24(2), 105-112.

Greenwald, A. G., \& Banaji, M. R. (1995). Implicit social cognition: Attitudes, selfesteem, and stereotypes. Psychological Review, 102(1), 4-27. 
Haaken, J. (1998). Pillar of salt: Gender, memory, and the perils of looking back.

New Brunswick, N.J: Rutgers University Press.

Haaken, J. (2008). PSY 510 Gender and Madness, Lecture notes.

Harp, H. (1994). Empowerment of mental health consumers in vocational rehabilitation. Psychosocial Rehabilitation Journal, 17(3), 83.

Haslam, N. (2000). Psychiatric categories as natural kinds: Essentialist thinking about mental disorder. Social Research, 67, 1031-1058.

Haslam, N., \& Ernst, D. (2002). Essentialist beliefs about mental disorders. Journal of Social and Clinical Psychology, 21(6), 628.

Haslam, N., Rothschild, L., \& Ernst, D. (2002). Are essentialist beliefs associated with prejudice? The British Journal of Social Psychology, 41(Pt), 87-100.

Hinshaw, S. P. (2007). The mark of shame: Stigma of mental illness and an agenda for change. New York: Oxford University Press.

Hinshaw, S. P., \& Cicchetti, D. (2000). Stigma and mental disorder: conceptions of illness, public attitudes, personal disclosure, and social policy. Development and Psychopathology, 12, 555 - 598.

Hinshaw, S. P., \& Stier, A. (2008). Stigma as related to mental disorders. Annual Review of Clinical Psychology, 4, 367-393.

Howarth, C. (2006). Race as stigma: Positioning the stigmatized as agents, not objects. Journal of Community \& Applied Social Psychology, 16(6), 442-451.

Hsieh, H.-F., \& Shannon, S. (2005). Three approaches to qualitative content analysis. Qualitative Health Research, 15(9), 1277-1288. 
Introductory FAQ's about MFI. (n.d.). Retrieved April 25th, 2012 from http://www.mindfreedom.org/mfi-faq/intro-FAQs

Järvinen, M. (2000). The biographical illusion: Constructing meaning in qualitative interviews. Qualitative Inquiry, 6(3), 370-391.

Jones, E. E., Farina, A., Hastorf, A. H., Markus, H., Miller, D. T., \& Scott, R. A. (1984). Social stigma: The psychology of marked relationships. New York: W.H. Freeman.

Jorm, A. F. (2000). Mental health literacy: Public knowledge and beliefs about mental disorders. The British Journal of Psychiatry, 177, 396-401.

Kirk, S. A., \& Kutchins, H. (1992). The selling of DSM : the rhetoric of science in psychiatry. New York: A. de Gruyter.

Kloos, B. (2005). Creating new possibilities for promoting liberation, well-being and recovery: Learning from experiences of psychiatric consumers/survivors. In G. B. Nelson \& I. Prilleltensky (Eds.), Community psychology: In pursuit of liberation and well-being (pp. 426-447). Houndmills, Basingstoke, Hampshire; New York: Palgrave Macmillan.

Kuzel, A. 1992. Sampling in qualitative inquiry. In Doing qualitative research, ed. B. Crabtree and W. Miller, 31-44. Newbury Park, CA: Sage.

Lam, D. C., \& Salkovskis, P. M. (2007). An experimental investigation of the impact of biological and psychological causal explanations on anxious and depressed patients' perception of a person with panic disorder. Behaviour Research and Therapy, 45(2), 405-411. 
Lewin, K. (1946). Action research and minority problems. Journal of Social Issues, 2, 34-46.

Lincoln, T. M., Arens, E., Berger, C., \& Rief, W. (2008). Can antistigma campaigns be improved? A test of the impact of biogenetic vs psychosocial causal explanations on implicit and explicit attitudes to schizophrenia. Schizophrenia Bulletin, 34(5), 984-994.

Lincoln, Y. S., \& Guba, E. G. (1985). Naturalistic inquiry. Beverly Hills, Calif.: Sage Publications.

Link, B. G., \& Phelan, J. C. (2006). Stigma and its public health implications. Lancet, $367,528-529$.

Link, B. G., Struening, E. L., Neese-Todd, S., Asmussen, S., \& Phelan, J. C. (2002). On describing and seeking to change the experience of stigma. Psychiatric Rehabilitation Skills, 6, 201 - 231.

Lukes, S. (2005). Power: A radical view. New York: Palgrave Macmillan.

Loring, M., \& Powell, B. (1988). Gender, Race, and DSM-III: A Study of the Objectivity of Psychiatric Diagnostic Behavior. Journal of health and social behavior, 29(1), $1-22$.

Major, B., \& O'Brien, L. T. (2005). The social psychology of stigma. Annual Review of Psychology, 56, 393-421.

Mann, C., \& Himelein, M. (2008). Putting the person back into psychopathology: an intervention to reduce mental illness stigma in the classroom. Social Psychiatry and Psychiatric Epidemiology, 43(7), 545-551. 
Marshall, C., \& Rossman, G. B. (1999). Designing qualitative research. Thousand Oaks, CA: Sage Publications.

Martin, J. K., Pescosolido, B. A., \& Tuch, S. A. (2000). Of fear and loathing: The role of 'disturbing behavior,' labels, and causal attributions in shaping public attitudes toward people with mental illness. Journal of Health and Social Behavior, 41(2), 208-223.

McHugh, P. R. (2005). Striving for coherence: Psychiatry's efforts over classification. Journal American Medical Association, 293(20), 2526-2527.

Mehta, S., \& Farina, A. (1997). Is being "sick" really better? Effect of the disease view of mental disorder on stigma. Journal of Social \& Clinical Psychology, 16(4), 405419.

Meissen, G. J. (1993). The Self-Help Clearinghouse: A New Development in Action Research for Community Psychology. The Journal of Applied Behavioral Science, 29(4), 446-463.

Morrison, L. J. (2005). Talking back to psychiatry: The psychiatric consumer/survivor/ex-patient movement. New York: Routledge.

Morrison, T., \& Whitehead, B. (2005). Strategies of stigma resistance among Canadian gay-identified sex workers. Journal of Psychology \& Human Sexuality, 17(1/2), 169-179.

Mowbray, C. T., Moxley, D. P., \& Collins, M. E. (1998). Consumers as mental health providers: first-person accounts of benefits and limitations. The Journal of Behavioral Health Services \& Research, 25(4), 397-411. 
Nelson, G., Ochocka, J., Janzen, R., \& Trainor, J. (2006). A longitudinal study of mental health consumer/survivor initiatives: Part 1 - Literature review and overview of the study. Journal of community psychology, 34(3), 247-260.

Nelson, G., Ochocka, J., Janzen, R., Trainor, J., Goering, P., \& Lomotey, J. (2007). A longitudinal study of mental health consumer/survivor initiatives: Part VOutcomes at 3-year follow-up. Journal of community psychology, 35(5), 655-665.

News and information about OCSC. (n.d.). Retrieved June 24th, 2011 from http://www.mindfreedom.org/as/act-archives/us/or/ocsc

Oaks, D. (2009). OCSC: Building a State-Wide Coalition! Synergist Consumer/Survivor 4.

Ochocka, J., Nelson, G., Janzen, R., \& Trainor, J. (2006). A Longitudinal Study of Mental Health Consumer/Survivor Initiatives: Part 3--A Qualitative Study of Impacts of Participation on New Members. Journal of community psychology, 34(3), 273-283.

Parker, R., \& Aggleton, P. (2003). HIV and AIDS-related stigma and discrimination: a conceptual framework and implications for action. Social science \& medicine, 57(1), 13-24.

Patton, M. Q. (1990). Qualitative evaluation and research methods (2nd ed.). . Newbury Park: Sage.

Pepper, T. (2005). Talking to the demons: Schizophrenia is no longer seen as a genetically predetermined disease. Newsweek, 146, 58. 
Phelan, J. C., \& Link, B. G. (1998). The growing belief that people with mental illnesses are violent: the role of the dangerousness criterion for civil commitment. Social Psychiatry \& Psychiatric Epidemiology, 33, S7.

Phelan, J. C., Link, B. G., Stueve, A., \& Pescosolido, B. A. (2000). Public conceptions of mental illness in 1950 and 1996: What is mental illness and is it to be feared? Journal of health and social behavior, 41(2), 188-207.

Phelan, J. C., Yang, L. H., \& Cruz-Rojas, R. (2006). Effects of attributing serious mental illnesses to genetic causes on orientations to treatment. Psychiatric Services, 57(3), 382-387.

Poindexter, C. C., \& Shippy, R. A. (2010). HIV diagnosis disclosure: Stigma management and stigma resistance. Journal of Gerontological Social Work, 53(4), 366-381.

Porter, R. (2002). Madness: A brief history. New York: Oxford University Press.

Prilleltensky, I. (2008). The role of power in wellness, oppression, and liberation: The promise of psychopolitical validity. Journal of Community Psychology, 36(2), 116-136.

Read, J., \& Harre, N. (2001). The role of biological and genetic causal beliefs in the stigmatisation of "mental patients'. Journal of Mental Health, 10(2), 223-235.

Read, J., Haslam, N., Sayce, L., \& Davies, E. (2006). Prejudice and schizophrenia: A review of the 'mental illness is an illness like any other' approach. Acta Psychiatrica Scandinavica, 114(5), 303-318.

Read, J., \& Masson, J. (2004). Genetics eugenics and mass murder. In J. Read, L. R. Mosher \& R. P. Bentall (Eds.), Models of madness: Psychological, social and 
biological approaches to schizophrenia (pp. 35-42). East Sussex: BrunnerRoutledge.

Read, J., Mosher, L. R., \& Bentall, R. P. (Eds.). (2004). Models of madness:

Psychological, social and biological approaches to schizophrenia. East Sussex: Brunner-Routledge.

Rich, A. (2011). Invisibility in academe. In The Broadview anthology of expository prose, ed. L. Buzzard. 210-220. Peterborough, ON: Broadview Press.

Riessman, C. K. (2000). Stigma and everyday resistance practices: Childless women in south India. Gender \& Society, 14(1), 111-135.

Ritchie, J., \& Lewis, J. (2003). Qualitative practice: A guide for social science students and researchers London: Sage.

Rivera, J. J., Sullivan, A. M., \& Valenti, S. S. (2007). Adding consumer-providers to intensive case management: Does it improve outcome? Psychiatric Services: A Journal of the American Psychiatric Association., 58(6), 802-809.

Rose, D., Thornicroft, G., Pinfold, V., \& Kassam, A. (2007). 250 labels used to stigmatise people with mental illness. BMC Health Services Research, 7(1), 97.

Rosenhan, D. L. (1973). On being sane in insane places. Science (New York, N.Y.), 179(70), 250-258.

Sarbin, T. R., \& Mancuso, J. C. (1970). Failure of a moral enterprise: Attitudes of the public toward mental illness. Journal of Consulting and Clinical Psychology, 35(2), 159-173.

Sartorius, N. (1998). Stigma: what can psychiatrists do about it? Lancet, 352(9133), 1058-1059. 
Sartorius, N., \& Schulze, H. (2005). Reducing the stigma of mental illness:

Cambridge, Cambridge University Press.

Sayce, L. (1998). Stigma, discrimination and social exclusion: What's in a word? Journal of Mental Health, 7(4), 331.

Sayce, L. (2003a). Beyond Good Intentions. Making Anti-discrimination Strategies Work. Disability \& Society, 18(5), 625 - 642.

Sayce, L. (2003b). Beyond Good Intentions. Making Anti-discrimination Strategies Work. Disability \& Society, 18(5), 625-642.

Schulze, B., \& Angermeyer, M. C. (2003). Subjective experiences of stigma. A focus group study of schizophrenic patients, their relatives and mental health professionals. Social science \& medicine, 56(2), 299-312.

Schulze, B., RichterWerling, M., Matschinger, H., \& Angermeyer, M. C. (2003). Crazy? So what! Effects of a school project on students' attitudes towards people with schizophrenia. Acta Psychiatrica Scandinavica, 107(2), 142-150.

Segal, S. P., \& Silverman, C. (2002). Determinants of client outcomes in self-help agencies. Psychiatric Services, 53(3), 304-309.

Services, U. S. D. o. H. a. H. (1999). Mental Health: A Report of the Surgeon General. Retrieved. from.

Smith, J. A. (1995). Semi-structured interviewing and qualitative analysis. In J. A. Smith, R. Harré \& L. v. Langenhove (Eds.), Rethinking methods in psychology. London; Thousand Oaks, Calif.: Sage Publications.

Sutker, P. B., \& Adams, H. E. (1993). Comprehensive handbook of psychopathology. New York: Plenum Press. 
Swarbrick, M. (2009). Historical perspective-from institution to community. Occup. Ther. Ment. Health Occupational Therapy in Mental Health, 25(3-4), 201-223.

Swim, J. K., \& Stangor, C. (1998). Prejudice: the target's perspective. San Diego: Academic Press.

Szasz, T. (1991). Noncoercive Psychiatry: An Oxymoron: Reflections on Law, Liberty, and Psychiatry. Journal of Humanistic Psychology, 31(2), 117-125.

Szasz, T. S. (1970). The manufacture of madness; a comparative study of the Inquisition and the mental health movement. New York: Harper \& Row.

Walker, I., \& Read, J. (2002). The differential effectiveness of psychosocial and biogenetic causal explanations in reducing negative attitudes toward "mental illness". Psychiatry: Interpersonal and Biological Processes, 65(4), 313-325.

Watson, A. C., Otey, E., Westbrook, A. L., Gardner, A. L., Lamb, T. A., Corrigan, P. W., et al. (2004). Changing Middle Schoolers' Attitudes About Mental Illness Through Education. Schizophrenia Bulletin, 30(3), 563-572.

Wituk, S. A., Shepherd, M. D., Warren, M., \& Meissen, G. (2002). Factors Contributing to the Survival of Self-Help Groups. American Journal of Community Psychology, 30(3), 349-366.

Zajicek, A. M., \& Koski, P. R. (2003). Strategies of resistance to stigmatization among white middle-class singles. Sociological Spectrum, 23(3), 377-403. 


\section{Appendix A: Initial contact email}

\section{Dear NAME OF PARTICIPANT,}

I am a doctoral student at Portland State University in the department Psychology.

I am currently working on my dissertation research project, "Let's try to change it: Psychiatric stigmatization, consumer/survivor activism, and the Link and Phelan model” which is a qualitative study that explores psychiatric stigma. Your name was given to me by (or I have identified your name by ). I think your perspective would be helpful in understanding people's needs and concerns regarding psychiatric stigma. I would like to invite you to participate in the study.

This study will consist of personal interviews with psychiatric consumer/survivors. I would like to invite you to participate in this study by providing your time for an interview of around 60-90 minutes.

Enclosed is a copy of the consent form that outlines the study and the measures that will be taken to provide confidentiality if you choose to participate in the study. I would like to call to answer any questions and to see if you are interested in participating in an interview. If you are interested in participating, we can set up a time to meet, at which point I'd discuss the consent form in person to answer any questions you might have. If you are not interested in participating and would prefer I did not call, please feel free to email me and let me know this. My email address is: jimena@pdx.edu and my phone number is 971-255-1168. Also, feel free to call or email if you are interested or have any questions prior to receiving my follow-up phone call.

Thank you for your consideration, 
Jimena Alvarado

Principal Investigator

Portland State University

Department of Psychology

Cramer Hall 317

Portland, OR 97201 


\section{Appendix B: Initial coding guide}

These are some of the themes and topics that I expect to see in the responses, based on my experience with the coalition, and the Link and Phelan model.

\section{Distinguishing and labeling differences}

- Resisting the labeling process/diagnosis within the medical model

- Calling attention to the process of differentiation, visibilizing it

- Calling for agency within the labeling process

- Rejecting differentiation, focusing on similarity

\section{Associating difference with negative} attributes

- Not accepting negativity, flipping it into positive identification. Calling for mad pride

- Celebrating difference, romantic, radical background
- Challenging myths, rejecting stereotypes

- Rejecting negative representations

- Focusing on positive interpretations of difference, for example, divine association

- Rejecting dependent, passive role assigned by medical model

\section{Separation - social distance -}

\section{exclusion}

- Pushing for inclusion and agency

- Calling attention to sites of exclusion

- Calling attention to dehumanizing practices 
- Demanding change of language separating condition from personhood.

\section{Status loss and discrimination}

- $\quad$ Resisting devalued status reclaiming own value and expertise

- Calling attention to patterns of discrimination: housing, workplace, etc

- Focusing on structural discrimination: pushing for policy changes

- Calling attention to unequal outcomes: life expectancy, rates of arrest, etc

\section{5.*Power}

- Naming power hierarchy (within medical system, diagnosis and care processes)

- Demanding participation in decision making: policy boards, treatment facilities
- Demanding active voice in creating rules, policies, laws

- Reclaiming communication structures, rejecting stereotyped representations, demanding more positive, complex representations

- Voicing evidence of exclusion from resources

- Demanding more access to resources

- Being critical of existing rules and standards

- Demanding a role in creating rules and standards

- Using communication structure to publicize alternative rules and standards

- Rejecting the mechanisms that have been used to enforce current rules: coercion, forced treatment, etc 
- Rejecting system of penalization that has been used to enforce current rules

- Calling attention to exclusion from economic power

- Demanding better economic circumstances: employment, support, funding

- Demanding more access to social institutions: housing, education, health care. Creates immediate material consequences.

- Reclaiming control over life opportunities

- Reclaiming legitimacy: rewriting history, calling for pride and celebration, claiming expertise 


\section{Appendix C: Entire interview transcript}

\section{M.J. Interview.}

The interviewer's words are indicated in italics.

I went to MHAO for a project OPEN, the Oregon peer employment network, so I did the training for that, and was working at empowerment initiatives. Are you familiar with the program?

A little bit yeah, from what I heard from $X X X$, it is based on brokerage, so people figure out how to plan their recovery program and how they want to use their benefits in hiring people.

So EI, each calendar year, per customer, there's 25 customers depending on the grant size of 3000 per customer, the funds go toward, we started doing WRAP plans, Wellness Recovery Action Plan, or the GAP plan, we have lots of acronyms. Person directed planning, which is much like the core of what we do there, major areas of consumers' lives and identifying what their main goals are, whether it's the biggest dream you ever had, or something really simple, and everything that that plan, sort of map out what can we help you attain, either money, or a budget plan. Working with MHAO and project OPEN was great, because I was the research worker for 25 consumers, so I had people, not every single person came to EI looking or employment, it could be volunteer work, going to school, classes leading up to employment, so I had a really nice set of people that I could say “If you're looking to maybe work a few days a week, or get off SSI, I'm working with MHAO's project OPEN to be a support" 
That's pretty cool

Yeah, I worked in alcohol and drug for quite a while, and we've got these communities and you run into a lot of sick people.

\section{Labeling}

So, what I have in terms of questions, is, it all stems from this theory that I kinda like. So there's these guys Link and Phelan who created this theory of stigma, they break it down into different elements, and there's some reasons that I like it, and some reasons that I don't. What I'd like to do is tell you some about it and see how that gels with your experience, and if that fits or not. So the first part that they talk about with stigma is, they say, there's a lot of focus on labeling, and language, and so they say for stigma to start, we have to start with a distinction or a differentiation, and the conversation I've heard around consumer survivors is there's a lot of focus on language and a lot of focus on labels. And I kinda wanted to get your take on the difference between saying "a schizophrenic" or "a person with schizophrenia" or client, or patient, or consumer, all the ways we work with language.

Well I guess overall, when it comes to language that you're trying to use in the mental health field, it really is, I feel in my experience, it's so much up to the individual and how that person identifies there's a very large spectrum of people who might be with the more traditional medical model, and do not mind being called patient, and there's some people who think it's completely stigmatizing and offensive to label them patient, so that's something that, while there's certain terms, realistically, more politically correct right now, and then, obviously that changes, and time moves on as you learn more, and people are more active, so it probably changed, the things 
that we're saying now might be really offensive in 20 years. But kind of a general language that is acceptable, like right now you're a consumer survivor, ex-patient consumer survivor movement, is pretty status quo, pretty safe to say. And as far as labels and stigma I was sociology major, so pardon me if I get on that path Well community psychology and sociology are about as close as they get My emphasis was in gender, health and media, I see them intersecting, in sociology if you have a deviant status, if you're anything outside of the WASP sector that becomes your primary status. It can be such a minute part of who you are, if you identify or are labeled as someone who is not Caucasian, Christian, that becomes your dominant status. So I think it's part of mental health, as soon as it's known, whether it's by your own disclosure or not, that you have a diagnosis, that tends to be what people, the number one thing that comes to their mind, there are people that either completely reject the idea of labels or diagnoses, which is perfectly fine, they'd say "I don’t have a diagnosis of schizophrenia”, they'd say "I have spiritual voices or experiences”. And some people like myself, I’m rather comfortable saying “I’ve had this in the past”, or "I’ve worked through this”, or "I am”. I'm always not a fan of, a therapist taught me called the IC-ing, alcoholC, or schizophrenIC, that kind of trending, a lot of people also say, I’ve heard, and I think this is language derived from their practitioners or from their providers, saying things like "I'm bipolar”, and that tends to be, I think, really common terminology, it's not as common to say "I was diagnosed with”, or “I have”, it's definitely “I am”, it's a lot more definitive. The way that I, or it was taught to me, you'd never hear somebody say "I am cancer" and so I think when it comes to working with people, care providers, your therapist or your 
doctor, your psychiatrist, that language can be, maybe not intentionally, but pretty subliminally powerful as far as identifying yourself, how you feel about your diagnosis, and it being part of your identity, and how people are able to relate, and your self image.

I think that makes a lot of sense

Ok all right

\section{Negativity}

the other element in this model they say "a label is all fine and good but you have to attach something negative to it, for it to start getting to be stigma" so there has to be some negativity, it can't be just a category that somebody is, but you have to attach something negative. So, some of the conversations that I've heard around the consumer survivor movement are kind of different, and they're interesting. Some folks say "this is an illness, just like any other illness", some folks say "this is just a part of human diversity" so I wanted to have you talk a little bit about those perspectives, and what clicks for you, or where you saw that going with stigma I think with mental health, it's a really intricate topic when it comes to, this isn't something you can go to the doctor and have a test done and have a formal diagnosis and there is a prognosis and treatment, if a person were to say "this is an actual illness that I have, this is something I deal with daily" I also believe medication is a total personal choice, there's a lot of really good literature talking about the benefits of medications, or not medicating, and there's people that believe that that's part of their wellness or their support. I really believe that it's however you identify; mental health is something that's so subjective to their experience that if they want to own just part 
of human diversity it really is up to them. For me personally, I know that genetically there is some predisposition going on in my family, so it's something kind of aware of, but it's also something that was, that I personally took notice of at a very young age, I felt like something was off with me, from a very early age, maybe like 6 or 7. For me it's been more of a mid-journey right now, I'm figuring out where, what category, well, I don’t want to categorize myself, I'm not too particular about the terminology, I'm really kind of laid back about it, and try not to get too tense about words that people might use about me. For me, I'm kind of in, I'd say that I'm midjourney right now I hope, with having had, experiences with hospitalizations, and being on medication, being a consumer, being in therapy, and so still trying to figure out where, I, how I feel like I fit in with all of this, speaking of stigma, something that I think as far as, I think is kind of, throws on a wrench in my wellness, figuring out really, for me the pressure has always been like "what's really going on, what's causing all of this" trying to really get at the root and I feel that because, I don't know, maybe it's because of the way I was groomed as a child, to behave and act and present, is another term, present. I don’t feel that I was taken seriously when I would report, or when I would say to a doctor or a therapist, “I’m feeling awful, or I'm feeling this, or I feel suicidal" it was usually the experience of "but you're a really nice girl, and you do really well in school, and this is just a rough patch, and we'll just get you on medication, and you can go to therapy like once a month, and you'll be ok" and it was really much more deep-rooted than that, and much more severe. And I was really left to my own devices trying to take care of this. --- when it comes to terminology when it comes to working with doctors, if you do decide to see a 
psychiatrist for medication, there's a whole side of this world that is not as up front as, people who are not familiar with psych drugs like Prozac, but there's not so much of the culture and community and those kind of support that aren't provided in the medical model, and I feel like if I had known about it I feel like maybe, not to say it wouldn’t have had some of my past experiences, but I feel like I would have had a better grasp of what was going on. So whereas stigma, some people would say. And I actually recently heard a really super great slash terrible story about stigma, but for the most part up until the past you know, twenty something years, I was by and large dismissed because I would always do well in school, because my mother dressed me a certain way you, know. So for me it was how could you possibly... you have all these things going for you. I was never taken seriously "You look so normal” That's really what it was, my personal reaction was, I was always terrified of getting in trouble, or being the black sheep, I always tried to be a type -A type of person, that I was really scared to ever really do things that some kids... the really common thing to do is to act out, but I never, I was too scared to do that, it was not in the realm of possibilities, it was more suffer in silence for however long. And so that really, I felt like I was never taken seriously, I was kind of dismissed, or that there was a feeling of “you're being a little dramatic”, or “you're really amplifying your experience”. So I started to really doubt myself “am I making this up? am I being too dramatic?” And so of course I started to question, which I knew in my gut, that something is definitely off here that needs to be addressed, never really had, but never being taken seriously enough. 
I didn’t think that it was enough, until it was to the point where I was not capable, I was at the point where I'd been neglecting mental health for so long, and not addressing it, that I got to the point where I lost control of myself So you had to get to an extreme before people would...

Oh completely, and that wasn't intentional, but I think also, especially stuff that's news, especially lately with the mental health and stigma is that people that have mental health diagnoses are dangerous. And it wasn't until, that I did something that they thought that made me unsafe to someone else, that I was taken seriously. And I found that really difficult to swallow

\section{It's kinda like you fit their idea}

Like "oh wait, now she's ACTUALLY unsafe?", so it didn't matter that the secret ways, or the private ways or whatever ways she's hurting herself, a myriad of self harm and all this stuff, "she's actually saying something about it now and a number had to be called, so she must have a problem" so that was kind of difficult for me, because I’m thinking “if there had been some sort of like” I don’t want to say intervention, but if there had been something significant, an intervention or a red flag that had been noticed or taken seriously, I don’t think that I would have needed to have a police car for having an episode, you know. It was just for me, it was completely... I'm sitting the back of the police car thinking “I'm being treated like an unsafe person, I'm being treated like a criminal”, for voluntarily calling and asking for help. “I must be dangerous, I must need restraint” and that was really probably my first experience with stigma, where it's like "wait a minute, I'm not being patted on the head, and being told to go to therapy and talking about your feelings and to stop 
being a perfectionist". Everyone thought that was what was wrong with me, was that I was too hard, I had too high standards for everything and that was my whole problem. And it wasn't until that happened where I had gotten to the point where I was so out of control, and I really needed help in the most severe way that I was then treated like I didn't fit in society which is for me pretty comical that that would be the case. I guess now, especially in the past, when this kind of all started for met, the really serious hospitalization, that was the first time that I'd been on the other side of the labeling and stigma, where it was taken seriously, “you're way too something something” vs "wait a second, you're actually dangerous now" when really nothing had changed mentally at all. I'd been the same person, I'd had the same experience and thoughts and feelings my entire life, I had just expressed them... So kind going from being dismissed to being overly controlled, or overly feared To having actual basic human decencies and courtesies taken away. For the past 27 years I've been just as depressed, just as suicidal as I ever have been, but all of a sudden, because I made a call and asked for help, I now wasn't even allowed to have plastic utensils. I wasn’t allowed to have any underwear; I wasn’t allowed to, how many other things. I went from an adult asking for help to incapable, dangerous person who was locked away in the ER for 5 days before they even started to talk to me like I was, like I had some sense about me. So that was very different, realizing how quickly, and unfortunately that experience... well know that we have the CASME the Crisis Assessment Treatment... now that they have that service, I feel if I ever had another crisis where I needed to call for help, that experience alone actually 
would deter me from asking for help. I would not want to return to that situation and let alone wondering if it's helpful...

The iatrogenic effects of hospitalization... I think it was my last day in the hospital, I was getting ready for discharge, and the social worker came in and asked me how I was feeling. And I told her that I was anxious and upset, and I felt awful, and she was like "why, what happened?", "well I haven’t seen sunlight in 5 days, I have not been allowed to use, I've been eating with my hands for 5 days, I've been spoken to like I'm an imbecile, and I haven't been allowed the common courtesy of wearing a bra, and I've been around other people, and that makes me incredibly self conscious and uncomfortable”. But they did allow me to have, ironically, to have my cell phone because, they don't want me to be around anything that might, they basically they want to, how I felt the whole point of it was to put you in a vacuum, where you have no stimulus, you have nothing coming at you that's going to disrupt you, or upset you or whatever, but I was allowed to have my phone, and I was receiving, really unfortunately guilt-ridden conversations from family members about "why are you doing this to yourself"

Wow.

I can't have a bra, but I could be berated by family, and so there's a lot... and so I said "I haven’t gone outside, or had a fork or had a bra, miss my dog, I'm upset" it seems pretty natural. And she said "oh OK, it makes sense". I'm a person and I miss having common decency and basic human luxuries, it was just very demoralizing. The term scared straight, I’m like "oh wait, I don’t want this to ever happen again!" so basically 
I will do whatever I can in my power to be on top of my wellness so that this never happens again, so that I do not get to a point where I go to an ER

So it serves as a warning, do not come here again

I was told, even though I said to everyone there knew, I have made the call, I have admitted, voluntarily, I was told by two people that it didn't happen and that it really didn't matter, and you know there's a reason why there are three locked doors along the hallway, between you and the outside. And that it was up to my psychiatrist there if I would be civilly committed.

\section{Separation}

So the other thing that these guys are talking about when it comes to stigma is how we separate people so they're saying separation is an important part of stigma and discrimination, and I wanted to get your take on it, from your experience and from the people you work with, how you see separation happening, or...

Especially of people coming out of hospital settings and are in group homes, and it's unfortunately how people that have mental health challenges are criminalized, I've heard some pretty offensive comments in the articles, about, really demeaning... they're living in group homes, and neighborhoods don't like that. You think about psych hospitals, and how far they are apart, they're not in the community, for the most part, aside from rather extreme cases, you're not dealing with dangerous people, and actually for the first time visited the OSH of Portland, never call it POSH to them, but the first time I had been to POSH, I have lived in NE Portland almost all my life, except when I moved to college, but I've lived in NE Portland most of my 
life, and I’ve never even seen or it's like a block or two away from the rose garden, it is so...

I live right around there too, and I'm trying to picture it, but I don't think I know where it is.

yeah, it's a huge hospital and you would never know it was there, and I find that really, there's a huge movement for exclusion, for segregation, not seen not heard, and that's why I think some place where you, moving away, toward day center, day treatment models, great program called Full Time. Full Time is a place where people go during the day, and they have activities, and they have outings, and peer support. It's been proven to be really beneficial and even sometimes more beneficial than traditional treatment. But there's, I think there's a movement to have somebody be able to identify or say, be open with their mental health challenge but still have that concept of treat people as equals, but that doesn't really happen very often. Once that comes out, once that's disclosed, I don’t think employers take it as seriously, it's almost seen as you are a special case on our hands, people think there's a lot more risk involved, and there's all these talks of health insurance and public health care and a lot of companies, I feel like there’s some discrimination in terms of hiring “are we taking on a cost? that person is gonna cost us x amount of dollars”. And I think a lot is definitely involved in that. Even in working for a consumer run agency, where every single employee identifies as a consumer, I had more than a few people, one somebody in my family, two another consumer, and a parent of one of the customers, basically say, I'm so glad you finally found a place that fits you, I'm glad you found a place where you can be successful. Like I wouldn’t be capable of holding the same 
job as a research worker at some other agency, very much in the sense of "It's really nice that there's a place for people like you. You aren't acceptable, and you can be yourself, you can take your mental health day, it's ok, you won't get in trouble for that"

Like there was a place where acceptance was acceptable.

Right. And all the other places are not. Right, very much. Especially of people like my family, there's also the idea that if you have a mental illness that you should not work at a job that creates stress. As little stress as possible and obviously we believe that whatever work you find meaningful is where you should be, and if somebody was happy doing a job where they.. if someone says "I want to be employed and I don't want to have a stressful job”, that's fine but I wouldn't think that for any human being I've been told that by a practitioner and by my parents that they worry that I do too much, they worry that I'm not able to handle stress.

So a little bit beyond over protective, And I know that when it comes from your parents, it's hard to take what they say in that sort of, like they're stigmatizing. They're just concerned “is my daughter suffering? I don't want her to go into crisis again, protect yourself” because they're parents. When it comes from somebody else... And that's pretty common. I worked with somebody before that was told "you're never going to be able to hold a job ever. You are not fit to work”. Which is so, I can’t even yeah, Yeah

That's actually really really common. And people who have mental health problems, need special jobs 
And should be kind of kept separate in their own kind of jobs, instead of regular people jobs.

Exactly.

\section{Discrimination}

So one of the things I like about this model is this next element. So we talked about labeling, we talked about negativity, we talked about separation, and these guys say that this is all attached to discrimination and institutions and status loss. And so they say, the institutions themselves start discriminating, and it doesn't have to be a person to person interaction where someone was mean to you, it could have been that nobody was mean to you, but the way the policies are written and the institutions are designed discriminate against you and your kind.

Oh, completely.

What gets covered, for example under health insurance, which ones get covered, which ones don't'. All these aspects. So I'm wondering how you think about these structural and policy discrimination issues

Well I definitely think, for example, if someone were to take FMLA, which really is no skin off the employers back, you're not paying your employee, they're voluntarily taking unpaid time off, of course we know that you're not obligated to disclose what's going on with your employers, but in fact, that doesn't really happen very often. If you're not going to be at work people want to know "why are you not at work? I need documentation to protect you job, if there's a legitimate reason why you're not going to be here”. Because I was working at a peer-run agency, it was promoted "if you think you need help, please go get help, talk to us, we're here for you” I don't think if 
someone were to say “listen I feel like I'm really in trouble here I need time to go into treatment”. Personally I went to providence IOP, it's like pretty standard it's kind of like the standard, providence was unfortunately known for their mental health service, and so if you were to say, I'm gonna go into, my insurance covers 30 full treatment days there, and that's what I want to do, it's something that's voluntary and you're seeking wellness, but western medicine is not about preventative medicine so much as it is about "you have a hemorrhaging limb, let’s put something on it", vs "I think my arm is gonna fall off, let's do an x-ray" and that isn't honored as much as if you were to say "I was diagnosed with cancer, I've chosen to undergo chemo for the next 30 days”. If you were to say I was diagnosed with major depressive disorder, I want to start taking medication and go to therapy and be in groups for the next 30 days, there definitely would be some judgment there.

And you gotta even wonder how insurance might cover it, if it's considered elective Right, and that totally depends on your insurance, and whatever you sign up for, and whatever your company offers. While there is, one of the most harmful concepts in modern psychiatry. I've had, he's the residing chair in the psych department and he said to me "well, you know M.J., mental health is like diabetes, and if you had diabetes you would take your insulin, wouldn't you?” The statement has so many logical holes in it, starting off with the fact that if you're not, first of all, if serotonin is not generated in yourself, there is no supplement that you can take to create serotonin whatsoever, so that alone is not a workable theory, but really, that's a really dangerous analogy, and while I think that on a pretty basic level it served its purpose, it's trying to explain to people who are not familiar with mental health problems that 
this is a legitimate health concern for many people. It is very real, it is very painful, it can be chronic, it can be fatal. And that's of course what you want people to understand. But I think what's happened is that people finally have gotten to a point after so long to accept that, that now it's like "I've finally proven that I have a disability, I’ve finally proven that I have these legitimate mental health problems.” And so to get your credibility back, to get that sense of “I'm still a person, I'm still a fully cognitive and capable and intelligent and responsible and non-violent" to get that back is very difficult. And so, while you may have places that have rather oppressive health insurance policies, or even follow some procedures around this kind of thing, people are at the point where they realize that not only is mental health something that is a legitimate health concern of many people, it's also something that you can recover from. I think people are not aware of the recovery aspects of mental health challenges. I think that also adds to the layer of stigma because once you're diagnosed, people don't think you're ever gonna lose that ever again. It's like you're a loose cannon, something could always go wrong. And I personally know, I've had to pretty much school my fiancé on a lot of this stuff because he's not familiar with it at all, and so it's been a learning process or him as well, and he said to me "I just wanna know that you're ok now, and that this is over, you're ok right?" so I got to the point where I told him "you can recover, recovery is a definite possible thing, some people might have one episode or 30 episodes in their life, it doesn't mean that it will happen indefinitely". But I said to him "I can’t promise you that I won't ever have another bout of depression again, and I can’t promise you that I won't get hit by a car tomorrow" there’s no.... I think people want that sort of safety, that definite factor of 
"ok, well it's a medical problem, so is it cured or is it not?" and it's obviously much more, there's a bigger grey area in mental health than in some other situation. It's just hard to, it's really tricky, coming from that place where you want people to recognize and validate your problems, but then once they've addressed that, getting to go back and say “ok but I’m still a person, you're not the boss of me forever”. I don’t think most people really get, or believe...

it seems like there's a lot of all or nothing, like you've been asking for help, you've been trying to catch people's attention, and then they just went overboard. Yeah, finally they're on the boat, they understand that this has been going on, and they're there with you, and even with medical professionals, my primary care provider, he got all the records from when I was in the hospital, and while he's a really nice guy and he's never said anything remotely offensive to me, never even used poor terminology, that's always gonna be something that, that's gonna be my primary diagnosis to him, that's what gonna be, he’s probable gonna ask me every time I see him, “are you taking your medication?”. Regardless if I go to see him for a runny nose or whatever, that's gonna be at the forefront of his mind, I truly believe that, as being the underlying problem. And as far as medical coverage and disclosing mental illness to providers there's definitely discrimination as far as prescribing, not being trusted with certain medications. If someone's mentally ill, you don't want to give them anything they can overdose on. If someone's mentally ill, you don't want to give them something that they may misuse or sell, again the criminality of just, all of a sudden you've lost the credibility, like you're not a trustworthy person. Not willing to give them too many pills at a time, that kind of thing. Even though medically they 
might be in totally different worlds, your primary care provider knows. The second an ER doctor, the second you go into an ER and they see that you have a psychiatric record, your treatment will drastically change. There will be extra precautions made when you're treated there, the first thing they say is "I see you were in here for dadada on this date" not "you had a broken leg when you were 14", it's "you were in the psych ward for a week" so this is really complex especially when it comes to health insurance and billing everything because, I can speak from experience having mental illness is extremely expensive. If you want to take care of yourself... if I do all the things that I know I need to do to be well, which really aren't anything above and beyond what any other person could be doing, a person with a diagnosis or symptoms as severe as mine, or a person who's going through a rough patch in their life, you might want to go to therapy, you wanna join a gym, you want to eat healthy, you might want to take medication or herb supplements, those are all things that I really want to be mindful of that I would want to use my health insurance for all of those services. I would want to be able to get supplements and see a naturopath and see my psychiatrist but that's really expensive. And then accessing that when you don't have health insurance can be devastating, and that's why I feel so much of mental health and people who are unemployed or don’t have health insurance or are low income, are constantly in a state of crisis, because you don’t have access. I was unemployed for 7-8 months and I made, about 170 a week from unemployment. And I spent two thirds of all of my money on my therapist, on my medication, on my psychiatrist. Because I knew that if I didn't do that, what was the point of looking for work? I knew I would not be capable of working if I did not take care of myself. And so it 
creates a major financial hardship, and that lends into discriminating as far as people that had... I recently went through an experience while I was in the hospital, I was kind of in a state of, I would say like prolonged crisis for a about a year, and accrued, like something really insignificant, I wasn’t working, I was very unwell, I was seeking help, but there's no overnight fix, I was in a long process of getting help, I was pretty much losing any of the extra income I had, I'd been homeless for a period of time, which again, I've had people not believe me when I said that I've been homeless, like "how could you be homeless, you have a mom and a dad that are alive, you have both sides of your family, and you have a job?". I'm like “it doesn’t make a difference when you put all your means toward trying to be in a state where you don't wanna kill yourself. It really drains the funds pretty quickly”. So I'd been though a period, a prolonged period of time, kind of crisis after crisis and I've always been, I'd say a pretty stable person, always really responsible, very law-abiding but I'd been in point in my life, where my symptoms had become so unmanageable, and so extreme, it really was just like crisis after crisis where, when you're in that state where just one bad thing after another happens, it's so difficult to get to a stable point again. I was in that pattern and that was for about a year and in that time I accrued parking tickets, really non violent, like nothing really drastic kind of stuff. I think I had expired tags, and I had parking tickets for not being able to pay for parking, I was ironically going to see my psychiatrist downtown... so that became not even secondary or tertiary that became like “I don’t even care about tickets right now, I need to pay for my rent, I need to pay for food, and I'm not receiving unemployment anymore, but I'm still receiving SNAP or food stamps." I still everyone I see is on a sliding scale, so that 
was just not anything I could even concern myself about. It was hard enough to even get gas in my car. And so my car, after this long period of where I was hospitalized and was in treatment, and was hopefully in a period of stability for a while, I was just starting to address the stuff that had backed up when I was not well, when it was not the most important thing, so I went down to, my car was impounded like two weeks ago, so here I am, I'm working again, I'm doing really really well, and my car gets impounded and they wanted like 1700 dollars or something completely ridiculous to even get it out of the impound, so I go, and I had a letter from my therapist, a letter from my psychiatrist about, "this came from, these tickets accrued in her life when she was financially unstable she was living in a home, getting treatment, anything you can do so she can stay self sufficient, and assist her" and so I gave the judge this documentation, and it's never super fun to disclose that kind of information, especially in traffic court, where there's guys trying to get out of a blown-out blinker or something. But I, this is a significant amount of many, I need to do whatever I can. so I tell the judge what had gone on, and he said to me "listen, I have sympathy for you, but I'm sure as you learned in treatment, that's part of dealing with the consequences of your past, this is a consequence, you need to deal with the wreckage, it's your responsibility now" obviously the implication was that there was some choice involved in the whole situation. So the irony of the situation was, that the day before I went to the opening of the Multnomah county crisis assessment treatment center, the CATSY, and Sam Adams was there, a lot of state officials were there, talking about how we really want to turn around the system for people that are, they use this term quite often, “the vulnerable population of Portland” which is 
another quirk of mine that I wasn’t happy about that. But yeah, “we want to start helping this population, we want to support them and we don't want to have barriers to treatment” and blablabla. And then the next day, on letterhead, from the office of Sam Adams, it's telling me "I want 1700 to get your car out of impound" and when I came forward and finally said "this is what I've been going thought, I'm trying to get back on my feet, trying to re-establish” pretty much I got treated like I was lazy and didn’t pay my tickets, and "you need to deal with the consequences of your choices" and so here I had this huge long period of "ohmygod listen to me I'm not well, help me, help me." Well finally I have experience that I feel actually legitimized what I’d been trying to say, and I've never been so disrespected in so many aspects of my life ever. I'm thinking of the people that have been dealing with this kind of system in this country for more than just a year, and I'm appalled, I can’t even imagine, it is the most aggravating, suffocating situation to be in, wanting to be validated and accepted for these circumstances that obviously no one would wish upon anybody. But then you're finally taken seriously, it's a definite cost. If that's a way long rambling answer to your question.

No, that makes a lot of sense

The craziness in trying to juggle conflicting institutions that are completely contradicting each other and so disjointed and...

Right, I think it was so difficult for me with this last situation, I don’t feel like I was even asking for special treatment whatsoever, I was just kind of like "can I have a payment plan, can I pay you like a hundred bucks a month until I die or something, I don't know, what can I do to pay off this full amount?" and instead I was taught a 
lesson. I was like tap on the head, and taught a lesson, when that wasn't even actually necessary. Logically, if they had taken my offer to make payments on this they would have actually gotten money, and now they're still asking for this lump sum in like 30 days, and I don’t really understand, it's not gonna happen. I've had a very neck breaking sort of like what's going on, cause I finally feel like I’ve been validated, ok it's serious, it's a real thing. And for me, as far as personal validation, I finally feel like I'm not just making this up, I have serious problems and while some people might find that scary, and it is scary to know that you have things going on that maybe you're not... my personal experience is, some things aren't always in my control or my awareness, and so that is scary, but not as relieving as is to know "ok there is something legitimately going on here, there is a way I can help myself get better" but again, at a great cost.

I am a strong believer in the incredible power of validation

So am I. To the point where I'm like "validate me, validate me, please someone tell me that what I'm going thought is a real, true thing"

I'm not making this up, you see it happening"

right, in mental health humor we make these sort of jokes about the way we're, how not seriously we're taken, and actually one of my bosses she said to me, she was going to meet with somebody about a legal situation, somebody she knew, who was trying to get out of some legal troubles they accrued while they were not well. She was like "they never take this seriously". Basically there's this vision in people's heads, we're gonna come in with home made quilted vests, with our cats, and bags 
around us and that really is the sort of image of like crazy cat lady, crazy bag lady, and that's just not...

Yeah and you ran into the problem of not presenting in the way that people expected you to.

Right. so it really was a bit of a catch-22 for me, if you look at some of the first things that doctors will say when they dictate their notes, they use for their guidelines of how well you are how you look how you speak, how you smell. For those doctors, those are like qualifying factors for how well you are, which is not only offensive to people who present well, but for people who don't have the means to present well. So it's infuriating, and that's what I finally said before, I kinda felt like I needed to go in naked with sharpies written all over my arms and talking about Jesus speaking to me before anyone would be like "oh, maybe something's going on". Unfortunately it's when people are taken seriously, is when it becomes a case...

So thinking of policy and structures and institutions, here's kind of an imagining question, if you wanted to start somewhere in improving people's lives, where would you start changing, or what would you find most urgent, where would you get moving?

I definitely think the people who are on the front lines need to be educated, so because, especially when you're dealing with people who may be having their first experience with mental illness, and maybe their first episode if you want to call it that, you're surrounded by people, it's safe to say if somebody is having extreme mental health problems that require immediate attention, chances are, they're not gonna have people around them who are gonna know what to do. People's first 
response is to call 911 "something is happening, my dadada wants to kill themselves, or they're talking about this or they haven't slept in 5 days or they've stolen my car” or whatever they're doing. That is so ingrained in our culture, if anything bad is happening, you call the police right away. And for me I think that just having like a day of sensitivity training or having like a required course in bed side manner, is not sufficient I think that there are people who are non the wise about the state and the holes of quality of care in the system than people who have the experience, who have basically been the guinea pigs for basically hundreds of years and when it comes to mental health I still feel that we've always been in that phase of being guinea pigs, “ok let's try lobotomies, those don’t work. Let’s try thorazine that's not so great. Let's try electro shock therapy”, because there is something so non-linear about mental health that I believe can make it difficult for a scientific mind to wrap their head around “ok this doesn't have like an a to z, I don't have the same prognosis for every single person”. And I think that also is a huge deficiency, is that no person's mental illness can be treated the same as the next person's. Even if, basically I believe that diagnosis and codes are written for billing purposes, because the doctors have to write down "ok how am I gonna charge this". For me that's the highest level of functioning for a formal diagnosis, I have found my diagnosis validating. Ok, I'm looking at this list of "If you experience a through z, and you have 15 out of 30" I'm like "ok well that makes sense" and that is enough to get kind of the rough sort of picture of like “you're experiencing this and we can categorize it as that, and here's something that's been effective for that kind of situation” but really it's just for the ease of billing and money, and every mental health case I believe needs to be treated 
as an individual, I don’t think anything can be gained from saying “it looks like you have bipolar”, which I think is about as egregiously over diagnosed as ADHD, terrifyingly so, especially considering the medications that people get put on. And so I think first of all to not have frontline people that are not sufficiently trained in dealing with these kinds of situations and even if they're able to realize, and I realize also, not that I'm trying to defend the police, but the place where they're coming from, at the end of the day they are doing their job and they legally have to respond to calls, and they have to use their judgment to make these decisions of what to do and unfortunately with the 911 system, it's not set up to deal with people who are having mental health crises, and that's where I would say a good fraction of their calls are coming from. And then once an officer, say you get a person without being brought by the police into the ER, to then be accurately dealt with and treated like an actual, if I went into the ER with a broken leg I would be treated totally different than if I were having an episode, and so, I think that some doctors, their bedside manner is poor regardless, but I think the terminology whether it's what they learned, whether it's their education, even if their work talk, and that's how they talk to their colleagues, that's really not my concern, I think if you're dealing with somebody that is not well, or that is maybe dealing with mental health problems for the first time, that terminology is so crucial in the beginning. Because obviously most of us are familiar with the medical model, the western medicine model and if a doctor tells you something, chances unless you felt like you'd been misdiagnosed and you'd been through this intense experience of trying to be heard in the system, you just accept what's said, and that's also part of our culture, doctors are authorities, police are 
authorities, doctors are authorities and if you're deemed dangerous by a police officer, and you're taken in and you're deemed schizophrenic by a doctor, that's why I can see people thinking very easily, "Oh my god, I really am a crazy criminal!" So I believe that the terminology and the diagnosis isn't as important as the treatment of the person just as a person and I think it would be really beneficial to have, I'm a big supporter of peer support, and peer support specialists, people who have actually gone through training, certified by the state. I did the training myself at Project Able down in Salem, where you are given a really intensive training, and it's for people who have identified. It was like 40 hours; you're given all these really amazing tools, and the culmination of the training is that in order to support people, you treat a person like a person. That's really how it can be summed up. Of course, there can be some delicacies, and there can be legalities for someone who is suicidal, and there can be some sticky areas, and those policies can change depending on where you're working; if you're the only support specialist there or if you're in that kind of setting in general. But I think having that kind of support, or somebody on staff is incredibly beneficial. I think especially when you're in a hospital setting like that it can be incredibly isolating, and there is this sense of, "maybe it's just me", but I've heard other people have the same experience, thinking "oh my god, I'm totally lost, this is going to be my life now, it's gotten so bad that I can't take care of myself anymore, even if I can, people don't trust me to take care of myself", and to not have... to basically not be able.. you're not helping anyone squash that question in your mind. Most people, I believe, can and will recover from mental health problems; and to not have that support, especially when you're at the most crisis, critical, first days can be 
really damaging and that's where I feel that I had some of the most damaging experiences, were those first few days when I was at my most vulnerable and I was being treated like I was a caged animal.

Yeah, and that's pretty similar from what I've heard from a lot of folks, is that initial intake being beyond crucial.

\section{Power}

So these guys in this model say, we have these four elements, we have labeling, negativity, separation, and structural discrimination, but none of these happen and create stigma without power. Power is the crucial ingredient here because power allows you to communicate the stereotypes you're gonna use: to have control of the media to present the images that you want to set up, have control of lawmaking, and policies and decisions and institutions. Power is crucial in making this into a stigma, so I wanted your take on that. And also, I love that aspect, but I also have the critique of it, which is: they're only thinking of power as top-down, and they're not really addressing the bottom-up power, the grassroots power, the consumer/survivor, power, which I think is really important. So, I wanted to have you think about power for a bit and how it plays a role in stigma, both top down and bottom up. Ok, well, actually I’m having some learning experiences lately. My fiancé and I adopted a rescue pit-bull and it sounds terrible to say this, but it's very true, but I've noticed so many, just the general concept of stigmatizing and discrimination. I've seen how certain things are criminalized. Of course media is going to be that big influencing factor in all our studies and everything. But basically I think, I really feel that you could take an article about a pit-bull attacking a child and an article from a 
mentally ill person going and doing something or a crime spree or however they're gonna say it, and interchange the words and really not know the difference in the articles; the content is pretty much the same "Here is something that we, as the public, think is dangerous and unsafe. Here's how it was treated, and we need to protect you. We need to protect society as a whole. We are letting you know to keep you safe. This is what's dangerous, and very much.”

So, that's the case of what's going on right now with MH. I was really amazed that, I read an article somewhere, a really famous actress was admitted to a treatment facility and was diagnosed with bipolar, and this was on every newspaper cover and she was still in treatment and had never disclosed this information. And of course now it's... that's just sort of... she's totally discredited now, and I do think that when it comes to the power aspect of it... the people that are coming from like a top-down, it has to do with people thinking they’re keeping everyone safe. "We're going to keep you safe, we're going to keep this element away from you. People don't want their children being taken care of by mental illness people cause they're not safe. You don't want your children being taught by them you don’t want them in your neighborhood." And so every attempt by any authoritative figure to talk about mental illness in a light that is anything but... completely not... an extraordinary case, extraordinary, it's all in the guise of I want to keep society safe from this dangerous element.

So whether or not that is what is specifically said, obvious you watch the news and most of the stories are cautionary tales. So, just the fact that you're running stories and identifying somebody as mentally ill, you are implying that mentally ill people are unsafe, and here's another reason why. For me, that's primarily where I see the 
motive behind legislature and separation, and that's another aspect, "public", it's seen for the greater good of the people. I think that in recent years, there have been a lot of amazing, impressive research done that is really demystifying mental health and medications and treatment and recovery, and I've been a consumer my whole life, and these are things that are new to me and I think it really has to do with disability as far as how "out there", how visible are we in the community, credibility... And unfortunately, in our culture there is no power without credibility. And so, until all these kind of myths, these rare horror stories, can be demystified, and mental health is made something like "this is a common human experience, something that, whatever the stat is, dadada, 4 people will have this kind of experience in their life" if you pair stats with... chances are if you've been abused emotionally, sexually, physically there's gonna be some trauma left behind, and that very well can manifest into a health problem and I believe that [unitelligible] is something that many people in our society have experienced, whether they choose to stress it or not... whether they choose to make it part of their recovery... whether they just want to stay with some antidepressants for whatever reason. So I feel like until mental health is, sort of, I want to say watered-down, but all people are getting are really sensationalistic stories... really strange stories... and that's always just been sort of the culture as far as people are looking. People love spectacle.

And it's really easy. I think it’s really acceptable and very common for the culture to make fun, discredit, stigmatize and make jokes about people with mental illness. It's a pretty easy go-to, and even I, and even the people I work with, how common is it for all of us to say, to use the adjective of crazy? it's really common, I do it at least 10 
times a day, I do it all the time, and so I think until people are able to really understand, and I'm not saying every single person, you're still gonna have people in their house on the mountains, like with their guns... but I think until the general consensus, and when it comes to power, all it takes is for the authorities to agree on something, and people start buying into it. I think until people are able to see mental health issues as something that's very common and very treatable, as something you can recover from, and it's not threatening and something that should be addressed, I think it will make our mission so much easier. Because there's just so many cultural taboos attached around this, and so many reasons why people don't feel comfortable disclosing, for discrimination, or health insurance, or that you'll be damaged goods to somebody. And so I think that there needs to be some sort of neutralizing force that says, for example we hear a lot these days about Robert Whitaker, he's sort of our canary in the coalmine, go out and tell everybody what we've, people have always been feeling and knowing, but have never been giving a quotable source. And now he's sort of like the authority on medication and mental health, which is great because it really does take just that, one person has those few letters behind their name, who are a credible source to say "ok listen what they've been saying all along is valid, and I will show you how it is". And just in the past ten years all the research has been proving how treatable mental health is how much more effective peer support is than the traditional medical model. I've been really impressed with the peer support work, that's about as grassroots as it gets right there, people working amongst themselves 
Right, I could be taking everyone coming from a place of being separated, being segregated from each other, because of course that's the most dangerous thing is to get people with a good idea together in one place, and that's where change really begins to happen. I don't know how many months ago it was but I was in a facebook group of peer support, and there was like a hundred and something members, and a lot of really influential people in the mental health movement conversing and sharing links and news or noteworthy articles about the subject, and it's really great seeing it out there. I think the most important thing is that unless you are directly exposed or you specifically go and seek out this kind of information, no one's gonna give it to you. It's not something that I believe that doctors, not only are doctors not aware of it, because it's not something that they respect or validate, and it's kind of a threat as well to the medical system that people don't need to be on medication their whole life, people don't need to be institutionalized, actually prolonged medication can be even more harmful in some cases and there are much more another, less stringent ways of recovery that have nothing to do with being in a hospital setting and are much more effective, and I think that can also be threatening. there's a really great article I should send to you, it happened at last year's Alternatives conference, Alternatives is the national mental health conference, it was in san Diego last year. So, Robert Whitaker, because he is like a total buzz, everyone's trying to get a piece of his knowledge, and have him speak, and he was invited to speak, and once the drug companies, I think it was Pfizer, found out what the was saying, his lecture or discussion turned into basically like a really, Hannity and Colmes kind of side-byside. Like he's on a podium over here and here's a drug rep from Pfizer over here, and 
he's presenting his information, as like "here's my book, here's what I've said" and you have somebody from the company saying, basically trying to discredit him, first they removed him from the entire conference, like "you're uninvited, you cannot come" and there was such a huge outcry cause everyone was like "listen this is a conference on mental health, and you're taking away the one person who's making innovative, groundbreaking information?” And it's called alternatives, people!

Right! There was a drug rep that was basically brought to task to sit there and discredit everything he said. And so it turned from him giving a lecture into having a debate and it was a huge brouhaha about it. There is a lot of money to be made in the mentally ill, it's a huge amount of money. Especially because it's one of the illnesses, or the diagnoses, that people readily accept that it's long term and chronic. "You're gonna have this forever, you're always gonna be on medication, you're always gonna spend a hundred dollars a month, or your Medicare bill will always be paying for your this or your that, and your five different medications and your mood stabilizers, or whatever”. It's a lot of money, so much money involved in that And it's just such an amazing image with the drug company vs this guy and trying to go head to head...

I think the reason why it was so scary to them is because it's true, it's such accurate, well-researched, valid information, and he had, I don't think he had, there was not, you know how people sometimes work backwards from their hypothesis "here's the point I wanna prove, so I go about proving it" he really started out saying "what to do with all of this stuff, let's find out" and found out something amazing, and that was 
really threatening, I think. I think that when information that valid and that credible and that powerful is presented people do listen. People have listen to him obviously, he is constantly on tour, and everyone wants to know "what do you have to say?" And I think that in my experience, the people that I've received services from, I think I had maybe one practitioner call me a consumer. And I was like "oh my god, you actually know what's going on!" But that's just not, it's kinda like this fluffy "oh you want to have your civil rights, isn't that cute" kind of thing, kind of patronizing. I don't think doctors wanna have to go back and re-learn everything they know about prescribing and mental health and treatment and recovery, it's a complete 180 from what they're practicing

Yeah, and re-organizing changing such a big system not to mention proving that short term medications, short term rapid recovery is possible, finding someone else's help for treatment, it's coming from people who aren’t even, haven’t paid 100,000 dollars for their medical school, and people who have been paying the money to pay for treatment that those are the real experts, and that's really threatening to a lot of psychiatrists. That's a actually a really good barometer, if you're ever talking to someone in the field, and you bring up that book, and I can guarantee you they know what that book is, you can tell within seconds what side of the fence they're on, it's so immediate. Which is kinda of fun... if you think about it, I think he's had like one book before, it's not like you're talking about Steven King, or someone on the New York Times’ bestseller, putting out a book that has sold millions of copies. Just a guy who researched, and put out a book, and it rang true and people are like "we need to read this". I think that even is more threatening 
than if a big name were to come out and say "here's what I think". Here's this guy who really started in a grassroots way doing his own stuff, just putting it out there, and he's being heard, and for us it's really awesome, for people who self-identify, that's really powerful for us. It's really difficult, if a person know about the book and the content, you'll get a definite reaction right away, so it tells you what you're gonna be dealing with, it's kind of been my... if I have to see a doctor "have you read this book, because I’ve been reading, dadada"

It's a good barometer

Oh completely.

Are there things that I haven't thought to ask you that I should be thinking about, or things that you want to add?

I think it's really great that people are wanting to do research on this, basically new to everyone else, but this side of mental health I think that really is what ultimately makes the difference. I think that so much of the stigmatizing and the labeling, I hope it's something that phases out generationally. I hope it's something that this kind of information will actually be curriculum for people that are in school or practice. We're not there yet, but everything that's been done now has been sort of independent and people doing their own thing, it hasn't really been (...). At this point, it's definitely not something that's going to happen over night, but I think in order for this kind of thing to work for people to be heard and respected, there really does need to be, I think as far as any movement ever, it has to come from the people who are experiencing the treatment. That's where it has to come from for it to be credible, for it to have the people who think of best practices for what to do in these situations, 
because theorizing about it, hypothesizing about it does no one any service whatsoever. And so I'm hoping maybe in ten to twenty years that there is a more progressive, open-minded model of what mental health treatment, what the standard is. Or if you call and say I'm having a crisis, then the first response is not going to be police escort, seclusion, restraint, medication. That's really kind of the process that is in now, and that definitely is really damaging and traumatizing for people and I think can lead to further problems. And so until that's really taken seriously... another step that's really important, I think OSH is finally hiring peer support specialists that are on staff, that's amazingly important because I think the only way, I think when it comes to funding and change, and everything, people want to see numbers, they want to see data, "show me from point a to point b", and I think it will take time for peers to be working in the field, working with people who are currently labeled as patients who are in the system for them to be collecting data. Because right now it's like "you're the peer support specialist, we're so glad you're here, why don’t you go play checkers with somebody" and that's still kind of

\section{Patronizing}

Right, and I feel like in general that because there's been so much progression in the movement that people are kind of saying "well at some point you have to listen, ok if people are really causing a stink about this, let's just do something to placate that, let's just hire some peer support specialists and good for us”, it's kind of like having a diversity hire, that's basically what it's like. But I think until there are long term results seen, in places that are hiring people probably on a grant money, or special budget, "ok, so we're gonna give you this special money for this special person”. And 
they are finding, they are seeing results and they are seeing how peer support work is not just in any one hospital in the state or in one area of the country where people are getting it, but for it to be just common practice will definitely take some time. But I think it will take, slowly people working within the system and giving people results that they can actually see, "well maybe it's actually working" for it to be widely accepted. Ultimately that's the model I would hope people are going for, because, not to sound fatalistic, but I don't see how things are going, for things to ever be really eliminated, I think that there is going to be that kind of criminalizing of people that are having a mental health crisis and seclusion, restraint, forcible medication, forcible commitments. But hopefully it will be, it will become less common ideally, and that's not gonna be plan A. Right now I think it is, and right now I think that alternative plans, holistic, and peer based are kind of a luxury, and hopefully that would change. It's definitely a time thing, but I think it's gonna take a long period of time where they're gonna have proven results that they can put on some pie chart at a conference and show to doctors and say "look, it works".

I like that. Well that was it for me. 